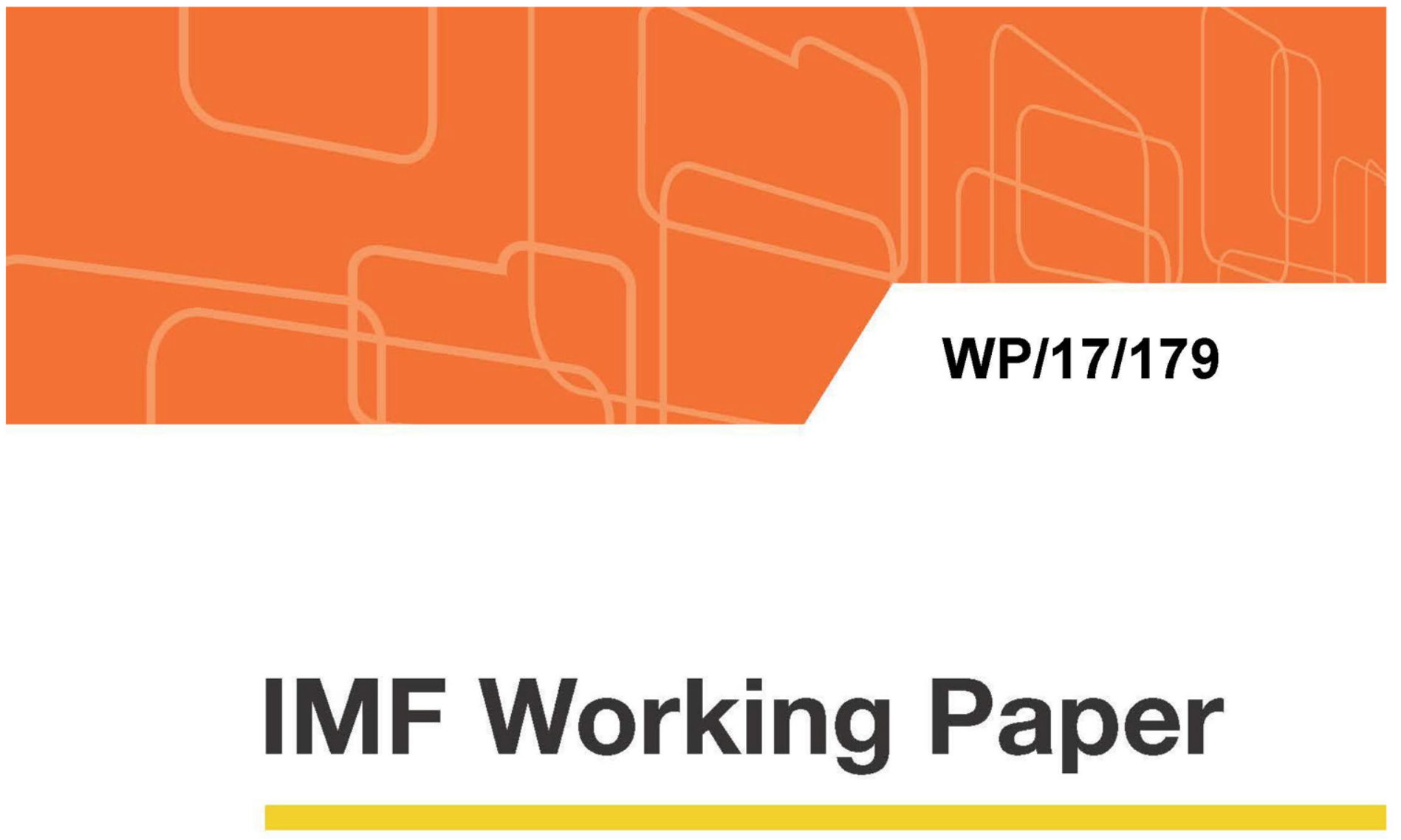

\title{
Leaning Against Windy Bank Lending
}

by Giovanni Melina and Stefania Villa

IMF Working Papers describe research in progress by the author(s) and are published to elicit comments and to encourage debate. The views expressed in IMF Working Papers are those of the author(s) and do not necessarily represent the views of the IMF, its Executive Board, or IMF management. 


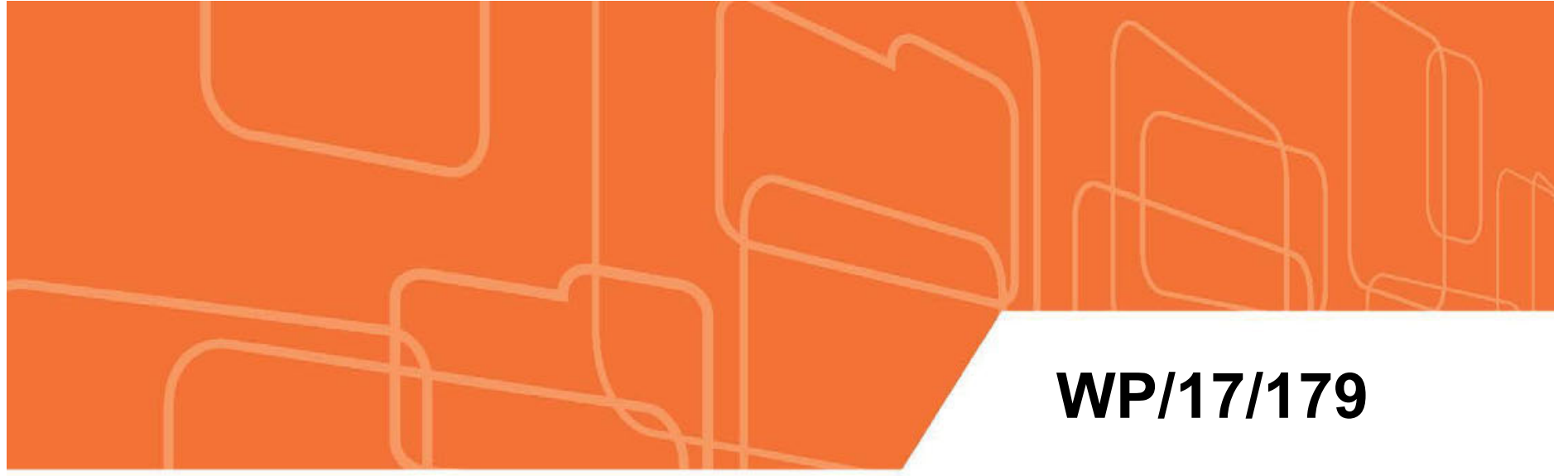

\section{IMF Working Paper}

\section{Leaning Against Windy Bank Lending}

by Giovanni Melina and Stefania Villa

IMF Working Papers describe research in progress by the author(s) and are published to elicit comments and to encourage debate. The views expressed in IMF Working Papers are those of the author(s) and do not necessarily represent the views of the IMF, its Executive Board, or IMF management.

I N T ER N A T I O N A L M O NETAR Y FU N D 


\title{
IMF Working Paper
}

Research Department

\section{Leaning Against Windy Bank Lending*}

\section{Prepared by Giovanni Melina and Stefania Villa}

\author{
Authorized for distribution by Chris Papageorgiou
}

July 2017

\section{IMF Working Papers describe research in progress by the author(s) and are published to elicit comments and to encourage debate. The views expressed in IMF Working Papers are those of the author(s) and do not necessarily represent the views of the IMF, its Executive Board, or IMF management.}

\begin{abstract}
Using an estimated dynamic stochastic general equilibrium model with banking, this paper first provides evidence that monetary policy reacted to bank loan growth in the US during the Great Moderation. It then shows that the optimized simple interest-rate rule features no response to the growth of bank credit. However, the welfare loss associated to the empirical responsiveness is small. The sources of business cycle fluctuations are crucial in determining whether a "leaning-against-the-wind" policy is optimal or not. In fact, the predominant role of supply shocks in the model gives rise to a trade-off between inflation and financial stabilization.

JEL Classification Numbers: E32, E44, E52

Keywords: lending relationships, credit growth, leaning against the wind, Bayesian estimation, optimal monetary policy

Author's E-Mail Address: gmelina@imf.org; stefania.villa@unifg.it

\footnotetext{
*Melina: Research Department, IMF; Villa: University of Foggia and KU Leuven. This version of the paper is forthcoming in Economic Inquiry. We are grateful to Marco Airaudo, Yunus Aksoy, Alejandro Justiniano, Paul Levine, Vivien Lewis, Thomas Lubik, Machiko Narita, Chris Papageorgiou, Joe Pearlman, Søren Hove Ravn, Felipe Zanna, participants to the 2014 BCAM conference at Birkbeck, University of London, the 20th CEF conference in Oslo, the 10th Dynare conference in Paris, the 2015 CESifo Area Conference on Macro, Money \& International Finance in Munich, a seminar at University of Milan Bicocca for useful comments and suggestions; and to Paul Levine for sharing his code for the computation of optimized simple rules. Stefania Villa acknowledges financial support from the European Community's Seventh Framework Programme (FP7/2007-2013) under grant agreement no. 612796. All remaining errors are ours.
} 


\section{Contents}

1 Introduction $\quad \underline{6}$

2 Model $\quad \underline{9}$

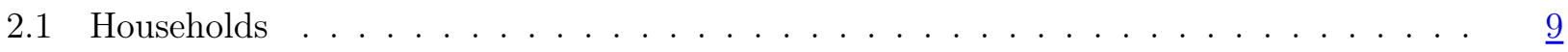

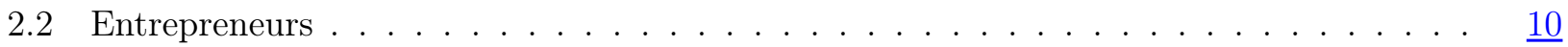

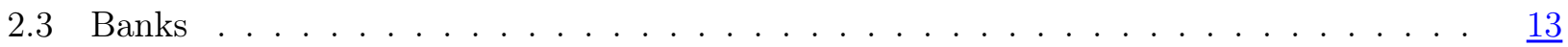

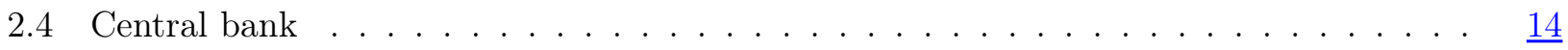

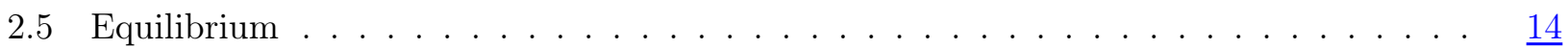

3 Estimation $\quad \underline{15}$

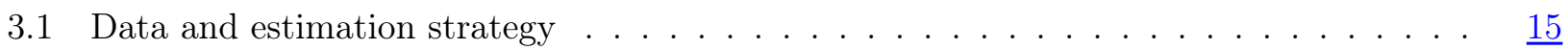

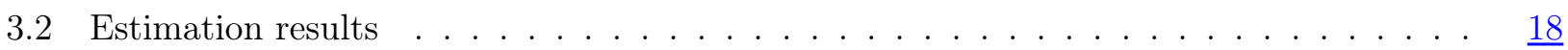

3.3 Dynamic properties of the estimated model . . . . . . . . . . . . . 20

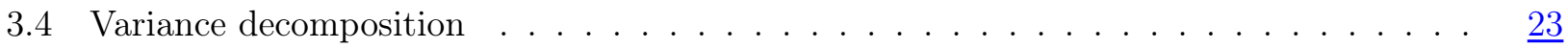

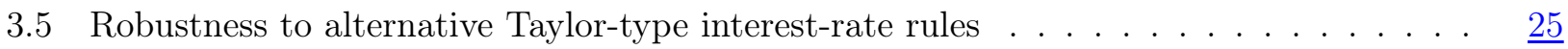

4 Optimized simple monetary policy rules $\quad \underline{28}$

4.1 Design of simple monetary policy rules . . . . . . . . . . . . . . . . . $\underline{29}$

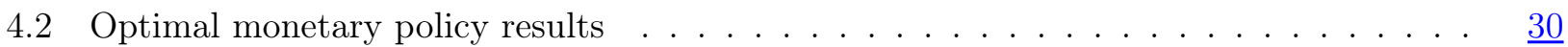

4.3 Welfare implications and counterfactual experiments . . . . . . . . . . . $\underline{32}$

5 Concluding remarks $\quad \underline{34}$

References $\quad \underline{35}$

$\begin{array}{ll}\text { Appendix } & \underline{40}\end{array}$

A Narrative analysis of FOMC meetings on concerns about credit $\quad \underline{40}$

B Symmetric equilibrium $\quad \underline{43}$

$\begin{array}{ll}\text { C Detrending } & \underline{45}\end{array}$

D Steady state $\quad \underline{48}$

E Ramsey problem $\quad \underline{51}$

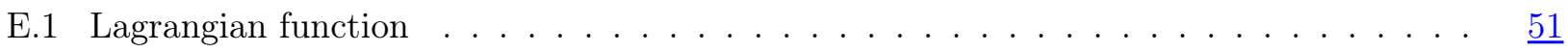

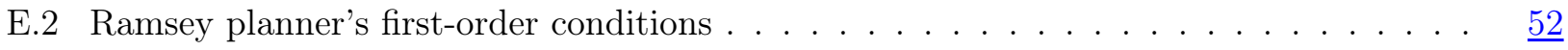




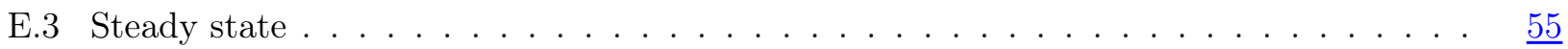

F Data sources and transformations $\quad \underline{55}$

G Robustness of results to alternative Taylor rules $\quad \underline{56}$

H Robustness exercises for optimal policy $\underline{64}$

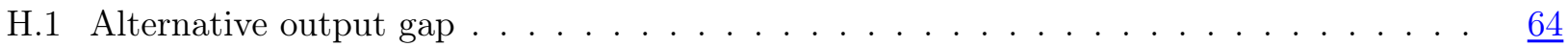

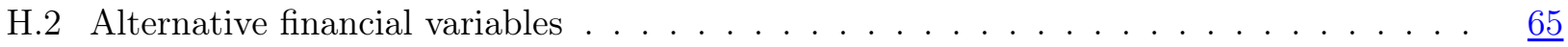

H.3 Implementable Taylor-type rules . . . . . . . . . . . . . . . . . . . . $\underline{65}$

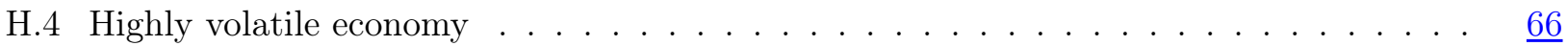

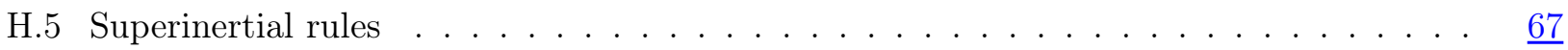

\section{List of Tables}

1 Descriptive statistics on intended changes in the Federal Funds Rate (FFR) and credit conditions mentioned in minutes of FOMC meetings (1984Q1-2008Q2) . . . . . . $\underline{8}$

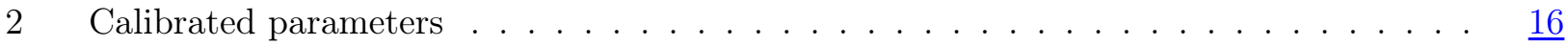

3 Prior and posterior distributions of estimated parameters (90\% confidence intervals are

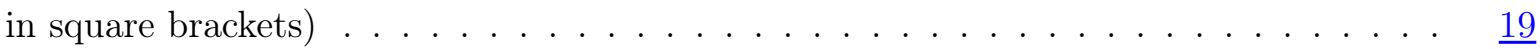

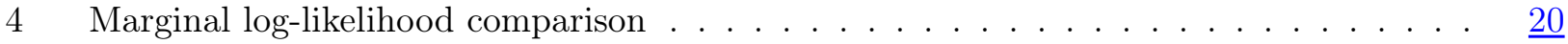

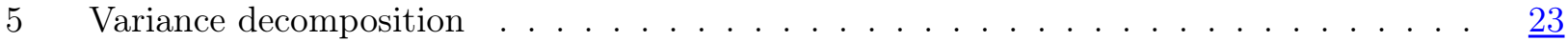

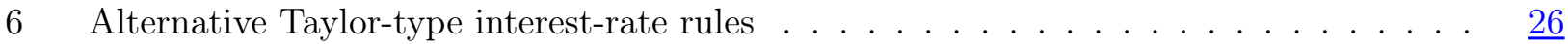

7 Prior and posterior distributions of estimated parameters of alternative Taylor-type interest-rate rules $(90 \%$ confidence intervals are in square brackets $) \ldots \ldots . \ldots$

$8 \quad$ Marginal log-likelihood comparisons for alternative Taylor-type interest-rate rules . . $\underline{28}$

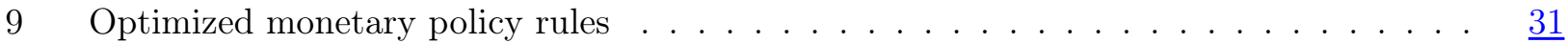

A.1 Intended changes in the federal funds rate (FFR) around FOMC meetings and quotes on credit conditions found in FOMC minutes . . . . . . . . . . . . . $\underline{42}$

G.1 Prior and posterior distributions of the estimated parameters of the model featuring an implementable Taylor-type interest-rate rule (I) - 90\% confidence intervals are in square

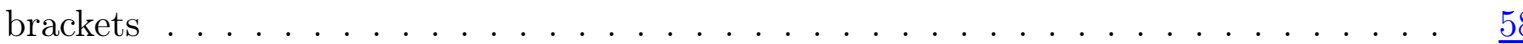

G.2 Prior and posterior distributions of the estimated parameters of the model featuring an implementable Taylor-type interest-rate rule augmented with output growth (II) $-90 \%$ confidence intervals are in square brackets 
G.3 Prior and posterior distributions of the estimated parameters of the model featuring a Taylor-type interest-rate rule augmented with stock prices (III) - 90\% confidence intervals are in square brackets . . . . . . . . . . . . . . .

G.4 Prior and posterior distributions of the estimated parameters of the model featuring a Taylor-type interest-rate rule augmented with AR(2) interest rate smoothing (IV) $-90 \%$ confidence intervals are in square brackets . . . . . . . . . . . . .

G.5 Prior and posterior distributions of the estimated parameters of the model featuring a Taylor-type interest-rate rule augmented with stock prices and $\operatorname{AR}(2)$ interest rate smoothing $(\mathrm{V})-90 \%$ confidence intervals are in square brackets . . . . . . . $\underline{62}$

G.6 Prior and posterior distributions of the estimated parameters of the model featuring a Taylor-type interest-rate rule in which potential output is constructed with no financial frictions $-90 \%$ confidence intervals are in square brackets . . . . . . . . . $\underline{63}$

H.1 Optimized monetary policy rules with an alternative output-gap (potential ouput constructed with no financial frictions) $\ldots \ldots \ldots \ldots \underline{64}$

H.2 Optimized monetary policy rules with alternative financial variables . . . . . . . $\underline{65}$

H.3 Optimized implementable monetary policy rules . . . . . . . . . . . . . . . $\underline{66}$

\section{List of Figures}

1 Intended federal funds rate changes around FOMC meetings and concerns on credit conditions raised in FOMC minutes (1984Q1-2008Q2; shaded areas indicate NBER re-

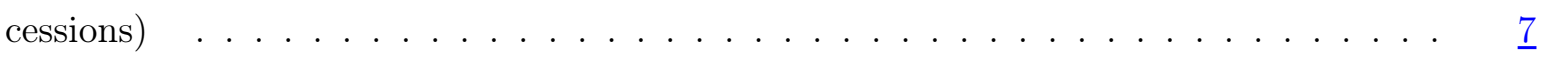

2 Prior and posterior probability densities of the Taylor rule parameters . . . . . . $\underline{20}$

3 Impulse responses of selected variables to structural shocks of size 1 percent in the estimated model featuring a Taylor rule augmented with a response to credit growth and in a restricted model with a standard Taylor rule . . . . . . . . . . . $\underline{21}$

4 Demeaned credit spreads in the US economy v.s. the model-implied measure (shaded areas indicate NBER recessions) . . . . . . . . . . . . . . . $\underline{24}$

$5 \quad$ Welfare implications of leaning against the wind and counterfactual experiments . . . $\underline{33}$

G.1 Prior and posterior probability densities of parameters of alternative Taylor rules . . $\quad \underline{57}$

H.1 Welfare cost associated to leaning against the wind for proportional increases in the volatilities of all shocks $(\mathrm{STD}=$ standard deviation of real output growth $) \ldots \ldots \underline{67}$

H.2 Welfare change associated to interest rate inertia $\left(\rho_{r}\right)$ and leaning against the wind $\left(\alpha_{s}\right)$ relative to the case $\rho_{r}=0.5 ; \alpha_{s}=0 \ldots \ldots \ldots \ldots \ldots$ 


\section{Introduction}

The role of central banks in promoting financial stability, in addition to inflation stability, has been debated well before the Great Recession. The so-called "Greenspan doctrine", which objects to the policy of leaning against the wind blowing from asset-prices, greatly influenced the central banking world before the crisis. However, in the aftermath of the Great Recession, the need to protect the banking sector from periods of unduly high or excessively low credit growth has led to a renewed interest in the "lean" versus "clean" role for monetary policy, with an emphasis on credit conditions. ${ }^{1}$

Indeed, the important role of credit markets in affecting business cycle fluctuations emerges also from the Basel III framework, aiming at protecting the financial sector from periods of excessive credit growth, often associated with an increase in systemic risk. On this aspect, Jordà et al. (2013) document that, in a sample of 14 countries and a period between 1870 and 2008, more credit-intensive expansions tended to be followed by deeper recessions and slower recoveries. Their measure of "excess credit" build-up during expansions is the rate of change of bank loans to GDP, in deviation from its mean. Furthermore, Bordo and Haubrich (2016) provide empirical evidence that bank lending significantly affects GDP fluctuations in the United States.

This paper focuses precisely on bank lending and it investigates whether monetary policy responded and should respond to credit exuberance. Figure 1 reports the intended changes in the Federal Funds Rate (FFR) around all meetings of the Federal Open Market Committee (FOMC) taken place during the Great Moderation, and whether, in the minutes of each meeting, credit was (i) not a particular concern; (ii) judged to be expanding; or (iii) judged to be weak or tight. ${ }^{2}$ As reported in Table 1, in the vast majority of FOMC meetings (79\%) in which the FFR was intended to be held constant, credit was not a particular concern. In most cases (79\%) in which the FOMC intended to raise the FFR, an expansion in credit was mentioned; while in the greatest part of FOMC meetings (78\%) in which the FFR was intended to be lowered, weak or tight credit was mentioned. ${ }^{3}$

This narrative analysis motivates an empirical investigation on the extent to which monetary policy had a concern on credit conditions beyond their implications for inflation and economic activity. To this end, we provide Bayesian estimates of a Dynamic Stochastic General Equilibrium (DSGE) model

\footnotetext{
${ }^{1}$ For instance, Aksoy et al. (2013) show that monetary policy can play an important role in terms of macroeconomic stabilization if a leaning-against-the-wind policy is implemented within a model featuring credit market imperfections. Galí (2014) calls into question the theoretical foundations of the case for leaning-against-the-wind monetary policies.

${ }^{2}$ We use the series of intended changes in FFR of Romer and Romer (2004) from 1984 to 1996 and extend it up to June 2008 by reading the statement released after each FOMC meeting. We end the series in June 2008, before the zero lower bound became binding. In the minutes of the 196 meetings taken place in the period, we search for sentences related to credit conditions and we construct two dummy variables. The first dummy takes value 1 if credit was judged to be expanding and zero otherwise. The second dummy takes value 1 if credit was judged to be weak or tight and zero otherwise. If both dummies take value zero we conclude that credit was not a particular concern. Table A.1 in the Appendix reports quotes leading to the binary choices for our dummies.

${ }^{3}$ In $48 \%$ of meetings occurred during NBER recessions, the FOMC intended to lower the FFR and mentioned weak or tight credit conditions.
} 


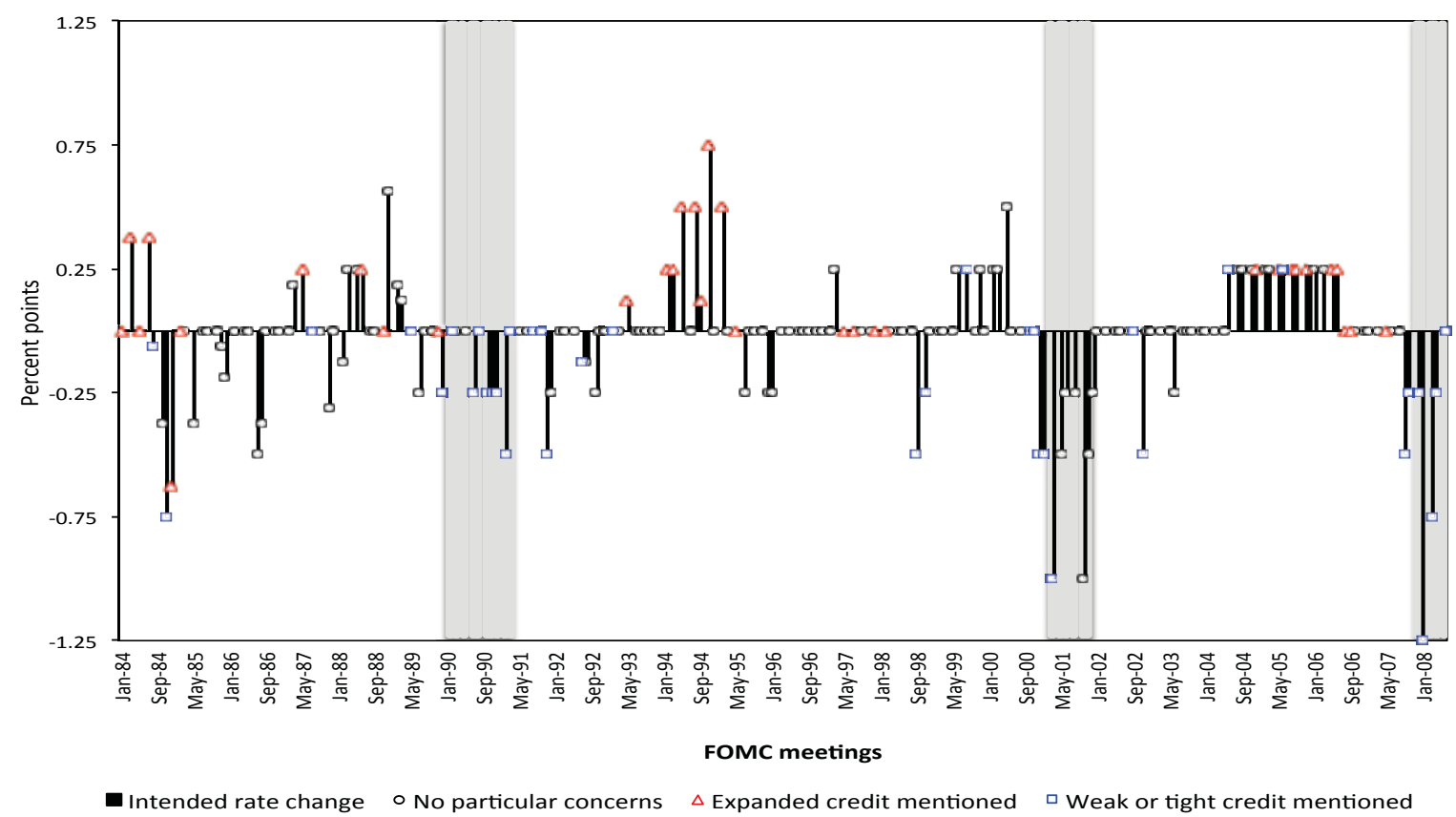

Figure 1: Intended federal funds rate changes around FOMC meetings and concerns on credit conditions raised in FOMC minutes (1984Q1-2008Q2; shaded areas indicate NBER recessions)

in which frictions in the bank loan market arise due to the presence of lending relationships, ${ }^{4}$ and monetary policy is set according to a credit-growth-augmented Taylor-type rule.

The estimated parameter representing the interest-rate response to nominal credit growth is statistically positive and economically important within various alternative monetary policy rules. Therefore, estimates point to the evidence that, during the Great Moderation, monetary policy leaned against the wind blowing from the loan market beyond its concern for price and output stability. To our knowledge, this is a novel result. In fact, in a model with financial frictions as in Bernanke et al. (1999), Christiano et al. (2010b) estimate a significant degree of "leaning against credit exuberance" in the euro area monetary policy framework, while Belke and Klose (2010) perform a similar analysis within a reduced-form GMM estimation. However, as far as estimated DSGE models for the US economy

\footnotetext{
${ }^{4}$ Lending relationships (LR) provide an appealing determinant of the bank spread, i.e. the difference between the loan rate and the deposit rate, and prove empirically important. Among empirical studies using US data, Aliaga-Diaz and Olivero $(2010,2011)$ provide substantial evidence of LR, the average duration of which is 11 years according to Petersen and Rajan (1994). This is in agreement with the study of Santos and Winton (2008) who find that during recessions banks raise the bank spread more for bank-dependent borrowers than for those with access to public bond markets. Among the studies analyzing LR in the DSGE arena, Aliaga-Diaz and Olivero (2010) introduce this friction into an otherwise standard Real Business Cycle model where counter-cyclical bank spreads play a financial accelerator role in the propagation mechanism of technology shocks. Aksoy et al. (2013) show that LR is a feature of financial intermediation relevant for monetary policy making in a New Keynesian (NK) model with staggered prices and cost channels. Melina and Villa (2014) use LR to study the implications that fiscal policy has on loan market conditions. In order to tractably introduce LR into a DSGE model, these studies assume that firms form habits at the level of each variety of loans. In other words they form deep habits in banking analogously to how consumers form deep habits in consumption in the model of Ravn et al. (2006).
} 
Number of FOMC meetings

Proportion of meetings in which:

FFR was intended to remain constant and credit was not a particular concern

FFR was intended to increase and expanded credit was mentioned

FFR was intended to decrease and weak or tight credit was mentioned
196

$79 \%$

$79 \%$

$78 \%$

Table 1: Descriptive statistics on intended changes in the Federal Funds Rate (FFR) and credit conditions mentioned in minutes of FOMC meetings (1984Q1-2008Q2)

are concerned, the literature has so far offered contributions focusing on the reaction of the monetary policy rate to stock prices (for which we also control), but not to credit conditions (see Castelnuovo and Nisticò, 2010, among others). ${ }^{5}$

Is this the welfare-optimal policy? The answer to this question heavily depends on the sources of business cycle fluctuations. We perform a welfare comparison of alternative interest-rate rules, relative to the Ramsey policy, imposing an approximate zero-lower-bound constraint in a way similar to Levine et al. (2008). We find that optimal monetary policy features almost-zero responses both to the output gap and to credit growth. While the former result is in line with the findings of SchmittGrohe and Uribe (2007) in a model with perfect credit markets, the latter is a novel contribution. ${ }^{6}$ The explanation of such a finding lies in the fact that supply shocks - technology, price and wage mark-up - turn out to be the main drivers of output, lending and inflation fluctuations in the estimated model. These shocks imply a trade-off between inflation and output stabilization. In other words, there is no "divine coincidence" (Blanchard and Galí, 2007) for the two targets. Given the pro-cyclical behavior of lending in the model, a monetary policy that responds also to financial variables should respond more aggressively to inflation. As a result, it turns out to be optimal for monetary policy to respond exclusively to inflation.

The remainder of the paper is structured as follows. Section 2 presents the DSGE model. Section 3 outlines the estimation strategy, discusses empirical results and investigates the dynamic properties of the estimated model. Section 4 examines the welfare implications of alternative interest-rate policies. Finally, Section 5 concludes. An online appendix complements the paper by providing (a) the narrative assessment of the minutes of FOMC meetings; (b) the full set of equilibrium conditions; (c) the detrended model; (d) the deterministic steady state; (e) the derivation of the Ramsey equilibrium;

\footnotetext{
${ }^{5}$ The theoretical argument for including credit conditions in the Taylor-type interest rate rule arises from the presence of financial frictions. As in the model credit growth and bank spread exhibit a consistently negative correlation, in principle both are good candidates to successfully augment the monetary policy rule. We focused on credit growth as our narrative analysis highlights that this indicator is frequently considered by the FOMC. In the literature, the rationale for including a monetary policy response to stock prices lies in the fact that swings in asset prices affect real activity via various channels, e.g., households' wealth, market value of collateral, and Tobin's Q.

${ }^{6}$ Ajello et al. (2016), in a stylized calibrated model, show that the optimal interest-rate policy does not change significantly in the face of financial conditions calibrated to match normal times, while it becomes more aggressive when the probability and severity of financial crises are uncertain. While they only compute the optimal policy, we also look at credit-growth-augmented Taylor-type rules within the context of a full-fledged estimated NK model.
} 
(f) details on the construction of the dataset; (g) additional estimation results; and (h) robustness exercises for optimal policy.

\section{Model}

The model features standard frictions and a deterministic growth rate $\gamma \grave{a}$ la Smets and Wouters (2007) and is augmented with a banking sector that exploits lending relationships. This section outlines the optimization problem of each agent in the model and discusses some important equilibrium conditions. The full set of equilibrium conditions, detrending, and the deterministic steady state are reported in appendices B, C and D, respectively.

\subsection{Households}

Households are infinitely-lived and solve an inter-temporal utility maximization problem. The economy is populated by a continuum of households indexed by $j \in(0,1)$. Each household's preferences are represented by the following inter-temporal utility function:

$$
U_{t}^{j}=E_{t} \sum_{s=0}^{\infty} e_{t+s}^{B} \beta^{t+s} \frac{\left[\left(X_{t+s}^{j}\right)^{\phi}\left(1-H_{t+s}^{j}\right)^{1-\phi}\right]^{1-\sigma_{c}}}{1-\sigma_{c}},
$$

where $\beta \in(0,1)$ is the discount factor, $e_{t}^{B}$ is a preference shock, $X_{t}^{j}$ is habit-adjusted consumption, $H_{t}^{j}$ is labor supply in terms of hours worked, $\sigma_{c}$ is the relative risk aversion parameter and $\phi$ is a preference parameter affecting labor supply. Total time available to households is normalized to unity, thus $1-H_{t}^{j}$ represents leisure time. As in Fuhrer (2000), $X_{t}^{j}$ is given by

$$
\begin{array}{r}
X_{t}^{j}=C_{t}^{j}-\theta S_{t-1}^{c}, \\
S_{t}^{c}=\rho S_{t-1}^{c}+(1-\rho) C_{t},
\end{array}
$$

where $C_{t}^{j}$ is the level of consumption, $S_{t}^{c}$ is the stock of external habit formation, $\theta \in(0,1)$ is the degree of habit formation, and $\rho \in(0,1)$ is the persistence of the stock of habit.

Each household $j$ is a monopolistic provider of a differentiated labor service and supplies labor $H_{t}^{j}$ to satisfy demand,

$$
H_{t}^{j}=\left(\frac{w_{t}^{j}}{w_{t}}\right)^{-e_{t}^{W} \eta^{W}} H_{t}
$$

where $w_{t}^{j}$ is the real wage charged by household $j, w_{t}$ is the average real wage in the economy, $\eta^{W}$ is the intra-temporal elasticity of substitution across labor services, $e_{t}^{W}$ is a wage mark-up shock, and 
$H_{t}$ is average demand of labor services by firms. Similarly to Zubairy (2014), the households' budget constraint also includes a Rotemberg quadratic cost of adjusting the nominal wage, $W_{t}^{j}$, which is zero at the steady state. This cost is proportional to the average real value of labor services as in Furlanetto (2011), $\frac{\xi^{W}}{2}\left(\frac{W_{t}^{j}}{\gamma W_{t-1}^{j}}-\Pi\right)^{2} w_{t} H_{t}=\frac{\xi^{W}}{2}\left(\frac{w_{t}^{j}}{\gamma w_{t-1}^{j}} \Pi_{t}-\Pi\right)^{2} w_{t} H_{t}$, where $\xi^{W}$ is the wage adjustment cost parameter, $\Pi_{t}=P_{t} / P_{t-1}$ is the gross inflation rate of price index $P_{t}$, and $\Pi$ is the steady state value of inflation.

The representative household enters period $t$ with $D_{t-1}^{j}$ units of real deposits in the bank. During period $t$, the household chooses to consume $C_{t}^{j}$; supplies $H_{t}^{j}$ hours of work; receives real wage $w_{t}$, profits of financial and non-financial firms $\mathcal{P}_{t}$, bears the wage adjustment cost, pays lump-sum taxes $T_{t}$, and allocates savings in deposits at the bank, $D_{t}^{j}$, that pay the net nominal interest rate $R_{t}^{D}$ one period ahead. Therefore, the budget constraint reads as

$$
C_{t}^{j}+D_{t}^{j}+\frac{\xi^{W}}{2}\left(\frac{w_{t}^{j}}{\gamma w_{t-1}^{j}} \Pi_{t}-\Pi\right)^{2} w_{t} H_{t} \leq w_{t}^{j} H_{t}^{j}+\frac{1+R_{t-1}^{D}}{\Pi_{t}} D_{t-1}^{j}+\mathcal{P}_{t}-T_{t} .
$$

Each household maximizes inter-temporal utility (1) with respect to $C_{t}^{j}, D_{t}^{j}, w_{t}^{j}$ subject to (2), (3), (4) and (5).

\section{$2.2 \quad$ Entrepreneurs}

Entrepreneurs are distributed over a unit interval and indexed by $e \in(0,1)$. They borrow from banks to produce a differentiated output, $Y_{t}^{e}$, sold in a imperfectly competitive market at price $P_{t}^{e}$. Firms solve two optimization problems: an intra-temporal problem - that can be thought of being solved by the financial department and gives rise to lending relationships - which determines the composition of their loan demand; and an inter-temporal problem in which they maximize the flow of discounted profits by choosing the quantity of factors for production and the price level.

Entrepreneurs minimize their borrowing costs by choosing their demand for each variety of loans and exhibit deep habits in lending. ${ }^{7}$ The literature has employed this feature to incorporate the effects of informational asymmetries on borrowers' creditworthiness that lead to lending relationships into a DSGE model (see Aliaga-Diaz and Olivero, 2010; Aksoy et al., 2013; Melina and Villa, 2014 and Ravn,

\footnotetext{
${ }^{7}$ An other important component of firm's debt in the US is non-banking finance. This paper focuses on bank-to-firm relationships, hence it abstracts from the issuance of corporate bonds. For a model featuring also corporate bonds see e.g. De Fiore and Uhlig (2011).
} 
2016, among others). ${ }^{8}$ The optimization problem consists in the following:

$$
\begin{aligned}
& \min _{L_{b t}^{e}} E_{t}\left[\int_{0}^{1} \frac{1+R_{b t}^{L}}{\Pi_{t+1}} L_{b t}^{e} d b\right] \\
& \text { s.t. } \quad\left[\int_{0}^{1}\left(L_{b t}^{e}-\theta^{L} S_{b t-1}^{L}\right)^{1-\frac{1}{\eta^{L}}} d b\right]^{1 /\left(1-\frac{1}{\eta^{L}}\right)}=\left(X_{t}^{L}\right)^{e}, \\
& \quad S_{b t}^{L}=\varrho^{L} S_{b t-1}^{L}+\left(1-\varrho^{L}\right) L_{b t},
\end{aligned}
$$

where $R_{b t}^{L}$ is the net lending rate, $L_{b t}^{e}$ is the demand by firm $e$ for loans issued by bank $b, \theta^{L}$ is the degree of habit in lending, $S_{b t}^{L}$ is the stock of (external) habit in lending, $\eta^{L}$ is the elasticity of substitution across varieties of loans, $\left(X_{t}^{L}\right)^{e}$ is the demand for loans by firm $e$ augmented by lending relationships and $\varrho^{L}$ is the persistence of lending relationships. Equation (6) represents overall lending expenditure, equation (7) imposes deep habits in lending, while equation (8) imposes persistence in the stock of habit.

The deep-habit-adjusted Dixit-Stiglitz aggregator in equation (7) captures two important findings in empirical finance literature: (i) banks differentiating loan products ${ }^{9}$ and (ii) firms holding multiple bank relationships (see e.g. Ongena and Smith, 2000). Solving the cost minimization problem yields a downward-sloping demand for loans, which becomes a constraint in the banks' profit maximization problem (equation 15). ${ }^{10}$

Entrepreneur $e$ faces also an inter-temporal problem by solving which she chooses employment, $H_{t}^{e}$, capital, $K_{t+1}^{e}$, investment, $I_{t}^{e}$, capital utilization, $U_{t}^{e}$, and the price level, $P_{t}^{e}$, to maximize the expected discounted value of its lifetime profits. Recalling that in this economy firms are owned by households, the stochastic discount factor of the former, $\Lambda_{t, t+1}$, is given by the inter-temporal marginal rate of

\footnotetext{
${ }^{8}$ Although the deep habits framework is not a formal setup of asymmetric information, it produces the same effects in the symmetric equilibrium (as shown by Aksoy et al., 2013, Appendix).

${ }^{9}$ According to DeYoung (2007) banks provide customized and differentiated loan contracts. Community banks, for example, try differentiation by knowing the names of their customers. Large banks differentiate through marketing campaigns that create brand images for their products. van Ewijk and Arnold (2014) emphasize that relationship banks create market power, and establish information monopolies given their ability to invest in customer-specific information (see also Elyasiani and Goldberg, 2004).

${ }^{10}$ The microeconomic theory of banking regards market power to be an important feature of the banking sector, usually modeled via: (i) asymmetric information generating switching costs, which in turn produce a "lock-in" effect (e.g. Diamond, 1984); (ii) menu costs such as application fees to obtain a new loan or to renegotiate an outstanding loan (e.g. Kim et al., 2003); (iii) transportation costs as in Salop (1979) between the customer's location and that of the bank (e.g. Freixas and Rochet, 2008, Section 3.3; Andrés and Arce 2012), among others. Our approach is in line with other recent contributions in the macroeconomic literature (Gerali et al., 2010, Pariès et al., 2011, Angelini et al., 2014, Gambacorta and Signoretti, 2014, Cuciniello and Signoretti, 2015, among others), which assume that firms stipulate composites of slightly differentiated loan contracts.
} 
substitution of the latter. The inter-temporal optimization problem is summarized by the following:

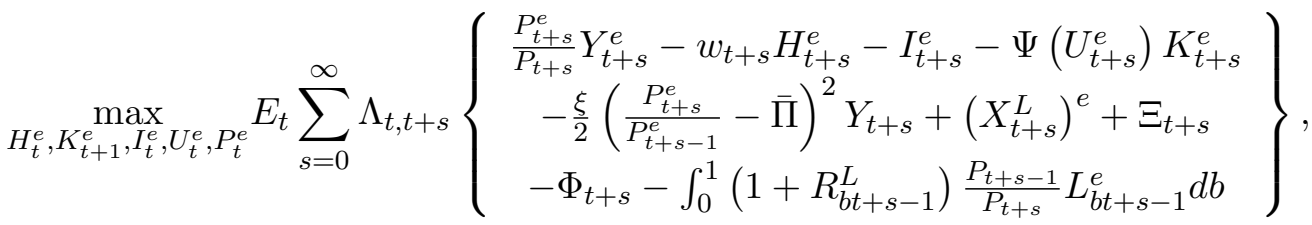

$$
\begin{aligned}
& \text { s.t. } K_{t+1}^{e}=I_{t}^{e}\left[1-S\left(\frac{I_{t}^{e}}{I_{t-1}^{e}}\right)\right] e_{t}^{I}+(1-\delta) e_{t}^{K} K_{t}^{e} \text {, } \\
& L_{t}^{e} \geq \zeta I_{t}^{e} \\
& Y_{t}^{e}=\left(\frac{P_{t}^{e}}{P_{t}}\right)^{-e_{t}^{P} \eta} Y_{t}=F\left(e_{t}^{A}, e_{t}^{K}, U_{t}^{e}, K_{t}^{e}, H_{t}^{e}\right) .
\end{aligned}
$$

Equation (9) is the sum of discounted profits expressed in terms of net cash flows, in which $w_{t} H_{t}^{e}$ is the wage bill; $I_{t}^{e}$ is the expenditure in investment goods; using capital at rate $U_{t}^{e}$ entails a cost of $\Psi\left(U_{t}^{e}\right) K_{t}^{e}$, where $\Psi\left(U_{t}\right)=\gamma_{1}\left(U_{t}-1\right)+\frac{\gamma_{2}}{2}\left(U_{t}-1\right)^{2} ;^{11} \frac{\xi}{2}\left(\frac{P_{t+s}^{e}}{P_{t+s-1}^{e}}-\bar{\Pi}\right)^{2} Y_{t+s}$ is a Rotemberg convex cost of adjusting prices; $\left(X_{t}^{L}\right)^{e}$ is the deep-habit-adjusted aggregate of loans; $\Xi_{t} \equiv \theta^{L} \int_{0}^{1} \frac{1+R_{b t}^{L}}{1+R_{t}^{L}} S_{b t-1}^{L} d b$ is a deep-habit-specific term analogous to that of Ravn et al. (2006); $\Phi_{t}$ is a lump-sum cost, not affecting the firms' behavior, needed to ensure that in equilibrium the amount of financing firms actually receive is given by the pure sum of all loans, i.e. $\left(X_{t}^{L}\right)^{e}+\Xi_{t}-\Phi_{t}=\int_{0}^{1} L_{b t}^{e} d b$; $^{12}$ while $\int_{0}^{1}\left(1+R_{b t+s-1}^{L}\right) \frac{P_{t+s-1}}{P_{t+s}} L_{b t+s-1}^{e} d b$ represents what they repay to banks. Equation (10) is a standard law of motion of capital, which depreciates at rate $\delta$, and investment is subject to adjustment costs, where $S(\gamma)=S^{\prime}(\gamma)=0$ and $S^{\prime \prime}(\gamma)>0$. In particular, following Smets and Wouters (2007), we assume that investment adjustment costs are quadratic: $S\left(\frac{I_{t}}{I_{t-1}}\right)=\frac{\psi}{2}\left(\frac{I_{t}}{I_{t-1}}-\gamma\right)^{2}, \psi>0$, where $\psi$ represents the elasticity of the marginal investment adjustment cost to changes in investment. The term $e_{t}^{I}$ represents a shock to the investment-specific technology process, while $e_{t}^{K}$ is a capital quality shock that enters the model as in Gertler and Karadi (2011) and represents a source of exogenous variations in the value of capital. ${ }^{13}$ We take constraint (11) from Aliaga-Diaz and Olivero (2010). This

\footnotetext{
${ }^{11}$ We normalize the steady-state utilization rate to unity, $u=1$. It follows that $\Psi(u)=0, \Psi^{\prime}(u)=\gamma_{1}, \Psi^{\prime \prime}(u)=\gamma_{2}$ and the elasticity of the utilization rate to changes in the marginal utilization cost is $\frac{\Psi^{\prime}(u)}{\Psi^{\prime \prime}(u) u}=\frac{\gamma_{1}}{\gamma_{2}} \equiv \sigma_{u} \equiv \frac{1-\eta_{u}}{\eta_{u}}$. Following Smets and Wouters (2007) we estimate $\eta_{u} \in[0,1]$.

${ }^{12}$ This cost has the intuitive economic interpretation of a switching cost, as it is given by the difference between what Aliaga-Diaz and Olivero (2010) and Ravn (2016) label effective borrowing, i.e. $\left(X_{t}^{L}\right)^{e}+\Xi_{t}$ (borrowing affecting firms' decisions), and actual borrowing, $\int_{0}^{1} L_{b t}^{e} d b$. To compute $\Phi_{t}$ note that at the equilibrium $\left(X_{t}^{L}\right)^{e}+\Xi_{t}=\int_{0}^{1} \frac{1+R_{b t}^{L}}{1+R_{t}^{L}} L_{b t}^{e} d b$, and $L_{b t}^{e}=\left(\frac{1+R_{b t}^{L}}{1+R_{t}^{L}}\right)^{-\eta^{L}}\left(X_{t}^{L}\right)^{e}+\theta^{L} S_{b t-1}^{L}$, hence $\Phi_{t}=\int_{0}^{1}\left(\frac{R_{b t}^{L}-R_{t}^{L}}{1+R_{t}^{L}}\right)\left[\left(\frac{1+R_{b t}^{L}}{1+R_{t}^{L}}\right)^{-\eta^{L}}\left(X_{t}^{L}\right)^{e}+\theta^{L} S_{b t-1}^{L}\right] d b$. Switching cost $\Phi_{t}$ can be nicely interpreted: (i) it is an increasing function of the difference between the rate charged by bank $b$ and the market rate $\left(R_{b t}^{L}-R_{t}^{L}\right)$; (ii) it decreases if market power decreases ( $\eta^{L}$ increases); (iii) it increases if lending relationships are stronger $\left(\theta^{L}\right.$ increases); (iv) it is equal to zero in the presence of perfect competition $\left(\eta^{L} \rightarrow \infty\right)$ and if there are no lending relationships $\left(\theta^{L}=0\right)$.

${ }^{13}$ For instance, Gertler et al. (2012) interpret negative capital quality shocks as capturing economic obsolescence as
} 
makes it necessary for firms to borrow from banks in order to finance a fraction $\zeta \in(0,1)$ of investment expenditures, i.e. it represents a financing constraint needed for external credit to play a role in the model. ${ }^{14}$ Without the imposition of this constraint, firms would always find it optimal to satisfy their financing needs via internal funds, given the presence of market power in the banking sector. Thus constraint (11) holds with equality in equilibrium and defines the total amount of loans demanded by firm e. Lastly, expression (12) equates the firm-specific Dixit-Stiglitz demand, with intra-temporal elasticity of substitution $\eta$ and subject to price mark-up shock $e_{t}^{P}$, to firm's production, which we assume to obey to a Cobb-Douglas technology, $F\left(e_{t}^{A}, U_{t}, K_{t}, H_{t}\right)=e_{t}^{A}\left(H_{t}\right)^{\alpha}\left(e_{t}^{K} U_{t} K_{t}\right)^{1-\alpha}$, with $\alpha$ being the labor share of income and $e_{t}^{A}$ being a total factor productivity shock.

\subsection{Banks}

Each bank $b$ chooses its demand for deposits, $D_{b t}$, the supply of loans to firms, $L_{b t}$, and the loan rate, $R_{b t}^{L}$, to maximize the expected discounted value of its lifetime profits. ${ }^{15}$ Banks are owned by households as well; therefore, their stochastic discount factor, $\Lambda_{t, t+1}$, is given by the inter-temporal marginal rate of substitution of households. The optimization problem is summarized by the following:

$$
\begin{aligned}
\max _{D_{b t}, L_{b t}, R_{b t}^{L}} E_{t} & \sum_{s=0}^{\infty} \Lambda_{t, t+s}\left\{\frac{1+R_{b t+s-1}^{L}}{\Pi_{t+s}} L_{b t+s-1}-\frac{1+R_{t+s-1}^{D}}{\Pi_{t+s}} D_{b t+s-1}\right\} \\
\text { s.t. } L_{b t} & =D_{b t} \\
L_{b t} & =\left(\frac{1+R_{b t}^{L}}{1+R_{t}^{L}}\right)^{-\eta^{L}} X_{t}^{L}+\theta^{L} S_{b t-1}^{L} .
\end{aligned}
$$

Equation (13) represents the profit of the bank in each period, given by the difference between earnings on assets and interest payments on liabilities. Equation (14) represents the bank's balance sheet, where loans on the asset side are equal to deposits on the liabilities side. Equation (15) represents the bankspecific demand for loans and arises from the solution to entrepreneurs' intratemporal problem.

By substituting the balance sheet constraint (14) in the profit function, the maximization problem simplifies to choosing the supply of loans and the loan rate, without the need of introducing a Lagrange multiplier associated to constraint (14). In the symmetric equilibrium, the first order condition with

opposed to physical depreciation.

${ }^{14}$ Chowdhury et al. (2006), Aksoy et al. (2013) and Melina and Villa (2014) implicitly assume that $\zeta=1$ and that firms need to borrow also to pay for the wage bill. This alternative specification of the financing constraint introduces both the so-called cost channel of monetary policy of Christiano et al. (2005) and Ravenna and Walsh (2006), who assume that workers need to be paid before production takes place, and an additional cost channel working through investment expenditures, which also need to be paid for in advance. We prefer to remain closer to financial frictions models in which firms borrow only to finance the acquisition of capital goods (e.g. Gertler and Karadi, 2011, impose that firms must finance the acquisition of the whole capital stock via bank lending, but they pay for the wage bill using internal finance). In addition, given that one of the goals of the paper is to bring the model to the data via Bayesian estimation, we deem appropriate to calibrate $\zeta$ to match the data instead of imposing $\zeta=1$.

${ }^{15}$ For a model in which banks also lend to households see Gerali et al. (2010). 
respect to $L_{b t}$ is

$$
\nu_{t}=E_{t} \Lambda_{t, t+1}\left[\left(\frac{R_{t}^{L}-R_{t}^{D}}{\Pi_{t+1}}\right)+\theta^{L}\left(1-\varrho^{L}\right) \nu_{t+1}\right]
$$

where $\nu_{t}$ is the Lagrange multiplier associated with constraint (15). Equation (16) states that the shadow value of lending an extra unit in period $t$ is equal to the benefit from the spread earned on this transaction, plus the benefit of expected future profits arising from a share $\theta^{L}$ of lending being held up at time $t+1$.

The first order condition with respect to $R_{b t}^{L}$ yields

$$
E_{t}\left[\Lambda_{t, t+s} L_{t+1} \frac{1+R_{t}^{L}}{\Pi_{t+1}}\right]=\nu_{t} \eta^{L} E_{t}\left[X_{t+1}^{L}\right]
$$

Equation (17) states that the marginal benefit of increasing the loan rate should be equal to its marginal cost given by the reduced demand for loans evaluated at $\nu_{t}$.

\subsection{Central bank}

A central bank conducts monetary policy by following a Taylor-type rule,

$$
\begin{aligned}
& \log \left(\frac{R_{t}^{n}}{R^{n}}\right)=\rho_{r} \log \left(\frac{R_{t-1}^{n}}{R^{n}}\right) \\
& +\left(1-\rho_{r}\right)\left[\begin{array}{c}
\rho_{\pi} \log \left(\frac{\Pi_{t}}{\Pi}\right)+\rho_{y} \log \left(\frac{Y_{t}}{Y_{t}^{f}}\right) \\
+\rho_{\Delta y}\left(\log \left(\frac{Y_{t}}{Y_{t}^{f}}\right)-\log \left(\frac{Y_{t-1}}{Y_{t-1}^{f}}\right)\right)+\rho_{s} \log \left(\frac{L_{t}}{\gamma L_{t-1}} \frac{\Pi_{t}}{\Pi}\right)
\end{array}\right]+\epsilon_{t}^{R},
\end{aligned}
$$

where $R_{t}^{n} \equiv 1+R_{t}^{D}$ is the gross nominal interest rate, and $\rho_{r}, \rho_{\pi}, \rho_{y}, \rho_{\Delta y}$ and $\rho_{s}$ are policy parameters referring to interest-rate smoothing, the responsiveness of the nominal interest rate to inflation deviations, the output gap, output gap growth, and nominal credit growth (as e.g. Christiano et al., 2010a,b, among others), respectively, while $\epsilon_{t}^{R}$ is a mean zero, i.i.d. random shock with standard deviations $\sigma_{R}$. Equation (18) represents an augmented version of the monetary policy rule employed by Smets and Wouters (2007). In particular the output gap is computed as the deviation of output from its potential level, $Y_{t}^{f}$, obtained in a flexible-price and flexible-wage version of the model. Various alternative rules are explored in Subsection 3.5. ${ }^{16}$

\subsection{Equilibrium}

The government is assumed to run a balanced budget, i.e. $T_{t}=e_{t}^{G}$, where $e_{t}^{G}$ is government spending. In the symmetric equilibrium all markets clear.

\footnotetext{
${ }^{16}$ Results are also robust to including real than nominal credit growth.
} 
The model is closed by the resource constraint,

$$
Y_{t}=C_{t}+I_{t}+e_{t}^{G}+\frac{\xi}{2}\left(\Pi_{t}-\Pi\right)^{2} Y_{t}+\frac{\xi^{W}}{2}\left(\frac{\Pi_{t}^{W}}{\gamma}-\Pi\right)^{2} w_{t} H_{t}+\Psi\left(U_{t}\right) K_{t}
$$

and a set of $\mathrm{AR}(1)$ processes,

$$
\log \left(\frac{e_{t}^{\varkappa}}{\bar{e}^{\varkappa}}\right)=\rho_{\varkappa} \log \left(\frac{e_{t-1}^{\varkappa}}{\bar{e}^{\varkappa}}\right)+\epsilon_{t}^{\varkappa},
$$

where $\varkappa=\{A, B, G, I, P, W, K\}, \bar{e}^{\varkappa}$ are steady-state values, $\rho_{\varkappa}$ are auto-regressive parameters, and $\epsilon_{t}^{\varkappa}$ are mean zero, i.i.d. random shocks with standard deviations $\sigma_{\varkappa}$.

\section{Estimation}

This section reports the results of the Bayesian estimation. Subsection 3.1 discusses the data and the estimation strategy. Subsection 3.2 presents parameter estimates and a marginal likelihood comparison confirming the leaning-against-the-wind policy from an empirical viewpoint. Subsection 3.3 discusses estimated impulse responses of key macroeconomic and financial variables to the structural shocks of the model and disentangles the stabilization properties of a credit-growth-augmented Taylor rule. Subsection 3.4 presents the analysis of the variance decomposition to assess the importance of the exogenous structural shocks. Finally, Subsection 3.5 checks the robustness of the empirical results to an array of alternative Taylor-type rules.

\subsection{Data and estimation strategy}

The model is estimated with Bayesian methods (see An and Schorfheide, 2007; Smets and Wouters, 2007, among others). The Kalman filter is used to evaluate the likelihood function of the observable variables. The likelihood function and the prior distribution of the parameters are combined to calculate the posterior distributions. The posterior Kernel is then simulated numerically using the MetropolisHasting algorithm with two chains of 150,000 draws each. This Markov Chain Monte Carlo method generates draws from the posterior density and updates the candidate parameter after each draw.

The model is estimated for the US over the Great Moderation period, 1984Q1-2008Q2, using a set of macroeconomic and financial variables. In particular, we use the following nine observable variables: GDP, consumption, investment, wage, lending, hours worked, GDP deflator inflation, the FFR and the lending rate. ${ }^{17}$ Although observations on all variables are available at least from 1955 onwards, we focus on the above-mentioned period because it is characterized by a single monetary policy regime. Extending the sample period to include the Great Recession may yield biased estimates due to the nonlinearities induced by the fact than the nominal interest rate in the US reached the zero lower

\footnotetext{
${ }^{17}$ See Appendix $\mathrm{F}$ for a detailed discussion of data sources, definitions and transformations.
} 


\begin{tabular}{lll}
\hline Parameter & & Value \\
\hline Discount factor & $\beta$ & 0.99 \\
Capital depreciation rate & $\delta$ & 0.025 \\
Production function parameter & $\alpha$ & 0.67 \\
Elasticity of substitution in goods & $\eta$ & 6 \\
Elasticity of substitution in labor & $\eta^{W}$ & 11 \\
Elasticity of substitution in banking & $\eta^{L}$ & set to target $R^{L}-R^{D}=0.0076$ \\
Preference parameter & $\phi$ & set to target $H=0.33$ \\
Government share of output & $\frac{G}{Y}$ & 0.19 \\
Fraction of financed investment & $\zeta$ & 0.63 \\
\hline
\end{tabular}

Table 2: Calibrated parameters

bound (on this see e.g. Galí et al., 2011). The following set of measurement equations show the link between the observables in the dataset and the endogenous variables of the DSGE model:

$$
\left[\begin{array}{c}
\Delta Y_{t}^{o} \\
\Delta C_{t}^{o} \\
\Delta I_{t}^{o} \\
\Delta W_{t}^{o} \\
\Delta L_{t}^{o} \\
H_{t}^{o} \\
\pi_{t}^{o} \\
r_{t}^{n, o} \\
r_{t}^{L, o}
\end{array}\right]=\left[\begin{array}{c}
\bar{\gamma} \\
\bar{\gamma} \\
\bar{\gamma} \\
\bar{\gamma} \\
\bar{\gamma} \\
\bar{h} \\
\bar{\gamma} \\
\bar{r}^{n} \\
\bar{r}^{L}
\end{array}\right]+\left[\begin{array}{c}
\hat{Y}_{t}-\hat{Y}_{t-1} \\
\hat{C}_{t}-\hat{C}_{t-1} \\
\hat{I}_{t}-\hat{I}_{t-1} \\
\hat{W}_{t}-\hat{W}_{t-1} \\
\hat{L}_{t}-\hat{L}_{t-1} \\
\hat{H}_{t} \\
\hat{\Pi}_{t} \\
\hat{R}_{t}^{n} \\
\hat{R}_{t}^{L}
\end{array}\right]+\left[\begin{array}{c}
0 \\
0 \\
0 \\
0 \\
\varepsilon_{L t}^{m e} \\
0 \\
0 \\
0 \\
\varepsilon_{R^{L} t}^{m e}
\end{array}\right],
$$

where variables on the left-hand side are the observables, $\bar{\gamma}$ is the common quarterly trend growth rate of GDP, consumption, investment, wages and lending; $\bar{h}$ is average hours worked; $\bar{\pi}$ is the average quarterly inflation rate; $\bar{r}^{n}$ is the average quarterly nominal interest rate; and $\bar{r}^{L}$ is the average quarterly lending rate. A hat over a variable indicates the log-deviation from its own steady state. The term $\varepsilon_{L t}^{m e}$ represents a measurement error in the equation for lending, while $\varepsilon_{R^{L} t}^{m e}$ is the measurement error in the equation for the lending rate. These measurement errors account for a possible mismatch between the financial variables in the model and those in the data, analogously to what Castelnuovo and Nisticò (2010) do for stock prices, among others.

Our general estimation and calibration strategy follows the standard procedure proposed by Smets and Wouters (2007). Table 2 shows the calibration of the parameters which could not be identified in the dataset and/or are related to steady-state values of the variables. The time period in the model corresponds to one quarter in the data. The discount factor, $\beta$, is equal to the conventional value of 0.99 , implying an annual steady-state real interest rate of $4 \%$. The capital depreciation rate, $\delta$, is 
equal to 0.025 , amounting to an annual depreciation of $10 \%$. As standard, the labor share of income, $\alpha$, is equal to 0.67 . The elasticity of substitution across different varieties, $\eta$, is equal to 6 in order to target a steady state gross mark-up equal to 1.20. The elasticity of substitution in the banking sector, $\eta^{L}$, is set in order to match a spread between the bank prime loan rate and the 3-month Treasury bill rate of 304 basis points per year - given the estimated value of lending relationship parameter $\theta^{L}$ consistently with US data during the Great Moderation. ${ }^{18}$ The elasticity of substitution in the labor market, $\eta^{W}$ is set equal to 11 as in Del Negro et al. (2011), implying a steady-state gross mark-up of 1.10. The preference parameter, $\phi$, is set to target steady-state hours of work equal to 0.33. The government-output ratio, $G / Y$, is calibrated at 0.19 , in line with the data. The steady state fraction of investment financed by bank loans, $\zeta$, is equal to 0.63 , again in line with our dataset.

The remaining parameters governing the dynamics of the model are estimated using Bayesian techniques. ${ }^{19}$ The locations of the prior means correspond to a large extent to those in previous studies on the US economy, e.g. Smets and Wouters (2007). ${ }^{20}$ We use the Inverse Gamma (IG) distribution for the standard deviation of the shocks and we set a loose prior with 2 degrees of freedom. We use the Beta distribution for all parameters bounded between 0 and 1. For the unbounded parameters we use the Normal distribution. In addition, we set the prior means of the constants in the measurement equations equal to average values in the dataset. As regards the parameters measuring lending relationships we choose prior means close to the values estimated by Aliaga-Diaz and Olivero (2010), equal to 0.70 for $\theta^{L}$ and to 0.80 for $\rho^{L}$, and we set a standard deviation of 0.125 for both. The prior distribution of the parameter measuring the response of the nominal interest rate to nominal credit growth, $\rho_{s}$, is on purpose loose. In fact, as shown in Figure 2, a prior mean of zero and a standard deviation of 0.30 enable the prior distribution to encompass a broad range of values around zero. This allows us to be agnostic on whether monetary policy leaned against the wind or not. Table 3 summarizes the prior distributions chosen to estimate the deep structural parameters and the shock processes.

\footnotetext{
${ }^{18}$ Note that, in our baseline model, given the estimated degree of deep habits in lending, the loan elasticity that matches an average spread of 304 basis points per year between the bank prime loan rate and the 3-month Treasury bill rate is 396. This number is higher but of the same order of magnitude of the GMM estimates for this parameter obtained by Aliaga-Diaz and Olivero (2010)-who use different definitions of credit spreads-and implies a much smaller degree of differentiation than that in the goods market.

${ }^{19}$ Version 4.4 .3 of the Dynare toolbox for Matlab is used for the estimation.

${ }^{20}$ While Smets and Wouters (2007) use the specification of price stickiness as in Calvo (1983), we use quadratic price adjustment costs as in Rotemberg (1982). However, up to a first-order approximation, the two specifications are observationally equivalent. The matching between the two works as follows (on this see Cantore et al. 2014, Appendix, and Jacob, 2015, among others). The log-linearized New-Keynesian Phillips Curve takes the following form: $\Pi_{t}=$ $\beta \Pi_{t+1}+\kappa M C_{t}$, where $\kappa=\frac{\eta-1}{\xi}$, under Rotemberg pricing; and $\kappa=\frac{\left(1-\beta \xi^{c}\right)\left(1-\xi^{c}\right)}{\xi^{c}}$, under Calvo contracts, where $\xi^{c}$ is in turn the Calvo parameter. Given a certain $\xi$, it is then possible to compute the implied analogous parameter in the Calvo world. In our case, the prior of $\xi=30$ corresponds to $\kappa=0.17$ and $\xi^{c}=0.67$, approximately the posterior mean of the Calvo parameter estimated by Smets and Wouters (2007). Our posterior mean turns out to be $\xi=45.43$, a value close to available estimates of the Rotemberg parameter for the US in the literature (e.g. Zubairy, 2014, estimates $\xi=48.90$ ).
} 


\subsection{Estimation results}

Table 3 reports the posterior mean with $90 \%$ probability intervals in square brackets and the marginal log-likelihood of the model computed as in Geweke (1999). There is evidence of both habit in consumption and habit persistence, with statistically positive parameter values, the mean of which equals 0.57 and 0.66 respectively. The degree of deep habits in banking is close to 0.58 with a persistence of 0.72. The degree of price stickiness implies that firms adjust prices about every three quarters and a half, while the estimate of the Rotemberg parameter for wage stickiness is higher, in line with Zubairy (2014). Technology and government spending shocks are more persistent than the other shocks.

As regards the Taylor rule parameters, in line with many other studies, estimates capture nominal interest rate inertia and that, during the Great Moderation, monetary policy was aggressive on inflation, with an estimated coefficient of 2. Similarly to Smets and Wouters (2007), there is evidence of a weak response to the output gap, with an estimated coefficient of 0.03 , and of a stronger response to changes in the output gap, with a posterior estimate of 0.16 .

A novel result is that the monetary authority is found to respond to nominal credit growth with a point estimate for coefficient $\rho_{s}$ of 0.25 and a confidence interval of $[0.16,0.34]$.

Figure 2 shows the prior and posterior densities of the Taylor rule parameters, which are well identified by the data. This is particularly important for $\rho_{s}$, i.e. the responsiveness of the nominal interest rate to credit growth, exhibiting a posterior distribution entirely located around positive values, with the probability density tightly gathered around the posterior mean, despite the loose prior.

This last result is confirmed also by a race between Geweke (1999) marginal log-likelihoods of the baseline model and a restricted model featuring a standard Taylor rule, i.e. with $\rho_{s}=0$. Table 4 reports the Bayes factor $(\mathrm{BF})$ and the statistics by Kass and Raftery (1995) (KR). ${ }^{21}$ Subsection 3.5 reports the estimated Taylor rule parameters and likelihood races for models featuring alternative monetary policy rules. Results turn out to be robust. With a BF well above 100, we find "decisive evidence" in favor of a model featuring a credit-growth-augmented Taylor rule over a standard one. The KR statistics is computed as twice the log of the BF. In this case this amounts to 22.94 and points to "very strong" evidence in favor of the unconstrained baseline model versus the restricted model featuring a standard Taylor rule. ${ }^{22}$ In other words, these results point to evidence that, during

\footnotetext{
${ }^{21}$ Let $m_{i}$ be a given model, with $m_{i} \in M$, and $L\left(Y \mid m_{i}\right)$ be the marginal data density of model $i$ for the common dataset $Y$, then the BF between model $i$ and model $j$ is computed as:

$$
B F_{i / j}=\frac{L\left(Y \mid m_{i}\right)}{L\left(Y \mid m_{j}\right)}=\frac{\exp \left(L L\left(Y \mid m_{i}\right)\right)}{\exp \left(L L\left(Y \mid m_{j}\right)\right)}
$$

where $L L$ stands for log-likelihood. According to Jeffreys (1998), a BF of 3 - 10 provides "slight" evidence in favor of model $i$ relative to model $j$; a BF in the range [10 - 100] provides "strong to very strong" evidence; and a BF greater than 100 provides "decisive evidence".

${ }^{22}$ Values of the KR statistics above 10 can be considered "very strong" evidence in favor of model $i$ relative to model $j$; between 6 and 10 represent "strong" evidence; between 2 and 6 "positive" evidence; while values below 2 are "not worth more than a bare mention".
} 


\begin{tabular}{|c|c|c|c|c|c|}
\hline \multirow[t]{2}{*}{ Parameter } & & \multicolumn{3}{|c|}{ Prior } & \multirow[t]{2}{*}{ Posterior Mean } \\
\hline & & Distrib. & Mean & $\mathrm{Std} / \mathrm{df}$ & \\
\hline \multicolumn{6}{|l|}{ Structural } \\
\hline Relative risk aversion & $\sigma_{c}$ & Normal & 1.50 & 0.10 & $1.5505[1.4095 ; 1.7305]$ \\
\hline Habits in consumption & $\theta$ & Beta & 0.70 & 0.10 & $0.5732[0.4781 ; 0.6671]$ \\
\hline Habit persist. in consumption & $\rho$ & Beta & 0.70 & 0.10 & $0.6563[0.5155 ; 0.8031]$ \\
\hline Deep habits in banking & $\theta^{L}$ & Beta & 0.70 & 0.125 & $0.5769[0.4336 ; 0.7188]$ \\
\hline Habit persist. in banking & $\varrho^{L}$ & Beta & 0.80 & 0.125 & $0.7173[0.5273 ; 0.8930]$ \\
\hline Price stickiness & $\xi$ & Normal & 30.0 & 5.00 & $45.4310[38.4095 ; 52.2765]$ \\
\hline Wage stickiness & $\xi^{W}$ & Normal & 100.0 & 10.00 & $93.8691[75.1532 ; 112.6440]$ \\
\hline Invest. adjust. costs & $\psi$ & Normal & 4.00 & 1.50 & $2.5747[0.8315 ; 3.9961]$ \\
\hline Capital utilization & $\eta_{u}$ & Beta & 0.50 & 0.15 & $0.8588[0.7776 ; 0.9500]$ \\
\hline Inflation -Taylor rule & $\rho_{\pi}$ & Normal & 1.50 & 0.20 & $1.9983[1.7193 ; 2.2547]$ \\
\hline Output gap -Taylor rule & $\rho_{y}$ & Gamma & 0.10 & 0.05 & $0.0271[0.0059 ; 0.0466]$ \\
\hline Output gap growth -Taylor rule & $\rho_{\Delta y}$ & Gamma & 0.10 & 0.05 & $0.1574[0.0405 ; 0.2674]$ \\
\hline Credit growth-Taylor rule & $\rho_{s}$ & Normal & 0.00 & 0.30 & $0.2522[0.1626 ; 0.3426]$ \\
\hline Interest rate smoothing & $\rho_{r}$ & Beta & 0.80 & 0.10 & $0.8390[0.8132 ; 0.8666]$ \\
\hline \multicolumn{6}{|l|}{ Averages } \\
\hline Trend growth rate & $\bar{\gamma}$ & Normal & 0.44 & 0.10 & $0.3917[0.3266 ; 0.4580]$ \\
\hline Inflation rate & $\bar{\pi}$ & Gamma & 0.63 & 0.10 & $0.6546[0.5826 ; 0.7343]$ \\
\hline Interest rate & $\bar{r}^{n}$ & Gamma & 1.31 & 0.10 & $1.2738[1.1714 ; 1.3792]$ \\
\hline Hours of work & $\bar{h}$ & Normal & 0.00 & 0.10 & $-0.0043[-0.1566 ; 0.1631]$ \\
\hline Lending rate & $\bar{r}^{L}$ & Gamma & 1.98 & 0.10 & $1.9357[1.8532 ; 2.0242]$ \\
\hline \multicolumn{6}{|l|}{ Exogenous processes } \\
\hline \multirow[t]{2}{*}{ Technology } & $\rho_{A}$ & Beta & 0.50 & 0.20 & $0.9630[0.9378 ; 0.9890]$ \\
\hline & $\sigma_{A}$ & IG & 0.10 & 2.0 & $0.0047[0.0042 ; 0.0053]$ \\
\hline \multirow[t]{2}{*}{ Government spending } & $\rho_{G}$ & Beta & 0.50 & 0.20 & $0.9576[0.9378 ; 0.9785]$ \\
\hline & $\sigma_{G}$ & IG & 0.10 & 2.0 & $0.0239[0.0211 ; 0.0269]$ \\
\hline Interest rate & $\sigma_{R}$ & $\mathrm{IG}$ & 0.10 & 2.0 & $0.0013[0.0012 ; 0.0015]$ \\
\hline \multirow[t]{2}{*}{ Investment-specific } & $\rho_{I}$ & Beta & 0.50 & 0.20 & $0.3647[0.0585 ; 0.6484]$ \\
\hline & $\sigma_{I}$ & $\mathrm{IG}$ & 0.10 & 2.0 & $0.0185[0.0002 ; 0.0348]$ \\
\hline \multirow[t]{2}{*}{ Preference } & $\rho_{B}$ & Beta & 0.50 & 0.20 & $0.6973[0.5139 ; 0.8875]$ \\
\hline & $\sigma_{B}$ & $\mathrm{IG}$ & 0.10 & 2.0 & $0.0104[0.0078 ; 0.0131]$ \\
\hline \multirow[t]{2}{*}{ Capital quality } & $\rho_{K}$ & Beta & 0.50 & 0.20 & $0.9311[0.8992 ; 0.9660]$ \\
\hline & $\sigma_{K}$ & $\mathrm{IG}$ & 0.10 & 2.0 & $0.0021[0.0014 ; 0.0029] \eta$ \\
\hline \multirow[t]{2}{*}{ Price mark-up } & $\rho_{P}$ & Beta & 0.50 & 0.20 & $0.8017[0.7279 ; 0.8817]$ \\
\hline & $\sigma_{P}$ & IG & 0.10 & 2.0 & $0.0151[0.0127 ; 0.0175]$ \\
\hline \multirow[t]{2}{*}{ Wage mark-up } & $\rho_{W}$ & Beta & 0.50 & 0.20 & $0.7775[0.6971 ; 0.8589]$ \\
\hline & $\sigma_{W}$ & $\mathrm{IG}$ & 0.10 & 2.0 & $0.0487[0.0366 ; 0.0610]$ \\
\hline Std - measurement error - lending & $\sigma_{\varepsilon_{L}}$ & $\mathrm{IG}$ & 0.10 & 2.0 & $0.0232[0.0205 ; 0.0259]$ \\
\hline Std - measurement error - lending rate & $\sigma_{\varepsilon_{R} L}$ & $\mathrm{IG}$ & 0.10 & 2.0 & $0.0172[0.0149 ; 0.0193]$ \\
\hline Marginal log-likelihood & & & & & -739.661 \\
\hline
\end{tabular}

Table 3: Prior and posterior distributions of estimated parameters (90\% confidence intervals are in square brackets)

the Great Moderation, monetary policy leaned against the wind blowing from the loan market. So far the literature has focused more on the response of monetary policy to asset prices. For instance, on 

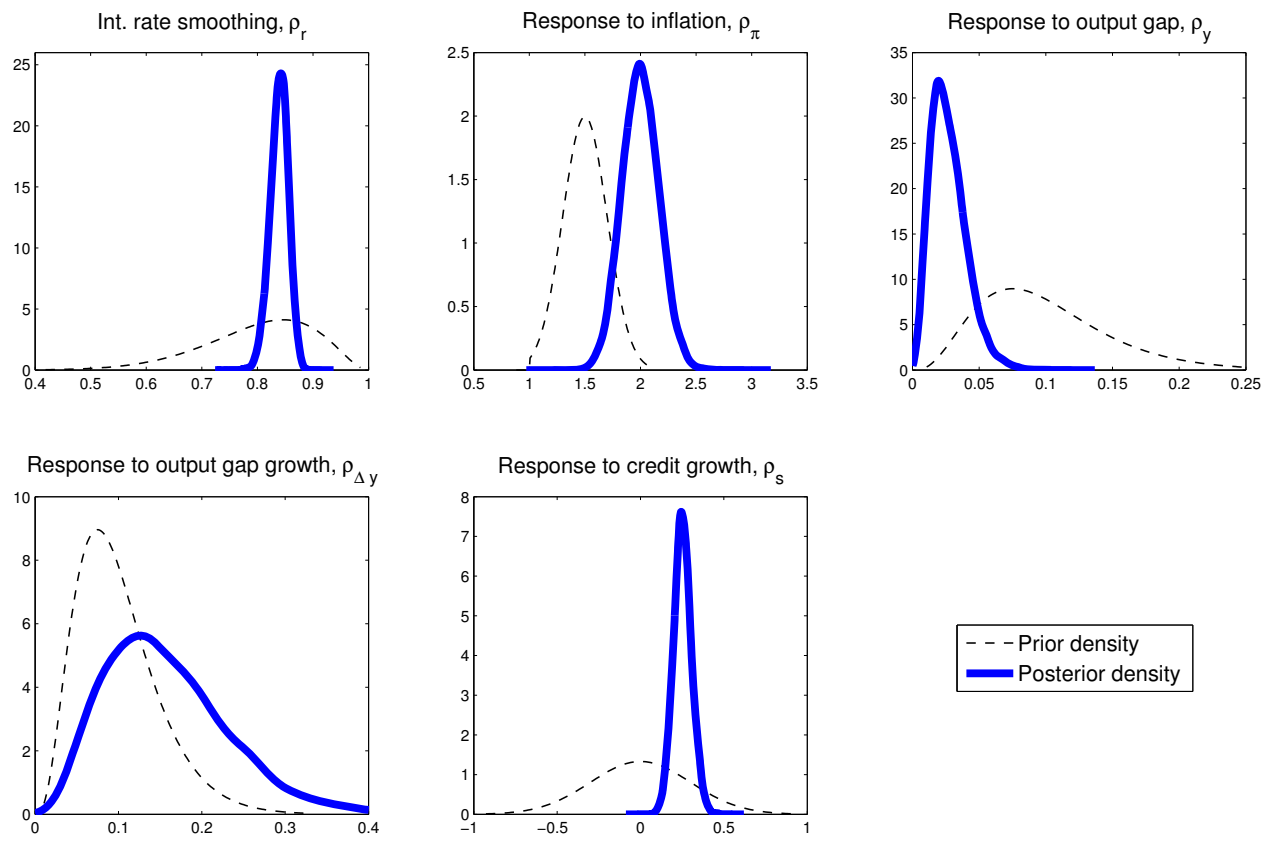

- - Prior density

Posterior density

Figure 2: Prior and posterior probability densities of the Taylor rule parameters

\begin{tabular}{lcc}
\hline & Baseline & $\rho_{s}=0$ \\
\hline Geweke (1999) marginal log-likelihood & -739.661 & -751.132 \\
Bayes factor & & $9.59 \times 10^{4}$ \\
Kass-Raftery statistics & & 22.94 \\
\hline
\end{tabular}

Table 4: Marginal log-likelihood comparison

the empirical side, Castelnuovo and Nisticò (2010) argue that a model where the monetary authority has an active concern towards stock-market fluctuations is supported by US data (as we also verify in Subsection 3.5). Christiano et al. (2010b) estimate a significant degree of "leaning against credit exuberance" in the euro area monetary policy framework for the period 1985Q1-2008Q2. Hence, the first novel contribution of our paper to this literature is to provide an analogous empirical result for the US economy, albeit with a different model.

\subsection{Dynamic properties of the estimated model}

In this section we disentangle the effects of the estimated leaning-against-the-wind policy versus a standard Taylor rule via the analysis of the responses of key macroeconomic variables to all eight structural shocks in the model. In Figure 3 we report impulse responses to shocks of size one percent that determine a fall in real output. 

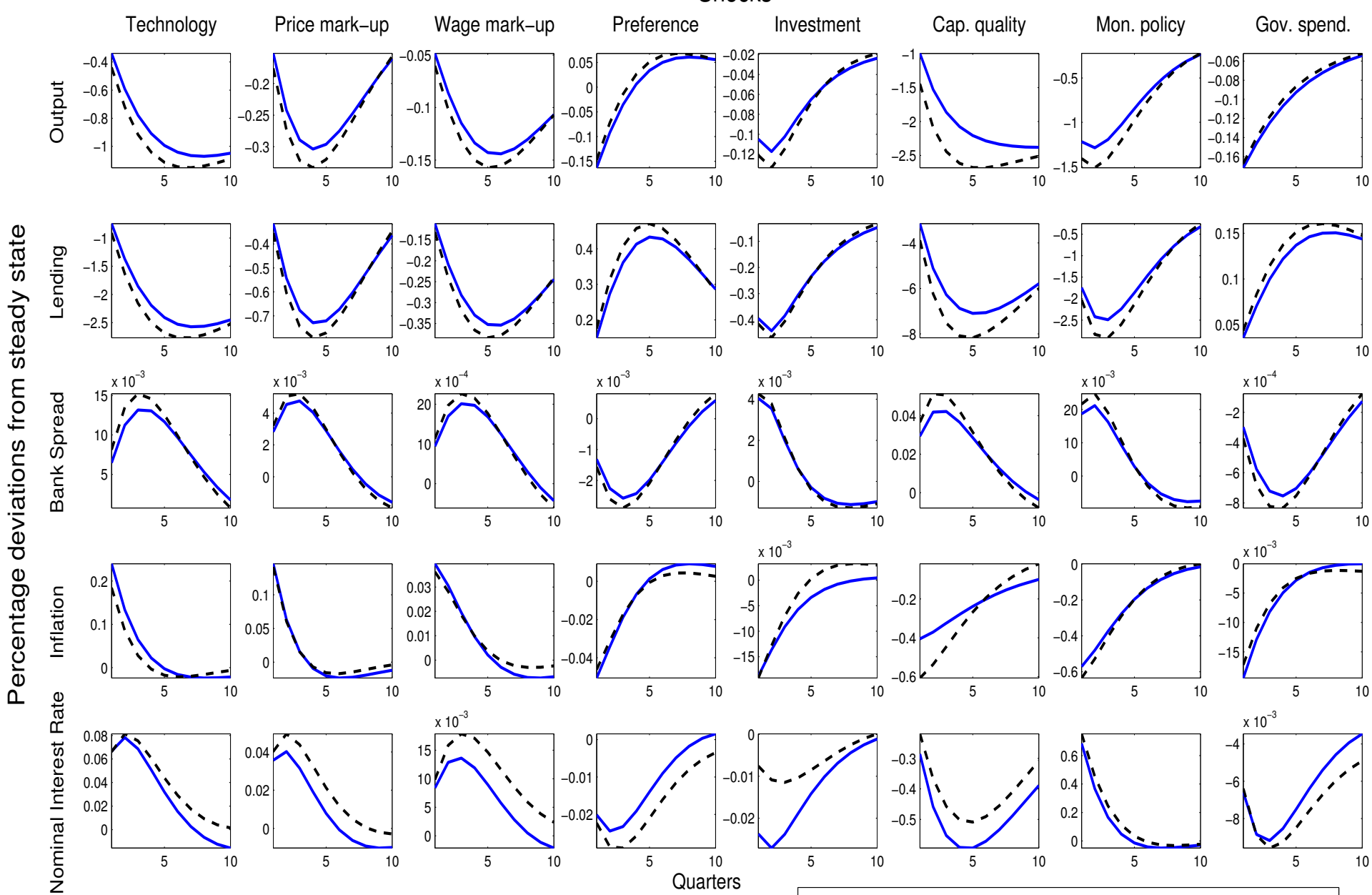

\section{- Taylor rule augmented with response to credit growth (baseline model) - - - Standard Taylor rule (restricted model)}

Figure 3: Impulse responses of selected variables to structural shocks of size 1 percent in the estimated model featuring a Taylor rule augmented with a response to credit growth and in a restricted model with a standard Taylor rule 
The solid line represents responses within the estimated model featuring the credit-growth augmented Taylor rule, whereas the dashed line represents responses of a counterfactual model with $\rho_{s}=0$.

In particular, the model features five aggregate demand shocks (preference, investment-specific, capital quality, government spending, monetary policy), in which output and inflation move in the same direction, and three aggregate supply shocks (technology, wage mark-up and price mark-up), in which output and inflation move in opposite directions.

A number of noteworthy results emerge from the inspection of Figure 3. First, while the sign of impulse responses is preserved across the two Taylor rule specifications, the severity of the economic downturn generated by each shock varies. Second, with the exception of the preference and government spending shocks, lending positively comoves with real output and the bank spread exhibits a countercyclical behavior. This is a feature of lending relationships: in the simulated contractions, future profits are expected to be low (indeed real output persistently remains below steady state), hence banks find it optimal to exploit current lending relationships by charging higher bank spreads and enhancing current profits.

As far as the preference shock is concerned, this generates a shorter-lived output contraction and an overshooting. The explanation is in the fact that such a shock determines a fall of future marginal utility of consumption relative to the current one, and this leads to a fall in consumption and an increase in savings.

The subsequent greater availability of financial funds makes banks willing to supply more loans, which in turn boost future economic activity and profits. The latter are anticipated by banks, which find it optimal to charge a lower spread and lock in new customers into bank-firm lending relationships. Similar arguments apply to the contractionary government spending shock, which crowds in private investment.

In the presence of a credit-growth-augmented Taylor rule, the central bank partially counteracts fluctuations of lending. In the model lending, has real effects because it is instrumental for the acquisition of capital. Therefore, for those shocks in response to which lending exhibits a pro-cyclical behavior, the contraction of output is more severe in the absence of a credit-growth-augmented Taylor rule. On the contrary, for the preference shock and the government spending shock - which yield a counter-cyclical lending response - such a Taylor rule leads to a slightly more severe output contraction. The presence of lending relationships consistently generates responses of the bank spread of opposite sign relative to those of lending. Thus, the general lesson to be learned from the inspection of impulse responses is that leaning against the wind has a stabilizing effect on output for those shocks that imply a pro-cyclical response of lending and a counter-cyclical response of the bank spread. 


\begin{tabular}{|c|c|c|c|c|c|c|c|c|c|}
\hline & \multirow[t]{2}{*}{ Horizon } & \multicolumn{5}{|c|}{ Structural shocks } & \multirow[b]{2}{*}{$\begin{array}{l}\text { Capital } \\
\text { quality }\end{array}$} & \multirow[b]{2}{*}{$\begin{array}{l}\text { Mon. } \\
\text { policy }\end{array}$} & \multirow[b]{2}{*}{$\begin{array}{r}\text { Gov. } \\
\text { spend. }\end{array}$} \\
\hline & & $\begin{array}{l}\text { Tech- } \\
\text { nology }\end{array}$ & $\begin{array}{r}\text { Price } \\
\text { mark-up }\end{array}$ & $\begin{array}{r}\text { Wage } \\
\text { mark-up }\end{array}$ & $\begin{array}{l}\text { Prefe- } \\
\text { rence }\end{array}$ & $\begin{array}{l}\text { Invest. } \\
\text { specific }\end{array}$ & & & \\
\hline \multirow[t]{6}{*}{ Output } & 1 & 5.81 & 11.95 & 12.53 & 6.87 & 8.14 & 10.22 & 6.05 & 38.43 \\
\hline & 4 & 13.21 & 18.30 & 30.06 & 1.31 & 4.33 & 15.57 & 3.15 & 14.07 \\
\hline & 8 & 17.89 & 15.48 & 35.91 & 0.68 & 2.20 & 18.55 & 1.66 & 7.62 \\
\hline & 20 & 25.50 & 10.03 & 28.19 & 0.49 & 1.23 & 28.87 & 0.90 & 4.80 \\
\hline & 40 & 28.51 & 7.78 & 21.98 & 0.39 & 0.96 & 35.85 & 0.69 & 3.84 \\
\hline & uncon. & 29.64 & 7.13 & 20.17 & 0.36 & 0.89 & 37.66 & 0.63 & 3.52 \\
\hline \multirow[t]{6}{*}{ Inflation } & 1 & 10.93 & 41.24 & 31.44 & 2.39 & 0.97 & 6.32 & 4.88 & 1.82 \\
\hline & 4 & 9.31 & 30.27 & 36.56 & 2.37 & 1.11 & 11.42 & 7.08 & 1.87 \\
\hline & 8 & 8.78 & 30.13 & 35.05 & 2.30 & 1.06 & 13.78 & 7.14 & 1.77 \\
\hline & 20 & 8.68 & 29.51 & 35.81 & 2.34 & 1.03 & 14.07 & 6.86 & 1.70 \\
\hline & 40 & 8.56 & 29.07 & 35.34 & 2.30 & 1.02 & 15.26 & 6.75 & 1.70 \\
\hline & uncon. & 8.49 & 28.44 & 34.60 & 2.25 & 1.00 & 16.94 & 6.60 & 1.68 \\
\hline \multirow[t]{6}{*}{ Lending } & 1 & 7.21 & 13.33 & 17.05 & 1.44 & 31.16 & 26.22 & 3.17 & 0.41 \\
\hline & 4 & 12.02 & 15.98 & 29.18 & 2.20 & 10.21 & 27.73 & 1.81 & 0.87 \\
\hline & 8 & 16.02 & 13.64 & 33.33 & 2.33 & 4.78 & 27.63 & 0.98 & 1.29 \\
\hline & 20 & 24.59 & 10.23 & 29.02 & 2.00 & 3.07 & 28.48 & 0.63 & 1.98 \\
\hline & 40 & 28.04 & 9.60 & 27.25 & 1.87 & 2.89 & 27.60 & 0.59 & 2.15 \\
\hline & uncon. & 27.50 & 9.24 & 26.25 & 1.80 & 2.78 & 29.77 & 0.57 & 2.09 \\
\hline \multirow[t]{6}{*}{ Bank spread } & 1 & 6.17 & 12.04 & 13.85 & 1.24 & 36.64 & 25.64 & 4.09 & 0.32 \\
\hline & 4 & 11.81 & 16.00 & 28.74 & 2.19 & 11.70 & 26.58 & 2.11 & 0.87 \\
\hline & 8 & 14.51 & 14.22 & 31.34 & 2.24 & 9.70 & 25.06 & 1.73 & 1.20 \\
\hline & 20 & 12.38 & 15.18 & 34.54 & 2.38 & 8.64 & 24.16 & 1.67 & 1.05 \\
\hline & 40 & 12.81 & 14.54 & 33.72 & 2.32 & 8.18 & 25.75 & 1.58 & 1.10 \\
\hline & uncon. & 12.94 & 14.50 & 33.62 & 2.32 & 8.15 & 25.79 & 1.57 & 1.10 \\
\hline
\end{tabular}

Table 5: Variance decomposition

\subsection{Variance decomposition}

Movements in output, lending, bank spread and inflation are now decomposed into parts caused by each shock at different time horizons. Table 5 reports both the conditional and the unconditional variance decomposition.

While, on impact, demand shocks play a dominant role in affecting output dynamics, in the mediumto-long term the technology shock together with the other two supply shocks - wage and price mark-up - are its main drivers. These three shocks together account for about $30 \%$ of output fluctuations on impact, $62 \%$ at a one-year horizon and almost $70 \%$ at a two-year horizon, with demand shocks having a more muted effect. The role of government and monetary policy shocks decay over time. Price and wage mark-up shocks are also the dominant factors behind both short-run and medium-run movements in inflation. These results are in line with Smets and Wouters (2007).

The variance decomposition of lending shows that the three supply shocks accounts for more than $60 \%$ of long-term variation in lending. However, differently from output dynamics, the investment- 


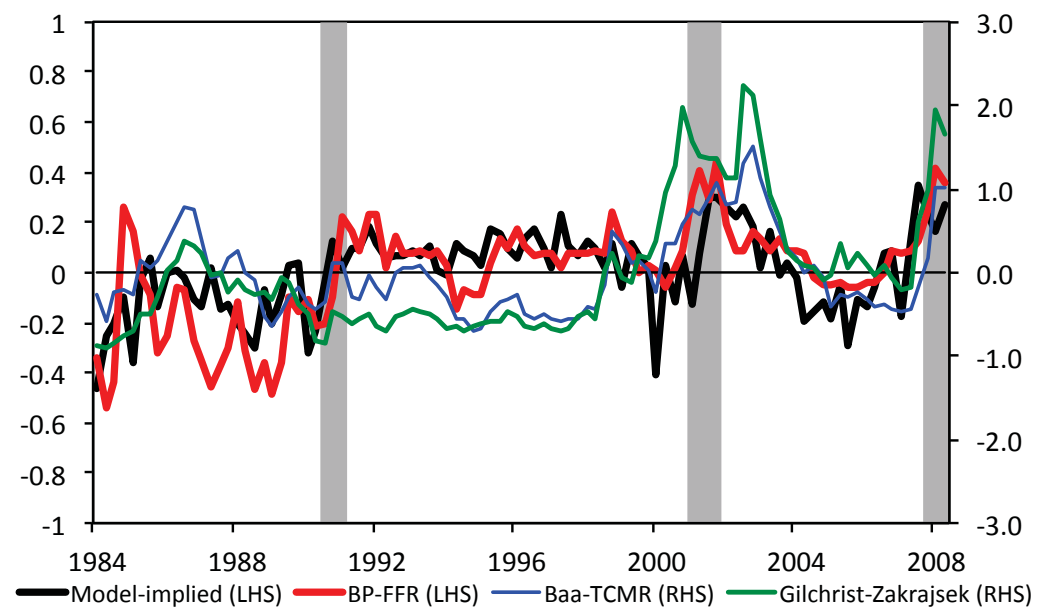

Figure 4: Demeaned credit spreads in the US economy v.s. the model-implied measure (shaded areas indicate NBER recessions)

specific technology and the capital quality shocks play a stronger role: on impact they dominate explaining $57 \%$ of lending fluctuations - and in the longer term they account for around $30 \%$ of the variation in lending. This result is not surprising as the investment-specific technology shock affects the investment Euler equation - lending being used to finance purchases of capital goods - and the capital quality shock affects the law of motion of capital. It is worth noticing that all dominant shocks in the variance decomposition of lending are those that foster a pro-cyclical response of lending itself (see Subsection 3.3).

Results on the variance decomposition of the bank spread show that, on impact, the investmentspecific technology shock and, to a minor extent, the capital quality shock are the main exogenous sources of its variation. Price and wage mark-up shocks also play an important role. As the model features a tight (negative) relationship between the bank spread and lending, those shocks playing a key role in explaining the dynamics of lending are likely to play a quantitatively similar role in accounting for the variation of the bank spread.

On this point it is important to note that the shocks that are dominant sources of movements in the spread are those implying a counter-cyclical response of the spread itself. Figure 4 depicts the model-implied spread (one-step-ahead forecast) along with three (demeaned) proxies: (i) Bank Prime (BP) rate minus FFR; (ii) Moody's Baa minus long-term Treasury constant maturity rate (TCMR); and (iii) the series of the spread constructed by Gilchrist and Zakrajšek (2012). ${ }^{23}$ Unsurprisingly, the model generates a forecast of the spread of an order of magnitude and behavior closest to the BP-FFR, given that both rates are used as observables in the estimation, and it represents the closest data

\footnotetext{
${ }^{23}$ Based on Compustat data, Gilchrist and Zakrajšek (2012) use prices of individual corporate bonds traded in the secondary market. As noted by Gelain and Ilbas (2014), this series of spread is closely related to measures of financial intermediary health, which makes it a highly informative financial indicator.
} 
counterpart of the theoretical definition of the spread in the model. Realistically the spread exhibits rapid surges during recessions. It shows a reasonable comovement also with the other two measures, which, however, are more volatile. ${ }^{24}$ In addition, the model indeed captures the low lending rates of the late 1990s, the burst of the dot-com bubble and the picking-up of the spread in correspondence to the end-of-sample crisis.

\subsection{Robustness to alternative Taylor-type interest-rate rules}

This subsection investigates whether our evidence in favor of a leaning-against-the wind policy is robust to different specifications of the Taylor rule. In particular, we consider the six formulations reported in Table 6.

Formulation (I) is a so-called simple and implementable rule, which includes output in deviation from steady state, $Y$, instead of a latent variable such as the output gap, so that the central bank responds only to observable variables (see e.g. Faia and Monacelli, 2007; Schmitt-Grohe and Uribe, 2007).

Formulation (II) is an augmented version of implementable rule (I) featuring not only a response to the deviation of output from its steady state, but also a response to output growth.

Formulation (III) is our baseline specification augmented with a response to the stock-price gap. In line with Castelnuovo and Nisticò (2010), this is defined as the gap between the stock price prevailing in the model with price and wage stickiness, $Q_{t}$, and the stock price that would prevail in a model without nominal stickiness, $Q_{t}^{f}$.

Formulation (IV) includes a second-order autoregressive interest rate smoothing as proposed by Coibion and Gorodnichenko (2012), and applied also by Ascari et al. (2011), to investigate whether the richer persistence structure might wipe out the response to nominal credit growth.

Formulation (V) combines both an $\mathrm{AR}(2)$ interest-rate smoothing structure and a response to stock prices, in addition to the response to nominal credit growth.

Lasly, formulation (VI) corresponds to the same baseline specification of equation (18), but with one important difference: the potential output $\left(\tilde{Y}_{t}^{f}\right)$ used to compute the output gap is the level that would prevail not only in the absence of price and wage stickiness (as standard in the literature), but also in the absence of financial frictions.

In estimating the models with formulation (III) and (V) for the Taylor rule we include an additional observable variable (stock prices). The corresponding additional measurement equation is given by:

$$
\Delta Q_{t}^{o}=\bar{Q}+\hat{Q}_{t}-\hat{Q}_{t-1}+\varepsilon_{Q t}^{m e}
$$

\footnotetext{
${ }^{24}$ The correlation coefficients between the model-implied variable and the BP-FFR, Baa-TCMR and Gilchrist-Zakrajsek proxies are $0.60,0.28$, and 0.29 , respectively. These are all statistically significant at a $1 \%$ level.
} 
(I)

$$
\begin{aligned}
& \log \left(\frac{R_{t}^{n}}{R^{n}}\right)=\rho_{r} \log \left(\frac{R_{t-1}^{n}}{R^{n}}\right)+\left(1-\rho_{r}\right)\left[\begin{array}{c}
\rho_{\pi} \log \left(\frac{\Pi_{t}}{\Pi}\right)+\rho_{y} \log \left(\frac{Y_{t}}{Y}\right) \\
+\rho_{s} \log \left(\frac{L_{t}}{\gamma L_{t-1}} \frac{\Pi_{t}}{\Pi}\right)
\end{array}\right]+\epsilon_{t}^{R} \\
& \log \left(\frac{R_{t}^{n}}{R^{n}}\right)=\rho_{r} \log \left(\frac{R_{t-1}^{n}}{R^{n}}\right)+\left(1-\rho_{r}\right)\left[\begin{array}{c}
\rho_{\pi} \log \left(\frac{\Pi_{t}}{\Pi}\right)+\rho_{y} \log \left(\frac{Y_{t}}{Y}\right) \\
+\rho_{\Delta y} \log \left(\frac{Y_{t}}{Y_{t-1}}\right)+\rho_{s} \log \left(\frac{L_{t}}{\gamma L_{t-1}} \frac{\Pi_{t}}{\Pi}\right)
\end{array}\right]+\epsilon_{t}^{R}
\end{aligned}
$$

$$
\log \left(\frac{R_{t}^{n}}{R^{n}}\right)=\rho_{r} \log \left(\frac{R_{t-1}^{n}}{R^{n}}\right)+\left(1-\rho_{r}\right)\left[\begin{array}{c}
\rho_{\pi} \log \left(\frac{\Pi_{t}}{\Pi}\right)+\rho_{y} \log \left(\frac{Y_{t}}{Y_{t}^{f}}\right) \\
+\rho_{\Delta y}\left(\log \left(\frac{Y_{t}}{Y_{t}^{f}}\right)-\log \left(\frac{Y_{t-1}}{Y_{t-1}^{f}}\right)\right) \\
+\rho_{s} \log \left(\frac{L_{t}}{\gamma L_{t-1}} \frac{\Pi_{t}}{\Pi}\right)+\rho_{q} \log \left(\frac{Q_{t}}{Q_{t}^{f}}\right)
\end{array}\right]+\epsilon_{t}^{R}
$$

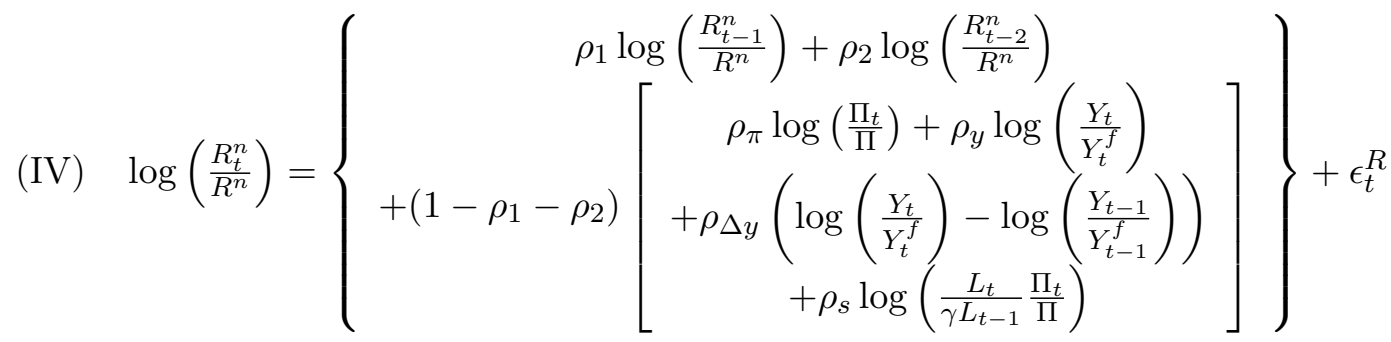

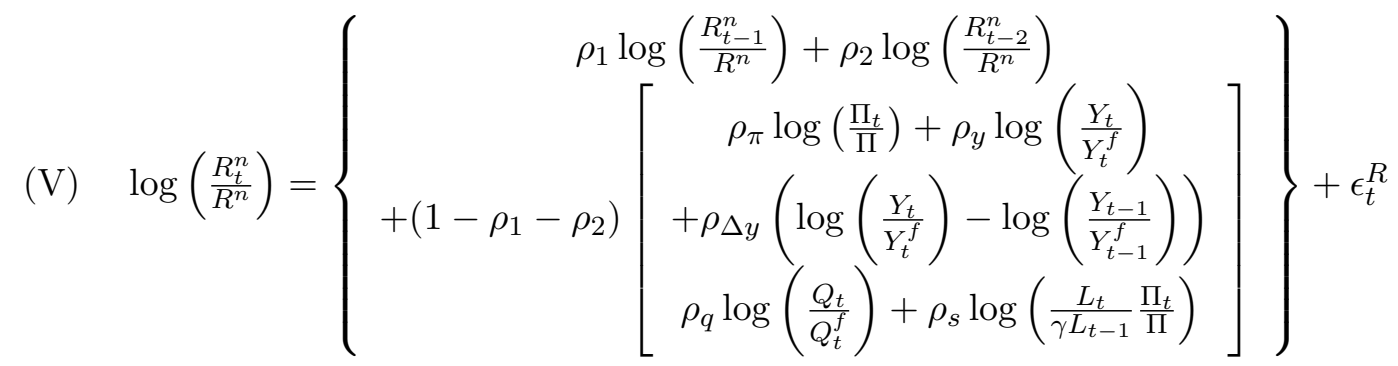

$(\mathrm{VI}) \log \left(\frac{R_{t}^{n}}{R^{n}}\right)=\rho_{r} \log \left(\frac{R_{t-1}^{n}}{R^{n}}\right)+\left(1-\rho_{r}\right)\left[\begin{array}{c}\rho_{\pi} \log \left(\frac{\Pi_{t}}{\Pi}\right)+\rho_{y} \log \left(\frac{Y_{t}}{\tilde{Y}_{t}^{f}}\right) \\ +\rho_{\Delta y}\left(\log \left(\frac{Y_{t}}{\tilde{Y}_{t}^{f}}\right)-\log \left(\frac{Y_{t-1}}{\tilde{Y}_{t-1}^{f}}\right)\right) \\ +\rho_{s} \log \left(\frac{L_{t}}{\gamma L_{t-1}} \frac{\Pi_{t}}{\Pi}\right)\end{array}\right]+\epsilon_{t}^{R}$

Table 6: Alternative Taylor-type interest-rate rules

where $\bar{Q}$ is the average quarterly growth rate of the stock price index and $\varepsilon_{Q t}^{m e}$ is a measurement error. ${ }^{25}$

Table 7 reports the prior distributions and posterior estimates of the Taylor rule parameters in the

\footnotetext{
${ }^{25}$ We follow Castelnuovo and Nisticò (2010) both in the choice the observable (the S\&P 500 index, downloaded from Datastream) and the inclusion of the measurement error. This, on one hand, allows us to include an additional observable without including an additional structural shock and to avoid stochastic singularity and, on the other hand, it helps us capture potential mismatches between the data and the asset price variable in the model.
} 


\begin{tabular}{|c|c|c|c|c|c|}
\hline \multirow[t]{2}{*}{ Parameter } & & \multicolumn{3}{|c|}{ Prior } & \multirow[t]{2}{*}{ Posterior Mean } \\
\hline & & Distrib. & Mean & \multirow[t]{2}{*}{$\mathrm{Std} / \mathrm{df}$} & \\
\hline \multicolumn{5}{|c|}{ (I) - Implementable } & \\
\hline Interest rate smoothing & $\rho_{r}$ & Beta & 0.80 & 0.10 & $0.8450[0.8187 ; 0.8689]$ \\
\hline Inflation & $\rho_{\pi}$ & Normal & 1.50 & 0.20 & $2.0208[1.7482 ; 2.2845]$ \\
\hline Output & $\rho_{y}$ & Gamma & 0.10 & 0.05 & $0.0213[0.0056 ; 0.0371]$ \\
\hline Credit growth & $\rho_{s}$ & Normal & 0.00 & 0.30 & $0.2861[0.1963 ; 0.3726]$ \\
\hline \multicolumn{6}{|c|}{ (II) - Output growth } \\
\hline Interest rate smoothing & $\rho_{r}$ & Beta & 0.80 & 0.10 & $0.8393[0.8129 ; 0.8670]$ \\
\hline Inflation & $\rho_{\pi}$ & Normal & 1.50 & 0.20 & $2.0052[1.7295 ; 2.2784]$ \\
\hline Output & $\rho_{y}$ & Gamma & 0.10 & 0.05 & $0.0192[0.0052 ; 0.0328]$ \\
\hline Output growth & $\rho_{\Delta y}$ & Gamma & 0.10 & 0.05 & $0.1250[0.0344 ; 0.2140]$ \\
\hline Credit growth & $\rho_{s}$ & Normal & 0.00 & 0.30 & $0.2512[0.1599 ; 0.3369]$ \\
\hline \multicolumn{6}{|c|}{ (III) - Stock prices } \\
\hline Interest rate smoothing & $\rho_{r}$ & Beta & 0.80 & 0.10 & $0.8430[0.8170 ; 0.8688]$ \\
\hline Inflation & $\rho_{\pi}$ & Normal & 1.50 & 0.20 & $2.0114[1.7422 ; 2.2659]$ \\
\hline Output gap & $\rho_{y}$ & Gamma & 0.10 & 0.05 & $0.0247[0.0061 ; 0.0433]$ \\
\hline Output growth & $\rho_{\Delta y}$ & Gamma & 0.10 & 0.05 & $0.1394[0.0312 ; 0.2370]$ \\
\hline Stock prices & $\rho_{q}$ & Gamma & 0.10 & 0.05 & $0.1320[0.0407 ; 0.2196]$ \\
\hline Credit growth & $\rho_{s}$ & Normal & 0.00 & 0.30 & $0.2393[0.1500 ; 0.3215]$ \\
\hline \multicolumn{6}{|c|}{$(I V)-A R(2)$ smoothing } \\
\hline $\mathrm{AR}(1)$ interest rate smoothing & $\rho_{1}$ & Normal & 1.10 & 0.50 & $1.3270[1.2089 ; 1.4512]$ \\
\hline $\mathrm{AR}(2)$ interest rate smoothing & $\rho_{2}$ & Normal & -0.20 & 0.50 & $-0.4623[-0.5823 ;-0.3492]$ \\
\hline Inflation & $\rho_{\pi}$ & Normal & 1.50 & 0.20 & $2.0225[1.7660 ; 2.2883]$ \\
\hline Output gap & $\rho_{y}$ & Gamma & 0.10 & 0.05 & $0.0230[0.0047 ; 0.0402]$ \\
\hline Output growth & $\rho_{\Delta y}$ & Gamma & 0.10 & 0.05 & $0.1632[0.0394 ; 0.2741]$ \\
\hline Credit growth & $\rho_{s}$ & Normal & 0.00 & 0.30 & $0.1956[0.1103 ; 0.2845]$ \\
\hline \multicolumn{6}{|c|}{$(V)$ - Stock prices and $A R(2)$ smoothing } \\
\hline $\mathrm{AR}(1)$ interest rate smoothing & $\rho_{1}$ & Normal & 1.10 & 0.50 & $1.3113[1.1947 ; 1.4312]$ \\
\hline $\mathrm{AR}(2)$ interest rate smoothing & $\rho_{2}$ & Normal & -0.20 & 0.50 & $-0.4416[-0.5598 ;-0.3330]$ \\
\hline Inflation & $\rho_{\pi}$ & Normal & 1.50 & 0.20 & $2.0394[1.7770 ; 2.3140]$ \\
\hline Output gap & $\rho_{y}$ & Gamma & 0.10 & 0.05 & $0.0209[0.0049 ; 0.0370]$ \\
\hline Output growth & $\rho_{\Delta y}$ & Gamma & 0.10 & 0.05 & $0.1411[0.0376 ; 0.2429]$ \\
\hline Stock prices & $\rho_{q}$ & Gamma & 0.10 & 0.05 & $0.1020[0.0279 ; 0.1695]$ \\
\hline Credit growth & $\rho_{s}$ & Normal & 0.00 & 0.30 & $0.1931[0.1087 ; 0.2808]$ \\
\hline \multicolumn{6}{|c|}{ (VI) - Potential output without financial frictions } \\
\hline Interest rate smoothing & $\rho_{r}$ & Beta & 0.80 & 0.10 & $0.8381[0.8117 ; 0.8664]$ \\
\hline Inflation & $\rho_{\pi}$ & Normal & 1.50 & 0.20 & $2.0048[1.7383 ; 2.2799]$ \\
\hline Output & $\rho_{y}$ & Gamma & 0.10 & 0.05 & $0.0273[0.0064 ; 0.0477]$ \\
\hline Output growth & $\rho_{\Delta y}$ & Gamma & 0.10 & 0.05 & $0.1544[0.0370 ; 0.2618]$ \\
\hline Credit growth & $\rho_{s}$ & Normal & 0.00 & 0.30 & $0.2494[0.1609 ; 0.3403]$ \\
\hline
\end{tabular}

Table 7: Prior and posterior distributions of estimated parameters of alternative Taylor-type interestrate rules (90\% confidence intervals are in square brackets)

six cases, while the estimates of all structural parameters are reported in Appendix G. In all cases the point estimate of the interest-rate response to credit growth $\left(\rho_{s}\right)$ is in the vicinity of 0.25 . In addition, 


\begin{tabular}{|c|c|c|c|c|c|c|}
\hline \multirow{5}{*}{$\begin{array}{l}\text { Marginal log-likelihood } \\
\text { Bayes factor } \\
\text { Kass-Raftery statistics }\end{array}$} & \multicolumn{2}{|c|}{ (I) - Implementable } & \multicolumn{2}{|c|}{ (II) -Output growth } & \multicolumn{2}{|c|}{ (III) -Stock prices } \\
\hline & Baseline & $\rho_{s}=0$ & Baseline & $\rho_{s}=0$ & Baseline & $\rho_{s}=0$ \\
\hline & \multirow{3}{*}{-742.302} & -756.149 & \multirow{3}{*}{-741.275} & -752.310 & \multirow[t]{3}{*}{-1086.730} & -1097.215 \\
\hline & & $1.03 \times 10^{6}$ & & $6.20 \times 10^{4}$ & & $3.58 \times 10^{4}$ \\
\hline & & 27.69 & & 22.07 & & 20.97 \\
\hline \multirow{4}{*}{$\begin{array}{l}\text { Marginal log-likelihood } \\
\text { Bayes factor } \\
\text { Kass-Raftery statistics }\end{array}$} & \multicolumn{2}{|c|}{$(I V)-A R(2)$ smoothing } & \multicolumn{2}{|c|}{$(V)$ - Stock prices $\&$ G $A(2)$} & \multicolumn{2}{|c|}{ (VI) - Pot. output w/o FF } \\
\hline & \multirow{3}{*}{-726.302} & -732.284 & \multirow{3}{*}{-1074.571} & -1079.948 & \multirow[t]{3}{*}{-739.639} & -751.115 \\
\hline & & $3.96 \times 10^{2}$ & & $2.16 \times 10^{2}$ & & $9.64 \times 10^{4}$ \\
\hline & & 11.96 & & 10.75 & & 22.95 \\
\hline
\end{tabular}

Table 8: Marginal log-likelihood comparisons for alternative Taylor-type interest-rate rules

the credible sets of parameter $\rho_{s}$ are well above zero across models, and the parameter itself is well identified in the data, as can be seen by inspecting prior and posterior probability densities reported in Appendix G. In sum, a credibly positive and economically important estimate of $\rho_{s}$ survives six alternative monetary policy formulations.

Moreover, the estimates of the parameters of the $\operatorname{AR}(2)$ interest-rate smoothing formulation $\left(\rho_{1}\right.$ and $\rho_{2}$ ) exhibit the same signs and comparable magnitudes of those of Ascari et al. (2011), while the responsiveness to stock-prices $\left(\rho_{q}\right)$ is close to that of Castelnuovo and Nisticò (2010).

Table 8 reports the Geweke (1999) marginal log-likelihoods, the Bayes factor, and the statistics by Kass and Raftery (1995) for the models estimated with Taylor rules (I)-(VI) versus the corresponding constrained versions obtained by setting $\rho_{s}=0$. For all specifications considered, the Bayes factor is always well above 100 and the Kass-Raftery statistics is always greater than 10, pointing to decisive evidence that during the Great Moderation monetary policy in the US leaned against the wind blowing from the loan market.

\section{Optimized simple monetary policy rules}

The analysis so far has brought a general equilibrium model with banking frictions to the data and has provided evidence that US monetary policy did lean against the wind blowing from the market for loans during the Great Moderation. The presence of the financial friction, making the bank spread countercyclical, implies that lending is more volatile than optimal over the business cycle. This would in principle create room for central bank intervention. Therefore, in this section, we pose a normative question: should the monetary policy rate react to developments in the loan market? To answer this question we compute optimized simple interest-rate feedback rules (in similar fashion to Schmitt-Grohe and Uribe, 2007; Levine et al., 2008) responding to macro-financial indicators that, we show, are able to closely mimic the Ramsey rule from a welfare perspective. 


\subsection{Design of simple monetary policy rules}

To design simple monetary policy rules, we rewrite the Taylor-type interest-rate feedback rule (18) as

$$
\begin{aligned}
\log \left(\frac{R_{t}^{n}}{\bar{R}^{n}}\right) & =\rho_{r} \log \left(\frac{R_{t-1}^{n}}{R^{n}}\right)+\alpha_{\pi} \log \left(\frac{\Pi_{t}}{\Pi}\right)+\alpha_{y} \log \left(\frac{Y_{t}}{Y_{t}^{f}}\right) \\
& +\alpha_{\Delta y}\left[\log \left(\frac{Y_{t}}{Y_{t}^{f}}\right)-\log \left(\frac{Y_{t-1}}{Y_{t-1}^{f}}\right)\right]+\alpha_{s} \log \left(\frac{L_{t}}{\gamma L_{t-1}} \frac{\Pi_{t}}{\Pi}\right),
\end{aligned}
$$

where $\alpha_{\pi} \equiv\left(1-\rho_{r}\right) \rho_{\pi}, \alpha_{y} \equiv\left(1-\rho_{r}\right) \rho_{y}, \alpha_{\Delta y} \equiv\left(1-\rho_{r}\right) \rho_{\Delta y}$ and $\alpha_{s} \equiv\left(1-\rho_{r}\right) \rho_{s}$. This re-parametrization allows for the possibility of integral rules with a unitary persistence parameter $\left(\rho_{r}=1\right)$. These are effectively price-level rules that make the price level trend-stationary as shown in Woodford (2003). Superinertial rules $\left(\rho_{r}>1\right)$ are examined in Appendix H.5. ${ }^{26}$ Then we numerically search for those feedback coefficients in rule (23) to maximize the present value of life-time utility, which reads

$$
\Omega_{t}=E_{t}\left[\sum_{s=0}^{\infty} \beta^{s} U\left(\tilde{X}_{t+s}, 1-H_{t+s}\right)\right],
$$

where $\tilde{X}_{t}$ is the stationarized consumption composite, given the equilibrium conditions of the model. Given the numerous frictions in the model, we refrain from deriving the welfare-based quadratic loss function and, more simply, rewrite equation (24) in recursive form as, e.g., Gertler and Karadi (2011):

$$
\Omega_{t}=U\left(\tilde{X}_{t}, 1-H_{t}\right)+\beta E_{t}\left[\Omega_{t+1}\right]
$$

In addition, as established by Schmitt-Grohe and Uribe (2007), while more stylized models allow for a first-order approximation to the equilibrium conditions to be sufficient to accurately approximate welfare up to a second order, the presence of the frictions requires taking a second-order approximation both of the mean of $\Omega_{t}$ and of the model's equilibrium conditions around the deterministic steady state. $^{27}$ In particular, we take the approximation around the steady state of the Ramsey equilibrium, outlined in Appendix E. Similarly to many other NK models in the literature (see e.g. Schmitt-Grohe and Uribe, 2004; Levine et al., 2008, among others), the steady-state value of the gross inflation rate in the Ramsey equilibrium turns out to be very close to unity $(\Pi=1.002)$, which implies an almost

\footnotetext{
${ }^{26}$ Our baseline results do not encompass superinertial rules as these imply additional inflation volatility. This is caused by an overshooting of the inflation rate necessary for the equilibrium to be determinate (see Rotemberg and Woodford, 1999). However, in line with Schmitt-Grohe and Uribe (2007), in Appendix H.5 we show that a greater-than-one interest rate inertia has immaterial effects on welfare relative to price level rules and that our conclusions survive also when $\rho_{r}>1$.

${ }^{27}$ In simpler models Cúrdia and Woodford (2009) and Carlstrom et al. (2010) derive the welfare based loss function using a linear-quadratic approximation, while Airaudo and Olivero (2014) show that the welfare costs of setting monetary policy under discretion (with respect to the optimal Ramsey plan) and of using simple policy rules are increasing in the magnitude of deep habits in credit markets and market power in banking.
} 
zero-inflation steady state.

As we approximate the solution to the equilibrium using perturbation methods and these do not easily allow incorporating non-negativity constraints, in similar fashion to Levine et al. (2008), we approximate the zero lower bound (ZLB) constraint on the nominal interest rate by introducing a penalty term in an auxiliary definition of welfare. While in Levine et al. (2008) the penalty term is a symmetric function, we adopt a specification meant to capture the inherent asymmetry implied by the zero lower bound. This is achieved by replacing our objective function (24) with modified welfare,

$$
\Omega_{t}^{*}=E_{t}\left\{\sum_{s=0}^{\infty} \beta^{s}\left[U\left(\tilde{X}_{t+s}, 1-H_{t+s}\right)-\Theta\left(R_{t+s}^{n}\right)\right]\right\}
$$

where term $\Theta\left(R_{t+s}^{n}\right) \equiv w_{r}\left(R_{t}^{n}-R^{n}\right)^{2} \exp \left[-w_{r}\left(R_{t}^{n}-1\right)\right]$ combines a quadratic with an exponential function, and represents a convex penalty for deviations of $R_{t}^{n}$ from its steady state. With weight parameter $w_{r}>0$ sufficiently large, this penalty increases exponentially if the nominal interest rate falls below zero $\left(R_{t}^{n}<1\right) .{ }^{28}$ Hence, the imposition of the approximate ZLB constraint translates into appropriately choosing the weight $w_{r}$ to achieve an arbitrarily low per-period probability of hitting the ZLB, $\operatorname{Pr}(Z L B) \equiv \operatorname{Pr}\left(R_{t}^{n}<1\right)$, which we set at 0.01 , i.e. once every 25 years.

We use the modified welfare specification for the sole purpose of imposing the ZLB constraint. In fact, we perform all welfare comparisons by using $\Omega_{t}$ and computing the consumption-equivalent welfare loss with respect to the Ramsey equilibrium, as in Schmitt-Grohe and Uribe (2007). For a particular regime associated to a given Taylor-type interest rate rule A, the welfare loss is implicitly defined as

$$
E_{t}\left\{\sum_{s=0}^{\infty} \beta^{s}\left[U\left((1-\omega) \tilde{X}_{t+s}^{R}, 1-H_{t+s}^{R}\right)\right]\right\}=E_{t}\left\{\sum_{s=0}^{\infty} \beta^{s}\left[U\left(\tilde{X}_{t+s}^{A}, 1-H_{t+s}^{A}\right)\right]\right\},
$$

where $\omega \times 100$ represents the percent permanent loss in consumption that should occur in the Ramsey regime $(\mathrm{R})$ in order agents to be as well off in regime $\mathrm{R}$ as they are in regime $\mathrm{A}$.

\subsection{Optimal monetary policy results}

Table 9 first shows the results arising from the computation of the Ramsey policy. Increasing the penalty parameter $w_{r}$ delivers a lower per-period probability of hitting the ZLB and small welfare losses (less than $0.1 \%$ in consumption-equivalent terms). ${ }^{29}$ With the penalty parameter equal to 5 ,

\footnotetext{
${ }^{28}$ This specification of the penalty term is more convenient than a simpler exponential function because the quadratic component implies a minimum at $R_{t}^{n}=R^{n}$, where $\Theta\left(R^{n}\right)=0$. The absence of this feature would generate a bias towards particularly high steady-state values of the nominal interest rate. It is also more realistic than a quadratic function alone because it penalizes negative interest rate deviations to a much greater extent than positive deviations. For sufficiently high values of $w_{r}$, the function becomes very steep when $R_{t}^{n}<1$ and rather flat when $R_{t}^{n}>1$. Also $\Omega_{t}^{*}$ can be expressed in recursive form analogously to $\Omega_{t}$.
} 


\begin{tabular}{|c|c|c|c|c|c|c|c|c|}
\hline$w_{r}$ & $\operatorname{Pr}(Z L B)$ & $\rho_{r}$ & $\alpha_{\pi}$ & $\alpha_{y}$ & $\alpha_{\Delta y}$ & $\alpha_{s}$ & $\Omega$ & $100 \times \omega$ \\
\hline \multicolumn{9}{|c|}{ Ramsey policy } \\
\hline 5.00 & 0.067 & - & - & - & - & - & -246.6634 & - \\
\hline 18.00 & 0.017 & - & - & - & - & - & -246.6750 & 0.04 \\
\hline 22.00 & 0.010 & - & - & - & - & - & -246.6777 & 0.05 \\
\hline \multicolumn{9}{|c|}{ Optimized Taylor-type rules } \\
\hline 3.85 & 0.067 & 0.875 & 2.101 & 0.016 & 0.000 & 0.000 & -246.8130 & 0.56 \\
\hline 11.50 & 0.017 & 1.000 & 1.122 & 0.006 & 0.000 & 0.000 & -246.8268 & 0.61 \\
\hline 22.00 & 0.010 & 1.000 & 0.885 & 0.000 & 0.000 & 0.000 & -246.8329 & 0.63 \\
\hline \multicolumn{9}{|c|}{ Estimated Taylor-type rule } \\
\hline- & 0.017 & 0.839 & 0.322 & 0.004 & 0.025 & 0.041 & -246.9724 & 1.15 \\
\hline
\end{tabular}

Table 9: Optimized monetary policy rules

the probability of hitting the ZLB is once every four years. It takes a $w_{r}=18$ for the probability of hitting the ZLB to decline to once every 15 years, as in the estimated monetary policy rule. A $w_{r}=22$ implies a probability of hitting the ZLB equal to 0.01 , which corresponds to once every 25 years. A higher penalty translates into a higher welfare loss.

We then move to optimized Taylor-type rules in which the nominal interest rate features inertia and reacts to inflation, output gap, changes to the output gap and nominal credit growth, $\left(L_{t} /\left(\gamma L_{t-1}\right)\right) \Pi_{t} / \Pi$-as in Christiano et al. (2010b,a) and Ozkan and Unsal (2014), among others-for the same probabilities of hitting the ZLB as those in the Ramsey policy. As $w_{r}$ increases, the optimal response to the output gap approaches zero. Irrespective of the value of $w_{r}$, it is always optimal not to respond to changes in the output gap, while a higher penalty $w_{r}$ delivers a lower optimal $\alpha_{\pi}$. As far as the main normative question of the paper is concerned, we find a zero optimal responsiveness to nominal credit growth for any value of $w_{r}$. In the table we compute the consumption equivalent welfare change $\omega$ relative to the Ramsey regime with $w_{r}=5$ (first row). With $w_{r}=22$ the welfare loss is equivalent to a permanent loss in consumption of $0.63 \%-0.05 \%=0.58 \%$.

The estimated monetary policy rule implies $\operatorname{Pr}(Z L B)=0.017$, i.e. that the nominal interest rate hits the ZLB once every 15 years and implies a consumption-equivalent welfare loss of $1.15 \%=1.10 \%$, relative to the Ramsey policy associated to the same probability of hitting the ZLB.

Appendices H.1, H.2 and H.3 check the robustness of the results to (i) Taylor-type rules with

\footnotetext{
${ }^{29}$ Given the asymmetric penalty term in the modified welfare specification, we do not assume any particular distribution for the nominal interest rate, which exhibits some skewness. We compute the probability of hitting the ZLB by resorting to simulations. In particular, we take 50 random draws of the vectors of stochastic shocks in the model and, for each draw, we simulate the model for 500 quarters. This yields a matrix containing 25,000 realizations of the nominal interest rate. The frequency with which this falls below zero represents the probability of hitting the ZLB.
} 
potential output defined as the level that would prevail in the absence of price stickiness, wage stickiness and financial frictions; (ii) interest rate rules reacting to alternative financial variables, such as lending and the bank spread, similarly to Cúrdia and Woodford (2010) and Aksoy et al. (2013); and (iii) the implementable specification of the Taylor rule as in Schmitt-Grohe and Uribe (2007), allowing also for a response to output growth.

\subsection{Welfare implications and counterfactual experiments}

To check the extent to which the welfare loss suffered from employing the empirical rule is due to the presence of the responsiveness to nominal credit growth, in Subfigure 5a, we isolate its effect on welfare by keeping $\rho_{r}, \alpha_{\pi}$ and $\alpha_{y}$ fixed at their optimal values obtained with $w_{r}=22$ and by changing $\alpha_{s}$ in the interval $[0,0.5]$. The estimated value of $\alpha_{s}=0.041$ implies a small consumption-equivalent loss of around $0.06 \%$. In addition, this exercise unveils also a positive relationship whereby the economy suffers an approximately double welfare loss if $\alpha_{s}$ doubles.

In a nutshell the second contribution of this paper is showing that it is not optimal for monetary policy to respond to credit growth, that the estimated responsiveness implies a small welfare loss (equivalent to a permanent loss in consumption of less than $0.1 \%$ ), and that bolder responses to financial conditions may represent a substantial detriment to welfare.

These findings can be rationalized by noticing that supply shocks (technology, price mark-up and wage mark-up) explain the largest share of business cycle fluctuations of lending and inflation. Indeed, Subsection 3.4 shows that the three supply shocks together explain around $63 \%$ and $72 \%$ of the unconditional variance of lending and inflation, respectively. A, say, contractionary shock of such a kind causes lending to decrease and inflation to rise. A monetary policy that leans against windy bank lending is more accommodative towards inflation in an attempt to boost lending (as shown in Subsection 3.3). But this turns out not to be optimal. In fact, in Subfigure $5 \mathrm{~b}$, for a $w_{r}=22$, we show that, if we fix $\alpha_{r}=1, \alpha_{y}=0$ (i.e. their optimal values), we let $\alpha_{s}$ vary in the interval [0, 0.1], and we optimize over $\alpha_{\pi}$, the optimal value of this last coefficient monotonically increases when $\alpha_{s}$ increases, while welfare (not shown) attains virtually the same level for any combination of the two parameter values. In other words, if monetary policy is forced to react more to a(n) tightening (expansion) of lending growth, it is optimal for it to react more also to the increase (decrease) in inflation. As the two objectives are conflicting, there is no "divine coincidence" (Blanchard and Galí, 2007) in this case and the nominal interest rate achieves a better outcome if it only stabilizes inflation. This result, on one hand, is in line with Faia and Monacelli (2007), who find that the presence of only one policy instrument - the nominal interest rate - cannot simultaneously neutralize both financial frictions and price stickiness and that a strong anti-inflationary stance always leads to the highest level of welfare.

To show the importance of the sources of business cycle fluctuations on the optimality of monetary 


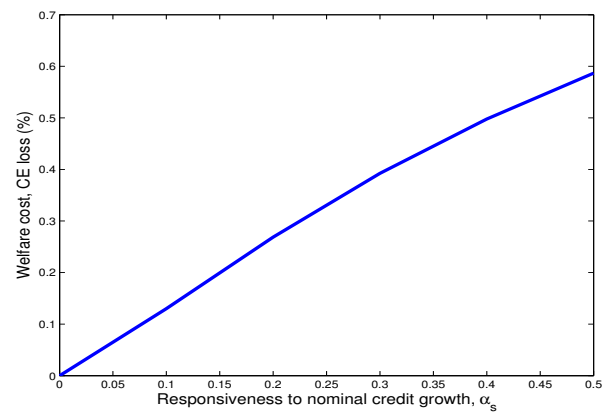

(a) Welfare cost associated to leaning against the wind

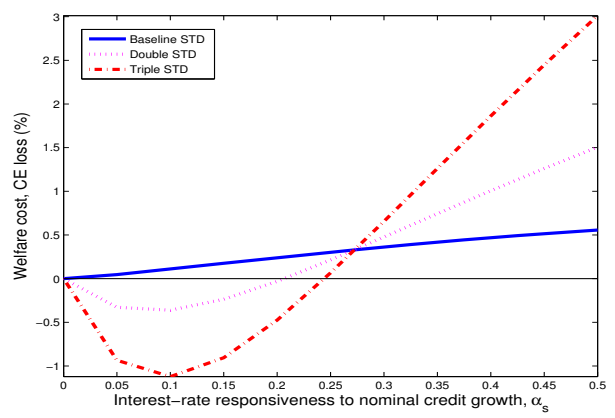

(c) Welfare cost associated to leaning against the wind for larger volatilities of the capital quality shock $(\mathrm{STD}=$ standard deviation of real output growth)

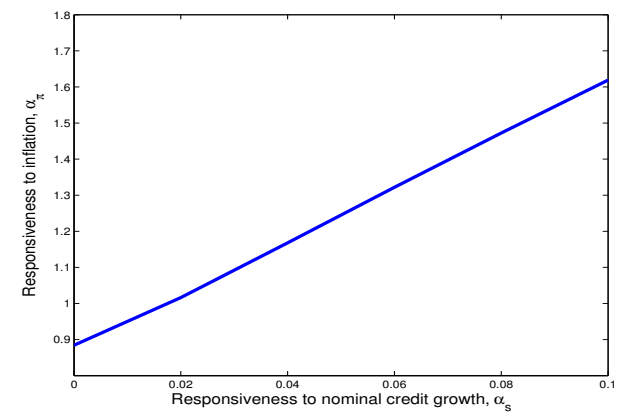

(b) Optimal responsiveness of inflation for given degrees of leaning against the wind

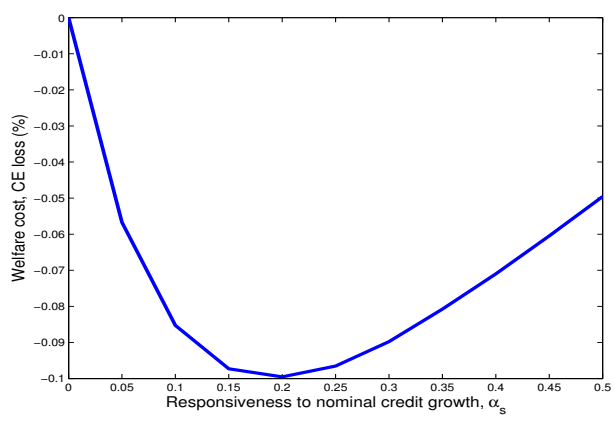

(d) Welfare cost associated to leaning against the wind in the absence of wage mark-up shocks

Figure 5: Welfare implications of leaning against the wind and counterfactual experiments

policy responses, Subfigure 5c presents a counterfactual experiment in which we artificially change the volatility of capital quality shocks to match a double and triple standard deviation of output growth compared to the baseline estimated model - by keeping $\rho_{r}, \alpha_{\pi}, \alpha_{y}$ and $\alpha_{\Delta y}$ at their optimal values when $w_{r}=22$, and by changing $\alpha_{s}$ in the interval $[0 ; 0.5] .{ }^{30}$ For the capital quality shock a form of "trinity" (in analogy to Justiniano et al., 2013) holds: inflation, the output gap and credit growth can be stabilized at the same time. This demand shock is important because it accounts for $38 \%$ of the unconditional variance of output and for $30 \%$ of that of lending. Such a counterfactual exercise shows that it would be indeed optimal to lean against windy bank lending, with an optimal $\alpha_{s}$ around 0.1 in the scenarios with higher volatility driven by capital quality shocks. ${ }^{31}$ In contrast, in Appendix H.4 we show that, if the increase in volatilty is due to a proportional increase in the standard deviations of all shocks, it remains optimal not to lean against windy bank lending.

This point can be also verified by suppressing a quantitatively relevant supply shock. Subfigure 5d

\footnotetext{
${ }^{30}$ The Great Recession witnessed a double standard deviation of real output growth compared to the average level observed during the Great Moderation.

${ }^{31}$ This result is similar in spirit to those of Ajello et al. (2016) and Bazarbash (2015).
} 
displays how the optimal $\alpha_{s}$ changes in the absence of wage mark-up shocks (again keeping $\rho_{r}, \alpha_{\pi}$, $\alpha_{y}$ and $\alpha_{\Delta y}$ at their optimal values when $w_{r}=22$ ). These shocks are the most prominent shocks in the unconditional variance decomposition of inflation and they play an important role for explaining fluctuations in output and lending. ${ }^{32}$ This exercise is important as (i) it shows that, in the absence of such shocks, it would be indeed optimal to lean against windy bank lending, with an optimal $\alpha_{s}$ around 0.2; and (ii) it allows reconciling our results with the literature. In fact, Aksoy et al. (2013) and Gambacorta and Signoretti (2014), in similar but simpler calibrated models with no wage mark-up shocks, find a leaning-against-the-wind policy to be optimal. Moreover, Cúrdia and Woodford (2010) and Nisticò (2012) show that the optimality of a leaning-against-the-wind-type of monetary policy is very sensitive to the source of business cycle fluctuations. Our research strategy entails first bringing a canonical model augmented with banking to the data; next, estimating a set of standard shocks; and last, on the estimation results, basing optimal policy computations.

Appendix H.5 investigates the robustness of the results also to superinertial rules. We find that superinertial responses of the interest rate have negligible effects on welfare relative to price level rules, and also in the superinertial case it is optimal not to lean against windy bank lending.

\section{Concluding remarks}

In recent times credit booms and busts have dramatically affected business cycle fluctuations. This has called for a deeper understanding of credit market conditions and the role of central banks in ensuring financial stability. This paper examines whether interest-rate policy has reacted and whether it should indeed react to bank lending growth in the US economy.

We first estimate a DSGE model in which banking frictions arise due to the presence of lending relationships and monetary policy is set according to a credit-growth-augmented Taylor-type rule. The empirical results provide evidence that during the Great Moderation monetary policy leaned against the wind blowing from the loan market. Such findings survive various specifications of the monetary policy rule, including when this features also a response to asset prices.

We then compare the welfare implications of estimated and optimized interest-rate rules. Results unveil that the estimated responsiveness of monetary policy to credit growth delivers a small welfare loss, but the higher such a responsiveness the higher is the detriment to welfare. Such a finding can be rationalized by noticing that supply shocks are the main medium-to-long run drivers of output, lending and inflation fluctuations in the estimated model and that these shocks imply a trade-off between inflation and output stabilization. Given the pro-cyclical behavior of lending, it turns out to be optimal for monetary policy to respond entirely to inflation. On this aspect, the paper highlights

\footnotetext{
${ }^{32}$ Justiniano et al. (2013) find that the trade-off between output and inflation stabilization policy becomes more relevant when wage mark-up shock are the main drivers of inflation fluctuations.
} 
that the optimality of a leaning-against-the-wind policy is sensitive to the sources of business cycle fluctuations.

The findings of this paper agree with the recent tendency in central banking to move towards macroprudential instruments as tools to promote financial stability. Indeed, a bolder research effort is necessary to identify effective instruments and design rules that achieve the goal of reducing financial instability without conflicting with the objective of inflation stabilization. 


\section{References}

Airaudo, M. and Olivero, M. P. (2014). Optimal monetary policy with counter-cyclical credit spreads. LeBow College of Business, Drexel University, Working Paper Series, 2014-1.

Ajello, A., Laubach, T., Lopez-Salido, J. D., and Nakata, T. (2016). Financial stability and optimal interest-rate policy. Federal Reserve Board, Finance and Economics Discussion Series, 2016-067.

Aksoy, Y., Basso, H., and Coto-Martinez, J. (2013). Lending relationships and monetary policy. Economic Inquiry, 51(1):368-393.

Aliaga-Diaz, R. and Olivero, M. (2010). Macroeconomic implications of 'deep habits' in banking. Journal of Money, Credit and Banking, 42(8):1495-1521.

Aliaga-Diaz, R. and Olivero, M. (2011). The cyclicality of price-cost margins in banking: An empirical analysis of its determinants. Economic Inquiry, 49(1):26-46.

An, S. and Schorfheide, F. (2007). Bayesian analysis of DSGE models. Econometric Reviews, 26(24):113-172.

Andrés, J. and Arce, O. (2012). Banking competition, housing prices and macroeconomic stability. The Economic Journal, 122(565):1346-1372.

Angelini, P., Neri, S., and Panetta, F. (2014). The interaction between capital requirements and monetary policy. Journal of Money, Credit and Banking, 46(6):1073-1112.

Ascari, G., Castelnuovo, E., and Rossi, L. (2011). Calvo vs. Rotemberg in a trend inflation world: An empirical investigation. Journal of Economic Dynamics and Control, 35(11):1852-1867.

Bazarbash, M. (2015). The macroeconomic effects of fluctuations in the productivity of banking. mimeo.

Belke, A. and Klose, J. (2010). (How) Do the ECB and the Fed react to financial market uncertainty?: The Taylor Rule in times of crisis. DIW Discussion Papers of Berlin, 972.

Bernanke, B., Gertler, M., and Gilchrist, S. (1999). The financial accelerator in a quantitative business cycle model. Handbook of Macroeconomics, 1:1341-1393.

Blanchard, O. and Galí, J. (2007). Real wage rigidities and the New Keynesian model. Journal of Money, Credit and Banking, 39(s1):35-65.

Bordo, M. D. and Haubrich, J. G. (2016). Deep recessions, fast recoveries, and financial crises: Evidence from the American record. Economic Inquiry.

Calvo, G. (1983). Staggered prices in a utility-maximizing framework. Journal of monetary Economics, 12(3):383-398.

Cantore, C., Levine, P., and Melina, G. (2014). A fiscal stimulus and jobless recovery. The Scandinavian Journal of Economics, 116(3):669-701.

Carlstrom, C. T., Fuerst, T. S., and Paustian, M. (2010). Optimal monetary policy in a model with agency costs. Journal of Money, Credit and Banking, 42(s1):37-70.

Castelnuovo, E. and Nisticò, S. (2010). Stock market conditions and monetary policy in a DSGE model for the US. Journal of Economic Dynamics and Control, 34(9):1700-1731. 
Chowdhury, I., Hoffmann, M., and Schabert, A. (2006). Inflation dynamics and the cost channel of monetary transmission. European Economic Review, 50(4):995 - 1016.

Christiano, L., Ilut, C., Motto, R., and Rostagno, M. (2010a). Monetary policy and stock market booms. Proceedings - Economic Policy Symposium - Jackson Hole, pages 85-145.

Christiano, L., Motto, R., and Rostagno, M. (2010b). Financial factors in economic fluctuations. ECB Working Paper Series, 1192.

Christiano, L. J., Eichenbaum, M., and Evans, C. L. (2005). Nominal rigidities and the dynamic effects of a shock to monetary policy. Journal of Political Economy, 113(1):1-45.

Coibion, O. and Gorodnichenko, Y. (2012). Why are target interest rate changes so persistent? American Economic Journal: Macroeconomics, 4(4):126-62.

Cuciniello, V. and Signoretti, F. M. (2015). Large banks, loan rate markup, and monetary policy. International Journal of Central Banking, 11(3):141-177.

Cúrdia, V. and Woodford, M. (2009). Credit frictions and optimal monetary policy. BIS Working Papers, 278.

Cúrdia, V. and Woodford, M. (2010). Credit spreads and monetary policy. Journal of Money, Credit and Banking, 42(s1):3-35.

De Fiore, F. and Uhlig, H. (2011). Bank finance versus bond finance. Journal of Money, Credit and Banking, 43(7):1399-1421.

Del Negro, M., Eggertsson, G., Ferrero, A., and Kiyotaki, N. (2011). The great escape? A quantitative evaluation of the Fed's liquidity facilities. Staff Reports, Federal Reserve Bank of New York, 520.

DeYoung, R. (2007). Safety, soundness, and the evolution of the US banking industry. Economic Review-Federal Reserve Bank of Atlanta, 92(1/2):41.

Diamond, D. W. (1984). Financial intermediation and delegated monitoring. The Review of Economic Studies, 51(3):393-414.

Elyasiani, E. and Goldberg, L. G. (2004). Relationship lending: A survey of the literature. Journal of Economics and Business, 56(4):315-330.

Faia, E. and Monacelli, T. (2007). Optimal interest rate rules, asset prices, and credit frictions. Journal of Economic Dynamics and Control, 31(10):3228-3254.

Freixas, X. and Rochet, J. (2008). Microeconomics of banking (2nd ed.).

Fuhrer, J. C. (2000). Habit formation in consumption and its implications for monetary-policy models. American Economic Review, 90(3):367-390.

Furlanetto, F. (2011). Fiscal stimulus and the role of wage rigidity. Journal of Economic Dynamics and Control, 35(4):512 - 527.

Galí, J. (2014). Monetary policy and rational asset price bubbles. American Economic Review, 104(3):721-52.

Galí, J., Smets, F., and Wouters, R. (2011). Unemployment in an estimated New Keynesian model. NBER Macroeconomics Annual, 26:329-360. 
Gambacorta, L. and Signoretti, F. M. (2014). Should monetary policy lean against the wind?: An analysis based on a DSGE model with banking. Journal of Economic Dynamics and Control, 43:146174 .

Gelain, P. and Ilbas, P. (2014). Monetary and macroprudential policies in an estimated model with financial intermediation. NBB Working Paper, 258.

Gerali, A., Neri, S., Sessa, L., and Signoretti, F. M. (2010). Credit and banking in a DSGE model of the euro area. Journal of Money, Credit and Banking, 42(s1):107-141.

Gertler, M. and Karadi, P. (2011). A model of unconventional monetary policy. Journal of Monetary Economics, 58(1):17-34.

Gertler, M., Kiyotaki, N., and Queralto, A. (2012). Financial crises, bank risk exposure and government financial policy. Journal of Monetary Economics, 59(S):S17-S34.

Geweke, J. (1999). Using simulation methods for Bayesian econometric models: Inference, development, and communication. Econometric Reviews, 18(1):1-73.

Gilchrist, S. and Zakrajšek, E. (2012). Credit spreads and business cycle fluctuations. American Economic Review, 102(4):1692-1720.

Jacob, P. (2015). Deep habits, price rigidities, and the consumption response to government spending. Journal of Money, Credit and Banking, 47(2-3):481-510.

Jeffreys, H. (1998). Theory of Probability. Oxford University Press.

Jordà, Ò., Schularick, M. H., and Taylor, A. M. (2013). When credit bites back. Journal of Money, Credit and Banking, 45(2S):3-28.

Justiniano, A., Primiceri, G. E., and Tambalotti, A. (2013). Is there a trade-off between inflation and output stabilization? American Economic Journal: Macroeconomics, 5(2):1-31.

Kass, R. E. and Raftery, A. E. (1995). Bayes factors. Journal of the American Statistical Association, 90(430):773-795.

Kim, M., Kliger, D., and Vale, B. (2003). Estimating switching costs: the case of banking. Journal of Financial Intermediation, 12(1):25-56.

Levine, P., McAdam, P., and Pearlman, J. (2008). Quantifying and sustaining welfare gains from monetary commitment. Journal of Monetary Economics, 55(7):1253-1276.

Melina, G. and Villa, S. (2014). Fiscal policy and lending relationships. Economic Inquiry, 52(2):696712 .

Nisticò, S. (2012). Monetary policy and stock-price dynamics in a DSGE framework. Journal of Macroeconomics, 34(1):126-146.

Ongena, S. and Smith, D. C. (2000). What determines the number of bank relationships? Cross-country evidence. Journal of Financial Intermediation, 9(1):26 - 56.

Ozkan, F. G. and Unsal, D. F. (2014). On the use of monetary and macroprudential policies for small open economies. IMF Working Paper, 14/112. 
Pariès, M. D., Sorensen, C. K., and Rodriguez-Palenzuela, D. (2011). Macroeconomic propagation under different regulatory regimes: Evidence from an estimated DSGE model for the euro area. International Journal of Central Banking, 7(4):49-113.

Petersen, M. and Rajan, R. (1994). The benefits of lending relationships: Evidence from small business data. Journal of Finance, 49:3-37.

Ravenna, F. and Walsh, C. (2006). Optimal monetary policy with the cost channel. Journal of Monetary Economics, 53(2):199-216.

Ravn, M., Schmitt-Grohé, S., and Uribe, M. (2006). Deep habits. Review of Economic Studies, 73(1):195-218.

Ravn, S. H. (2016). Endogenous credit standards and aggregate fluctuations. Journal of Economic Dynamics and Control, 69:99-111.

Romer, C. D. and Romer, D. H. (2004). A new measure of monetary shocks: Derivation and implications. American Economic Review, 94(4):1055-1084.

Rotemberg, J. J. (1982). Monopolistic price adjustment and aggregate output. Review of Economic Studies, 49(4):517-31.

Rotemberg, J. J. and Woodford, M. (1999). Interest rate rules in an estimated sticky price model. In Monetary policy rules, pages 57-126. National Bureau of Economic Research, Inc.

Salop, S. C. (1979). Monopolistic competition with outside goods. The Bell Journal of Economics, 10(1):141-156.

Santos, J. and Winton, A. (2008). Bank loans, bonds, and information monopolies across the business cycle. The Journal of Finance, 63(3):1315-1359.

Schmitt-Grohe, S. and Uribe, M. (2004). Optimal monetary and fiscal policy under sticky prices. Journal of Economic Theory, 114(2):198-230.

Schmitt-Grohe, S. and Uribe, M. (2007). Optimal simple and implementable monetary and fiscal rules. Journal of Monetary Economics, 54(6):1702-1725.

Smets, F. and Wouters, R. (2007). Shocks and frictions in US business cycles: A Bayesian DSGE approach. American Economic Review, 97(3):586-606.

van Ewijk, S. E. and Arnold, I. J. (2014). How bank business models drive interest margins: evidence from US bank-level data. The European Journal of Finance, 20(10):850-873.

Woodford, M. (2003). Interest and prices: Foundations of a theory of monetary policy. Princeton University Press.

Zubairy, S. (2014). On fiscal multipliers: Estimates from a medium scale DSGE model. International Economic Review, 55(1):169-195. 


\section{Appendix}

\section{A Narrative analysis of FOMC meetings on concerns about credit}

\begin{tabular}{|c|c|c|c|}
\hline Dates & $\begin{array}{l}\text { Intended } \\
\text { FFR }\end{array}$ & $\begin{array}{c}\text { Intended } \\
\text { change }\end{array}$ & Quotes \\
\hline $01 / 31 / 84$ & 9.375 & 0 & 'Growth in total credit at U.S. commercial banks remained strong in December" \\
\hline $03 / 27 / 84$ & 10.125 & 0.375 & $\begin{array}{l}\text { "rate of credit growth, which had accelerated considerably in early } 1984 \text { and } \\
\text { which appeared to be an important factor in recent interest rate increases" }\end{array}$ \\
\hline $05 / 22 / 84$ & 10.5 & 0 & "credit growth had shown no sign of slowing so far" \\
\hline $07 / 17 / 84$ & 11 & 0.375 & "strong private credit growth" \\
\hline $08 / 21 / 84$ & 11.5625 & -0.0625 & "credit growth was relatively low" \\
\hline $10 / 02 / 84$ & 11.25 & -0.375 & no particular concerns \\
\hline $11 / 07 / 84$ & 10 & -0.75 & "At commercial banks, credit expansion slowed" \\
\hline $12 / 18 / 84$ & 8.75 & -0.625 & "strong growth in private credit" \\
\hline $02 / 13 / 85$ & 8.5 & 0 & "strong private credit growth" \\
\hline $03 / 26 / 85$ & 8.5 & 0 & no particular concerns \\
\hline $05 / 21 / 85$ & 8.125 & -0.375 & no particular concerns \\
\hline $07 / 10 / 85$ & 7.625 & 0 & no particular concerns \\
\hline $08 / 20 / 85$ & 7.8125 & 0 & no particular concerns \\
\hline $10 / 01 / 85$ & 7.875 & 0 & no particular concerns \\
\hline $11 / 05 / 85$ & 8 & -0.0625 & no particular concerns \\
\hline $12 / 17 / 85$ & 7.9375 & -0.1875 & no particular concerns \\
\hline $02 / 12 / 86$ & 7.8125 & 0 & no particular concerns \\
\hline $04 / 01 / 86$ & 7.375 & 0 & no particular concerns \\
\hline $05 / 20 / 86$ & 6.875 & 0 & no particular concerns \\
\hline $07 / 09 / 86$ & 6.875 & -0.5 & no particular concerns \\
\hline $08 / 19 / 86$ & 6.3125 & -0.375 & no particular concerns \\
\hline $09 / 23 / 86$ & 5.875 & 0 & no particular concerns \\
\hline $11 / 05 / 86$ & 5.875 & 0 & no particular concerns \\
\hline $12 / 16 / 86$ & 6 & 0 & no particular concerns \\
\hline $02 / 12 / 87$ & 6 & 0 & no particular concerns \\
\hline $03 / 31 / 87$ & 6.0625 & 0.1875 & no particular concerns \\
\hline $05 / 19 / 87$ & 6.5 & 0.25 & "stronger expansion in bank credit" \\
\hline $07 / 07 / 87$ & 6.75 & 0 & no particular concerns \\
\hline $08 / 18 / 87$ & 6.625 & 0 & no particular concerns \\
\hline $09 / 22 / 87$ & 7.25 & 0 & no particular concerns \\
\hline $11 / 03 / 87$ & 7.125 & -0.3125 & no particular concerns \\
\hline $12 / 16 / 87$ & 6.8125 & 0 & no particular concerns \\
\hline $02 / 10 / 88$ & 6.625 & -0.125 & no particular concerns \\
\hline $03 / 29 / 88$ & 6.5 & 0.25 & no particular concerns \\
\hline $05 / 17 / 88$ & 7 & 0.25 & no particular concerns \\
\hline $06 / 30 / 88$ & 7.375 & 0.25 & "robust credit growth at depository institutions" \\
\hline $08 / 16 / 88$ & 8.125 & 0 & no particular concerns \\
\hline $09 / 20 / 88$ & 8.125 & 0 & no particular concerns \\
\hline $11 / 01 / 88$ & 8.25 & 0 & "resumption in growth of bank credit" \\
\hline $12 / 14 / 88$ & 8.4375 & 0.5625 & no particular concerns \\
\hline $02 / 08 / 89$ & 9 & 0.1875 & no particular concerns \\
\hline $03 / 28 / 89$ & 9.75 & 0.125 & no particular concerns \\
\hline $05 / 16 / 89$ & 9.8125 & 0 & no particular concerns \\
\hline $07 / 06 / 89$ & 9.5625 & -0.25 & no particular concerns \\
\hline $08 / 22 / 89$ & 9.0625 & 0 & no particular concerns \\
\hline $10 / 03 / 89$ & 9 & 0 & no particular concerns \\
\hline $11 / 14 / 89$ & 8.5 & 0 & "substantially stronger expansion of bank credit" \\
\hline $12 / 19 / 89$ & 8.5 & -0.25 & "greater caution in credit extensions" \\
\hline $02 / 07 / 90$ & 8.25 & 0 & "reduced availability of credit to some borrowers" \\
\hline $03 / 27 / 90$ & 8.25 & 0 & no particular concerns \\
\hline $05 / 15 / 90$ & 8.25 & 0 & no particular concerns \\
\hline $07 / 03 / 90$ & 8.25 & -0.25 & "some businesses were finding it more difficult to obtain credit from banks" \\
\hline $08 / 21 / 90$ & 8 & 0 & "credit conditions were tighter than appropriate" \\
\hline $10 / 02 / 90$ & 8 & -0.25 & "reduced availability of credit" \\
\hline $11 / 13 / 90$ & 7.75 & -0.25 & "continuing constraints on the supply of credit, reflected in tighter terms and reduced availability" \\
\hline $12 / 18 / 90$ & 7.25 & -0.25 & "damped credit growth at depository institutions" \\
\hline
\end{tabular}




\begin{tabular}{|c|c|c|c|}
\hline Dates & $\begin{array}{c}\text { Intended } \\
\text { FFR }\end{array}$ & $\begin{array}{c}\text { Intended } \\
\text { change }\end{array}$ & Quotes \\
\hline $03 / 26 / 91$ & 6 & 0 & "reduced availability of credit" \\
\hline $05 / 14 / 91$ & 5.75 & 0 & no particular concerns \\
\hline $08 / 20 / 91$ & 5.5 & 0 & "weakness in credit growth at depository institutions" \\
\hline $10 / 01 / 91$ & 5.25 & 0 & "continuing weakness in [...] overall credit growth" \\
\hline $11 / 05 / 91$ & 5.25 & -0.5 & "Many business borrowers continued to complain about the difficulty of obtaining credit" \\
\hline $03 / 31 / 92$ & 4 & 0 & no particular concerns \\
\hline $05 / 19 / 92$ & 3.75 & 0 & "easing of restraints on credit supplies" \\
\hline $07 / 01 / 92$ & 3.75 & -0.125 & "weakness in $[\ldots]$ credit" \\
\hline $08 / 18 / 92$ & 3.25 & -0.125 & no particular concerns \\
\hline $10 / 06 / 92$ & 3 & -0.25 & no particular concerns \\
\hline $11 / 17 / 92$ & 3 & 0 & "weaker expansion" \\
\hline $12 / 22 / 92$ & 3 & 0 & no particular concerns \\
\hline $07 / 07 / 93$ & 3 & 0 & no particular concerns \\
\hline $08 / 17 / 93$ & 3 & 0 & no particular concerns \\
\hline $09 / 21 / 93$ & 3 & 0 & no particular concerns \\
\hline $11 / 16 / 93$ & 3 & 0 & no particular concerns \\
\hline $12 / 21 / 93$ & 3 & 0 & no particular concerns \\
\hline $02 / 04 / 94$ & 3 & 0.25 & "readier availability of financing from lending institutions" \\
\hline $03 / 22 / 94$ & 3.25 & 0.25 & "more accommodative lending policies of many depository institutions" \\
\hline $05 / 17 / 94$ & 3.75 & 0.5 & "more aggressive lending practices at banks and other institutions" \\
\hline $07 / 06 / 94$ & 4.25 & 0 & no particular concerns \\
\hline $08 / 16 / 94$ & 4.25 & 0.5 & "surge in bank credit" \\
\hline $09 / 27 / 94$ & 4.75 & 0.125 & "ready availability of financing from increasingly aggressive bank lenders" \\
\hline $11 / 15 / 94$ & 4.75 & 0.75 & "increasingly accommodative loan policies by depository institutions" \\
\hline $12 / 20 / 94$ & 5.5 & 0 & no particular concerns \\
\hline $01 / 31 / 96$ & 5.5 & -0.25 & no particular concerns \\
\hline $03 / 26 / 96$ & 5.25 & 0 & no particular concerns \\
\hline $05 / 21 / 96$ & 5.25 & 0 & no particular concerns \\
\hline $07 / 03 / 96$ & 5.25 & 0 & no particular concerns \\
\hline $08 / 20 / 96$ & 5.25 & 0 & no particular concerns \\
\hline $09 / 24 / 96$ & 5.25 & 0 & no particular concerns \\
\hline $11 / 13 / 96$ & 5.25 & 0 & no particular concerns \\
\hline $12 / 17 / 96$ & 5.25 & 0 & no particular concerns \\
\hline $02 / 04 / 97$ & 5.25 & 0 & no particular concerns \\
\hline $03 / 25 / 97$ & 5.5 & 0.25 & no particular concerns \\
\hline $05 / 20 / 97$ & 5.5 & 0 & "expansion of bank credit" \\
\hline $07 / 01 / 97$ & 5.5 & 0 & "robust expansion of bank credit" \\
\hline $08 / 19 / 97$ & 5.5 & 0 & no particular concerns \\
\hline $09 / 30 / 97$ & 5.5 & 0 & no particular concerns \\
\hline $11 / 12 / 97$ & 5.5 & 0 & no particular concerns \\
\hline $12 / 16 / 97$ & 5.5 & 0 & "more rapid growth in bank credit" \\
\hline $02 / 03 / 98$ & 5.5 & 0 & "solid expansion of bank credit" \\
\hline $03 / 31 / 98$ & 5.5 & 0 & no particular concerns \\
\hline $05 / 19 / 98$ & 5.5 & 0 & no particular concerns \\
\hline $06 / 30 / 98$ & 5.5 & 0 & no particular concerns \\
\hline $08 / 18 / 98$ & 5.5 & 0 & no particular concerns \\
\hline $09 / 29 / 98$ & 5 & -0.5 & "tightening credit availability in U.S. financial markets" \\
\hline $11 / 17 / 98$ & 4.75 & -0.25 & "financing generally had become less available" \\
\hline $12 / 22 / 98$ & 4.75 & 0 & no particular concerns \\
\hline $02 / 02 / 99$ & 4.75 & 0 & no particular concerns \\
\hline $03 / 30 / 99$ & 4.75 & 0 & no particular concerns \\
\hline $05 / 18 / 99$ & 4.75 & 0 & no particular concerns \\
\hline
\end{tabular}




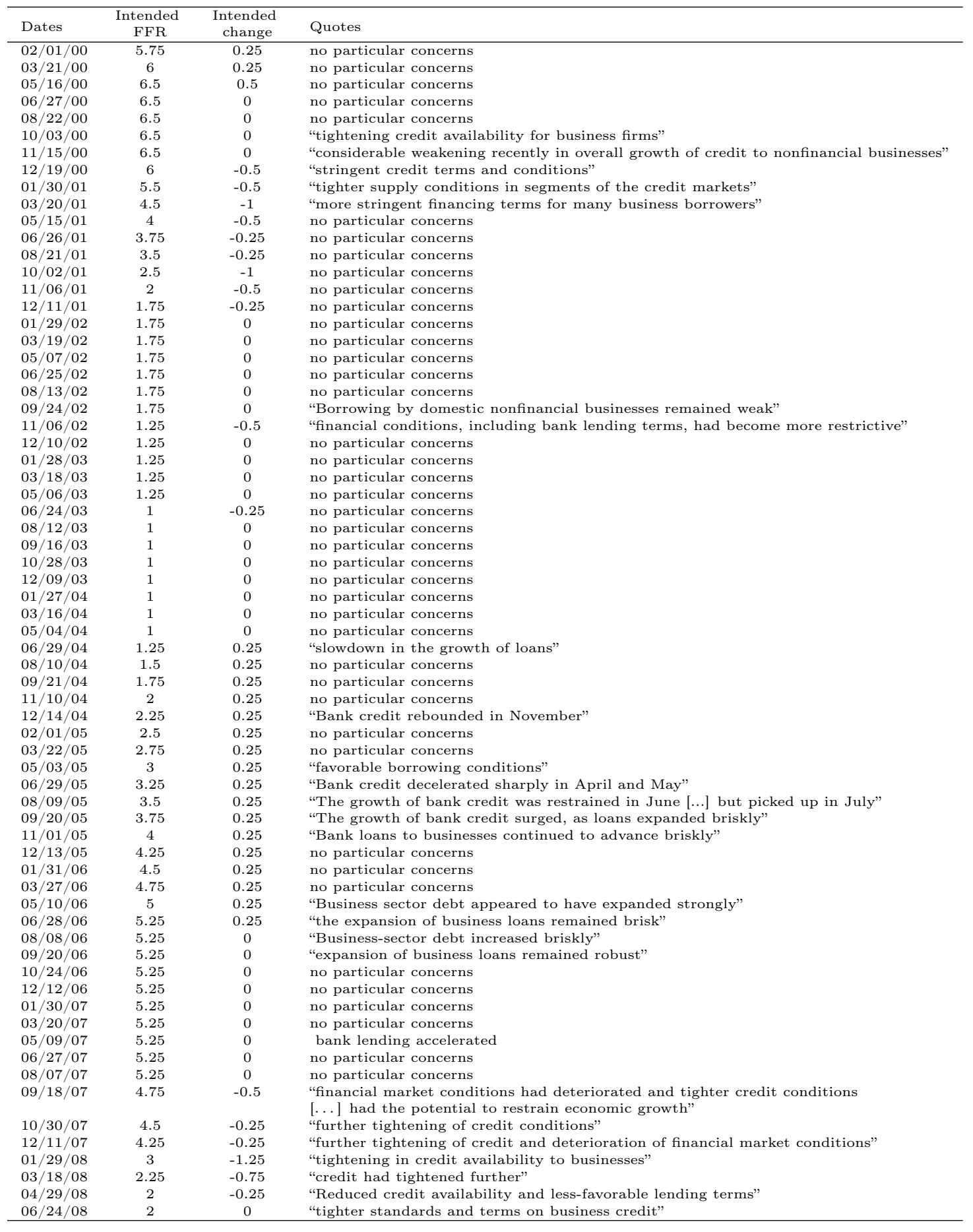

Table A.1: Intended changes in the federal funds rate (FFR) around FOMC meetings and quotes on credit conditions found in FOMC minutes 


\section{B Symmetric equilibrium}

Production function and marginal products:

$$
\begin{gathered}
Y_{t}=e_{t}^{A} H_{t}^{\alpha}\left(U_{t} e_{t}^{K} K_{t}\right)^{1-\alpha} \\
F_{K, t}=\frac{(1-\alpha)}{\mu_{t}} \frac{Y_{t}}{U_{t} e_{t}^{K} K_{t}} \\
F_{H, t}=\frac{\alpha}{\mu_{t}} \frac{Y_{t}}{H_{t}}
\end{gathered}
$$

Marginal utilities, Euler equation, and wage setting:

$$
\begin{aligned}
& U_{X_{t}}=\phi\left(1-H_{t}\right)^{1-\phi}\left[X_{t}^{\phi}\left(1-H_{t}\right)^{1-\phi}\right]^{-\sigma_{c}} X_{t}^{\phi-1} \\
& U_{H_{t}}=-(1-\phi)\left(1-H_{t}\right)^{-\phi} X_{t}^{\phi}\left[X_{t}^{\phi}\left(1-H_{t}\right)^{1-\phi}\right]^{-\sigma_{c}} \\
& X_{t}=C_{t}-\theta S_{t-1}^{c} \\
& S_{t}^{c}=\rho S_{t-1}^{c}+(1-\rho) C_{t} \\
& e_{t}^{B} U_{X_{t}}=\beta E_{t}\left[e_{t+1}^{B} U_{X_{t+1}} \frac{1+R_{t}^{D}}{\Pi_{t+1}}\right] \\
& \left(1-e_{t}^{W} \eta^{W}\right)+\frac{e_{t}^{W} \eta^{W}}{\mu_{t}^{W}}-\xi^{W}\left(\frac{\Pi_{t}^{W}}{\gamma}-\Pi\right) \frac{\Pi_{t}^{W}}{\gamma} \\
& +\xi^{W} E_{t}\left[\Lambda_{t, t+1}\left(\frac{\Pi_{t+1}^{W}}{\gamma}-\Pi\right) \frac{\Pi_{t+1}^{W}}{\gamma} \frac{w_{t+1} H_{t+1}}{w_{t} H_{t}}\right]=0 \\
& \mu_{t}^{W}=\frac{w_{t}}{-\frac{U_{H, t}}{U_{X_{t}}}} \\
& \Pi_{t}^{W}=\frac{w_{t}}{w_{t-1}} \Pi_{t}
\end{aligned}
$$

Investment demand, labor demand, and price setting:

$$
K_{t+1}=(1-\delta) e_{t}^{K} K_{t}+I_{t}\left[1-S\left(\frac{I_{t}}{I_{t-1}}\right)\right] e_{t}^{I}
$$




$$
\begin{gathered}
S\left(\frac{I_{t}}{I_{t-1}}\right)=\frac{\psi}{2}\left(\frac{I_{t}}{I_{t-1}}-\gamma\right)^{2} \\
S^{\prime}\left(\frac{I_{t}}{I_{t-1}}\right)=\psi\left(\frac{I_{t}}{I_{t-1}}-\gamma\right) \\
Q_{t}=E_{t} \Lambda_{t, t+1}\left[U_{t+1} e_{t+1}^{K} F_{K, t+1}-\Psi_{t+1}+Q_{t+1}(1-\delta) e_{t+1}^{K}\right] \\
E_{t}\left[\Lambda_{t, t+1} \zeta \frac{1+R_{t}^{L}}{\Pi_{t+1}}\right]+(1-\zeta)=e_{t}^{I} Q_{t}\left[1-S\left(\frac{I_{t}}{I_{t-1}}\right)-S^{\prime}\left(\frac{I_{t}}{I_{t-1}}\right) \frac{I_{t}}{I_{t-1}}\right] \\
+E_{t} \Lambda_{t, t+1}\left[e_{t+1}^{I} Q_{t+1} S^{\prime}\left(\frac{I_{t+1}}{I_{t}}\right)\left(\frac{I_{t+1}}{I_{t}}\right)^{2}\right] \\
\Psi_{t}=\gamma_{1}\left(U_{t}-1\right)+\frac{\gamma_{2}}{2}\left(U_{t}-1\right)^{2} \\
\Psi_{t}^{\prime}=\gamma_{1}+\gamma_{2}\left(U_{t}-1\right) \\
\Psi_{t}^{\prime}=F_{K, t} \\
\mu_{t}^{P} \eta+e_{t}^{P} \eta M C_{t}-\xi\left(\Pi_{t}-\Pi_{t}\right) \Pi_{t}+\xi E_{t}\left[\Lambda_{t, t+1}\left(\Pi_{t+1}-\Pi\right) \Pi_{t+1} \frac{Y_{t+1}}{Y_{t}}\right]=0 \\
\Lambda_{t, t+1}=\beta E_{t}\left[\frac{U_{X_{t+1}}}{U_{X_{t}}}\right] \\
F_{t}
\end{gathered}
$$

\section{Demand and supply for loans:}

$$
\begin{gathered}
L_{t}=\zeta I_{t} \\
L_{t}=X_{t}^{L}+\theta^{L} S_{t-1}^{L} \\
S_{t}^{L}=\varrho^{L} S_{t-1}^{L}+\left(1-\varrho^{L}\right) L_{t} \\
\nu_{t}=E_{t} \Lambda_{t, t+1}\left[\left(\frac{R_{t}^{L}-R_{t}^{D}}{\Pi_{t+1}}\right)+\theta^{L}\left(1-\varrho^{L}\right) \nu_{t+1}\right] \\
E_{t}\left[\Lambda_{t, t+s} L_{t+1} \frac{1+R_{t}^{L}}{\Pi_{t+1}}\right]=\nu_{t} \eta^{L} E_{t}\left[X_{t+1}^{L}\right] \\
L_{t}=D_{t}
\end{gathered}
$$




$$
\operatorname{spread}_{t}=\left(1+R_{t}^{L}\right) /\left(1+R_{t}^{D}\right)
$$

Taylor rule:

$$
\begin{gathered}
1+R_{t}^{D}=R_{t}^{n} \\
\log \left(\frac{R_{t}^{n}}{R^{n}}\right)=\rho_{r} \log \left(\frac{R_{t-1}^{n}}{R^{n}}\right) \\
+\left(1-\rho_{r}\right)\left[\begin{array}{c}
\rho_{\pi} \log \left(\frac{\Pi_{t}}{\Pi}\right)+\rho_{y} \log \left(\frac{Y_{t}}{Y_{t}^{f}}\right) \\
+\rho_{\Delta y}\left(\log \left(\frac{Y_{t}}{Y_{t}^{f}}\right)-\log \left(\frac{Y_{t-1}}{Y_{t-1}^{f}}\right)\right)+\rho_{s} \log \left(\frac{L_{t}}{\gamma L_{t-1}} \frac{\Pi_{t}}{\Pi}\right)
\end{array}\right]+\epsilon_{t}^{R},
\end{gathered}
$$

Resource constraint and exogenous processes:

$$
\begin{gathered}
Y_{t}=C_{t}+I_{t}+G_{t}+\frac{\xi}{2}\left(\Pi_{t}-\Pi\right)^{2} Y_{t}+\frac{\xi^{W}}{2}\left(\Pi_{t}^{W}-\Pi\right)^{2} w_{t} H_{t}+\Psi_{t} K_{t} \\
\log \left(\frac{e_{t}^{\varkappa}}{\bar{e}^{\varkappa}}\right)=\rho_{\varkappa} \log \left(\frac{e_{t-1}^{\varkappa}}{\bar{e}^{\varkappa}}\right)+\epsilon_{t}^{\varkappa}, \quad \varkappa=\{A, B, G, I, P, W, K\}
\end{gathered}
$$

\section{Detrending}

Following Smets and Wouters (2007), we assume that all real variables grow at the same exogenous rate $\gamma$. To take this into account, in all model's equilibrium conditions we divide all real non-stationary variables by $\gamma^{t}$. Define:

$$
\begin{gathered}
\tilde{Y}_{t}=\frac{Y_{t}}{\gamma^{t}}, \quad \tilde{K}_{t}=\frac{K}{\gamma^{t}}, \quad \tilde{F}_{H t}=\frac{F_{H t}}{\gamma^{t}}, \quad \tilde{U}_{X t}=\frac{U_{X t}}{\gamma^{\left[\phi\left(1-\sigma_{c}\right)-1\right] t}}, \quad \tilde{U}_{H t}=\frac{U_{H t}}{\gamma^{\left[\phi\left(1-\sigma_{c}\right)\right] t}}, \quad \tilde{X}_{t}=\frac{X_{t}}{\gamma^{t}}, \quad \tilde{C}_{t}=\frac{C_{t}}{\gamma^{t}} \\
\tilde{S}_{t}^{c}=\frac{S_{t}}{\gamma^{t}}, \quad \tilde{w}_{t}=\frac{w_{t}}{\gamma^{t}}, \quad \tilde{I}_{t}=\frac{I_{t}}{\gamma^{t}}, \quad \tilde{L}_{t}=\frac{L_{t}}{\gamma^{t}}, \quad \tilde{X}_{t}^{L}=\frac{X_{t}^{L}}{\gamma^{t}}, \quad \tilde{S}_{t}^{L}=\frac{S_{t}^{L}}{\gamma^{t}}, \quad \tilde{D}_{t}=\frac{D_{t}}{\gamma^{t}}, \quad \tilde{Y}_{t}^{f}=\frac{Y_{t}^{f}}{\gamma^{t}}
\end{gathered}
$$

\section{Production function and marginal products:}

$$
\begin{gathered}
\tilde{Y}_{t}=e_{t}^{A} H_{t}^{\alpha}\left(U_{t} e_{t}^{K} \tilde{K}_{t}\right)^{1-\alpha} \\
F_{K, t}=\frac{(1-\alpha)}{\mu_{t}} \frac{\tilde{Y}_{t}}{U_{t} e_{t}^{K} \tilde{K}_{t}} \\
\tilde{F}_{H, t}=\frac{\alpha}{\mu_{t}} \frac{\tilde{Y}_{t}}{H_{t}}
\end{gathered}
$$


Marginal utilities, Euler equation, and wage setting:

$$
\begin{aligned}
& \tilde{U}_{X_{t}}=\phi\left(1-H_{t}\right)^{1-\phi}\left[\tilde{X}_{t}^{\phi}\left(1-H_{t}\right)^{1-\phi}\right]^{-\sigma_{c}} \tilde{X}_{t}^{\phi-1} \\
& \tilde{U}_{H_{t}}=-(1-\phi)\left(1-H_{t}\right)^{-\phi} \tilde{X}_{t}^{\phi}\left[\tilde{X}_{t}^{\phi}\left(1-H_{t}\right)^{1-\phi}\right]^{-\sigma_{c}} \\
& \tilde{X}_{t}=\tilde{C}_{t}-\frac{\theta}{\gamma} \tilde{S}_{t-1}^{c} \\
& \tilde{S}_{t}^{c}=\frac{\rho}{\gamma} \tilde{S}_{t-1}^{c}+(1-\rho) \tilde{C}_{t} \\
& e_{t}^{B} \tilde{U}_{X_{t}}=\beta E_{t}\left[e_{t+1}^{B} \gamma \tilde{U}_{X_{t+1}} \frac{1+R_{t}^{D}}{\Pi_{t+1}}\right] \\
& \left(1-e_{t}^{W} \eta^{W}\right)+\frac{e_{t}^{W} \eta^{W}}{\mu_{t}^{W}}-\xi^{W}\left(\frac{\Pi_{t}^{W}}{\gamma}-\Pi\right) \frac{\Pi_{t}^{W}}{\gamma} \\
& +\gamma \xi^{W} E_{t}\left[\Lambda_{t, t+1}\left(\frac{\Pi_{t+1}^{W}}{\gamma}-\Pi\right) \frac{\Pi_{t+1}^{W}}{\gamma} \frac{\tilde{w}_{t+1} H_{t+1}}{\tilde{w}_{t} H_{t}}\right]=0 \\
& \mu_{t}^{W}=\frac{\tilde{w}_{t}}{-\frac{\tilde{U}_{H, t}}{\tilde{U}_{X_{t}}}} \\
& \Pi_{t}^{W}=\frac{\gamma \tilde{w}_{t}}{\tilde{w}_{t-1}} \Pi_{t}
\end{aligned}
$$

Investment demand, labor demand, and price setting:

$$
\begin{aligned}
& \gamma \tilde{K}_{t+1}=(1-\delta) e_{t}^{K} \tilde{K}_{t}+\tilde{I}_{t}\left[1-\tilde{S}\left(\gamma \frac{\tilde{I}_{t}}{\tilde{I}_{t-1}}\right)\right] e_{t}^{I} \\
& \tilde{S}\left(\gamma \frac{\tilde{I}_{t}}{\tilde{I}_{t-1}}\right)=\frac{\psi}{2}\left(\gamma \frac{\tilde{I}_{t}}{\tilde{I}_{t-1}}-\gamma\right)^{2} \\
& \tilde{S}^{\prime}\left(\gamma \frac{\tilde{I}_{t}}{\tilde{I}_{t-1}}\right)=\psi\left(\gamma \frac{\tilde{I}_{t}}{\tilde{I}_{t-1}}-\gamma\right) \\
& Q_{t}=E_{t} \Lambda_{t, t+1}\left[U_{t+1} e_{t+1}^{K} F_{K, t+1}-\Psi_{t+1}+Q_{t+1}(1-\delta) e_{t+1}^{K}\right]
\end{aligned}
$$




$$
\begin{gathered}
E_{t}\left[\Lambda_{t, t+1} \zeta \frac{1+R_{t}^{L}}{\Pi_{t+1}}\right]+(1-\zeta)=E_{t} \Lambda_{t, t+1}\left[e_{t+1}^{I} Q_{t+1} \tilde{S}^{\prime}\left(\gamma \frac{\tilde{I}_{t+1}}{\tilde{I}_{t}}\right)\left(\gamma \frac{\tilde{I}_{t+1}}{\tilde{I}_{t}}\right)^{2}\right] \\
+e_{t}^{I} Q_{t}\left[1-\tilde{S}\left(\gamma \frac{\tilde{I}_{t}}{\tilde{I}_{t-1}}\right)-\tilde{S}^{\prime}\left(\gamma \frac{\tilde{I}_{t}}{\tilde{I}_{t-1}}\right) \gamma \frac{\tilde{I}_{t}}{\tilde{I}_{t-1}}\right] \\
\Psi_{t}=\gamma_{1}\left(U_{t}-1\right)+\frac{\gamma_{2}}{2}\left(U_{t}-1\right)^{2} \\
\Psi_{t}^{\prime}=\gamma_{1}+\gamma_{2}\left(U_{t}-1\right) \\
\Psi_{t}^{\prime}=F_{K, t} \\
\Lambda_{t, t+1}=\gamma \beta E_{t}\left[\frac{\tilde{U}_{X_{t+1}}}{\tilde{U}_{X_{t}}}\right] \\
\tilde{F}_{H, t}=\tilde{w}_{t} \\
1-e_{t}^{P} \eta+e_{t}^{P} \eta M C_{t}-\xi\left(\Pi \Pi_{t}-\Pi\right) \Pi_{t}+\gamma \xi E_{t}\left[\Lambda_{t, t+1}\left(\Pi_{t+1}-\Pi_{t+1} \frac{\tilde{Y}_{t+1}}{\tilde{Y}_{t}}\right]=0\right. \\
\mu_{t}=1 / M C
\end{gathered}
$$

Demand and supply for loans:

$$
\begin{gathered}
\tilde{L}_{t}=\zeta \tilde{I}_{t} \\
\tilde{L}_{t}=\tilde{X}_{t}^{L}+\frac{\theta^{L}}{\gamma} \tilde{S}_{t-1}^{L} \\
\tilde{S}_{t}^{L}=\frac{\varrho^{L}}{\gamma} \tilde{S}_{t-1}^{L}+\left(1-\varrho^{L}\right) \tilde{L}_{t} \\
\nu_{t}=E_{t} \Lambda_{t, t+1}\left[\left(\frac{R_{t}^{L}-R_{t}^{D}}{\Pi_{t+1}}\right)+\theta^{L}\left(1-\varrho^{L}\right) \nu_{t+1}\right] \\
E_{t}\left[\Lambda_{t, t+s} \tilde{L}_{t+1} \frac{1+R_{t}^{L}}{\Pi_{t+1}}\right]=\nu_{t} \eta^{L} E_{t}\left[\tilde{X}_{t+1}^{L}\right] \\
\tilde{L}_{t}=\tilde{D}_{t}
\end{gathered}
$$

Taylor rule:

$$
1+R_{t}^{D}=R_{t}^{n}
$$




$$
\begin{aligned}
& \log \left(\frac{R_{t}^{n}}{R^{n}}\right)=\rho_{r} \log \left(\frac{R_{t-1}^{n}}{R^{n}}\right) \\
& +\left(1-\rho_{r}\right)\left[\begin{array}{c}
\rho_{\pi} \log \left(\frac{\Pi_{t}}{\Pi}\right)+\rho_{y} \log \left(\frac{\tilde{Y}_{t}}{\tilde{Y}_{t}^{f}}\right) \\
+\rho_{\Delta y}\left(\log \left(\frac{\tilde{Y}_{t}}{\tilde{Y}_{t}^{f}}\right)-\log \left(\frac{\tilde{Y}_{t-1}}{\tilde{Y}_{t-1}^{f}}\right)\right)+\rho_{s} \log \left(\frac{\tilde{L}_{t}}{\tilde{L}_{t-1}} \frac{\Pi_{t}}{\Pi}\right)
\end{array}\right]+\epsilon_{t}^{R},
\end{aligned}
$$

Resource constraint and exogenous processes:

$$
\begin{gathered}
\tilde{Y}_{t}=\tilde{C}_{t}+\tilde{I}_{t}+\tilde{G}_{t}+\frac{\xi}{2}\left(\Pi_{t}-\Pi\right)^{2} \tilde{Y}_{t}+\frac{\xi^{W}}{2}\left(\frac{\Pi_{t}^{W}}{\gamma}-\Pi\right)^{2} \tilde{w}_{t} H_{t}+\Psi_{t} \tilde{K}_{t} \\
\log \left(\frac{e_{t}^{\varkappa}}{\bar{e}^{\varkappa}}\right)=\rho_{\varkappa} \log \left(\frac{e_{t-1}^{\varkappa}}{\bar{e}^{\varkappa}}\right)+\epsilon_{t}^{\varkappa}, \quad \varkappa=\{A, B, G, I, P, W, K\}
\end{gathered}
$$

\section{Steady state}

$K$ and $H$ solve equations (B.26) and (B.3), evaluated at the steady state, while the value of the remaining variables is found recursively by using the following relationships

$$
\begin{gathered}
\Pi^{W}=\gamma \Pi \\
\Lambda=\gamma \beta \\
U=1 \\
\mu^{W}=\frac{\tilde{\eta}}{\tilde{\eta}-1} \\
M C=\frac{\eta-1}{\eta} \\
\mu=1 / M C \\
R^{D}=\frac{\Pi}{\gamma \beta}-1 \\
I=(\gamma-1+\delta) K \\
Y=H^{\alpha} K^{1-\alpha} \\
G=\frac{G}{Y} Y
\end{gathered}
$$




$$
\begin{aligned}
& C=Y-I-G \\
& S^{c}=\frac{1-\rho}{1-\rho / \gamma} C \\
& X=C-\frac{\theta}{\gamma} S^{c} \\
& U=\frac{\left[(X)^{\phi}(1-H)^{1-\phi}\right]^{1-\sigma_{c}}}{1-\sigma_{c}} \\
& U_{X}=\phi(1-H)^{1-\phi}\left[X^{\phi}(1-H)^{1-\phi}\right]^{-\sigma_{c}} X^{\phi-1} \\
& U_{H}=-(1-\phi)(1-H)^{-\phi} X^{\phi}\left[X^{\phi}(1-H)^{1-\phi}\right]^{-\sigma_{c}} \\
& W=\mu^{W}\left(-U_{H} / U_{X}\right) \\
& L=\zeta I \\
& S^{L}=\frac{1-\varrho^{L}}{1-\varrho^{L} / \gamma} L \\
& X^{L}=L-\frac{\theta^{L}}{\gamma} S^{L} \\
& D=L \\
& F_{K}=\frac{(1-\alpha)}{\mu} \frac{Y}{K} \\
& R=\Pi \frac{\gamma \beta\left(F_{K}+(1-\zeta)(1-\delta)\right)-(1-\zeta)}{\zeta \gamma \beta-(\gamma \beta)^{2} \zeta(1-\delta)}-1 \\
& \nu=\Lambda L\left(\frac{1+R^{L}}{\Pi}\right) /\left(\eta^{L} X^{L}\right) \\
& \text { spread }=\left(1+R^{L}\right) /\left(1+R^{D}\right) \\
& F_{H}=W \\
& Q=\Lambda \zeta\left(\frac{1+R^{L}}{\Pi}\right)+(1-\zeta) \\
& \Psi=0 \\
& \gamma_{1}=F_{K}
\end{aligned}
$$




$$
\begin{gathered}
\Psi^{\prime}=\gamma_{1} \\
\gamma_{2}=\frac{\gamma_{1}}{\sigma_{u}} \\
S=S^{\prime}=0
\end{gathered}
$$




\section{E Ramsey problem}

\section{E.1 Lagrangian function}

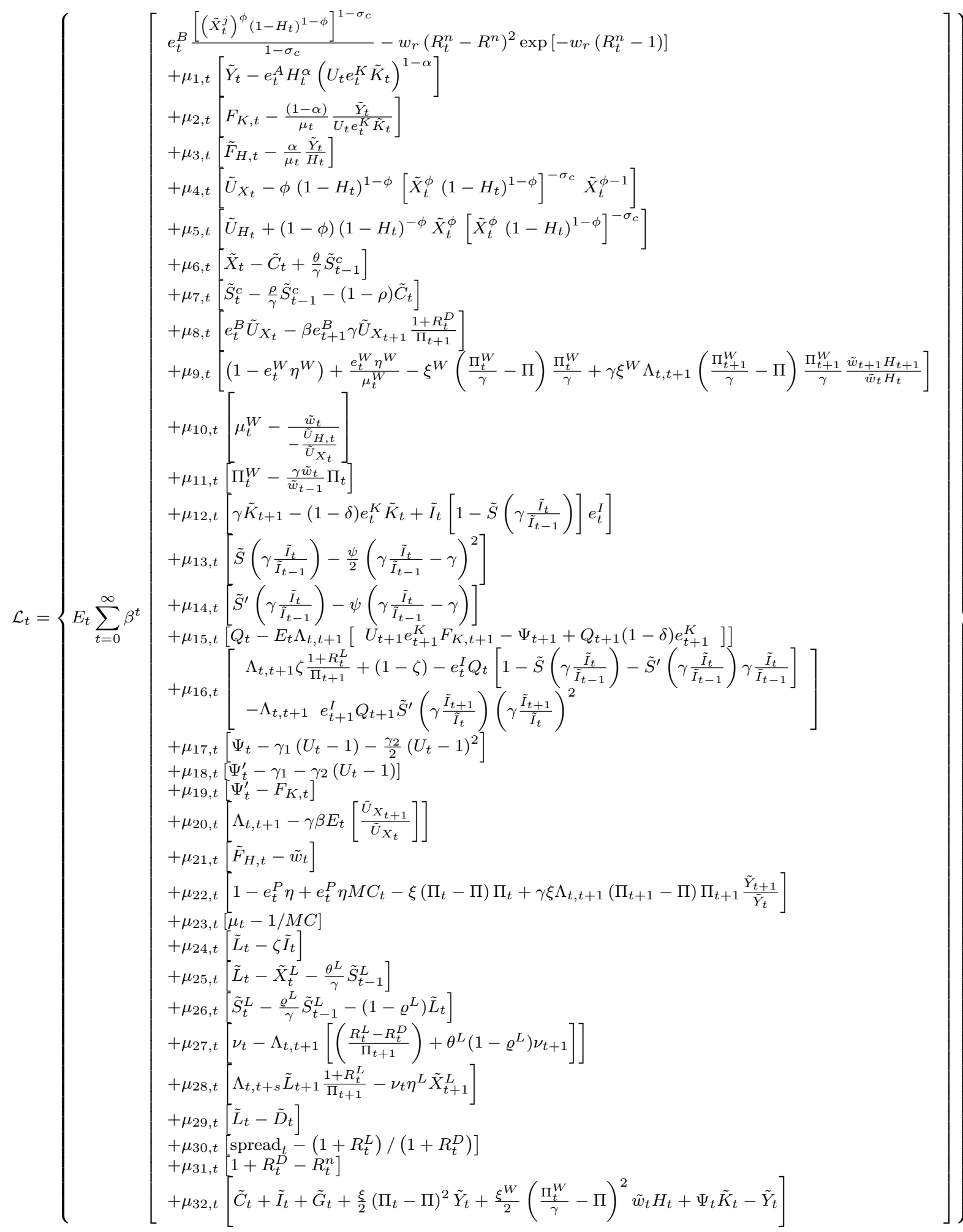




\section{E.2 Ramsey planner's first-order conditions}

Differentiating the Lagrangian function reported in Section E.1 with respect to $\tilde{C}_{t}, \tilde{D}_{t}, \tilde{F}_{H}, F_{K}, H_{t}$, $\tilde{I}_{t}, \tilde{K}_{t}, \tilde{L}_{t}, \Lambda_{t}, \mu_{t}, M C_{t}, \nu_{t}, \Pi_{t}, \Pi_{t}^{W}, \Psi_{t}, \Psi_{t}^{\prime}, Q_{t}, r_{t}, R_{t}, R_{t}^{n}, \tilde{S}_{t}, \tilde{S}_{t}^{c}, \tilde{S}_{t}^{L}, \operatorname{spread}_{t}, \tilde{S}_{t}^{\prime}, u_{t}, \tilde{U}_{H, t}, \tilde{U}_{X^{c} t}$, $\tilde{w}_{t}, \mu_{t}^{W}, \tilde{X}_{t}, X_{t}^{L}$ and $\tilde{Y}_{t}$, and setting the first derivatives equal to zero yields the following first-order conditions:

$$
\begin{aligned}
& \mu_{6, t}-\mu_{32, t}+\mu_{7, t}(1-\rho)=0 \\
& -\mu_{29, t}=0 \\
& \mu_{3, t}+\mu_{21, t}=0 \\
& \mu_{2, t}-\mu_{19, t}-\frac{\Lambda_{t-1, t} U_{t} e_{t}^{K}}{\beta}=0 \\
& \frac{\tilde{X}_{t}^{\phi}(\phi-1)}{\left[\tilde{X}_{t}^{\phi}\left(1-H_{t}\right)^{(1-\phi)}\right]^{\sigma_{c}}\left(1-H_{t}\right)^{\phi}} \\
& -\mu_{5, t}\left\{\frac{e_{t}^{B} \phi \tilde{X}_{t}^{\phi}(\phi-1)}{\left[\tilde{X}_{t}^{\phi}\left(1-H_{t}\right)^{(1-\phi)}\right]^{\sigma_{c}}\left(1-H_{t}\right)^{\phi+1}}-\frac{e_{t}^{B} \sigma_{c} \tilde{X}_{t}^{2 \phi}(\phi-1)^{2}}{\left[\tilde{X}_{t}^{\phi}\left(1-H_{t}\right)^{(1-\phi)}\right]^{\sigma_{c}+1}\left(1-H_{t}\right)^{2 \phi}}\right\} \\
& -\mu_{4, t}\left\{\frac{e_{t}^{B} \phi \tilde{X}_{t}^{\phi-1}(\phi-1)}{\left[\tilde{X}_{t}^{\phi}\left(1-H_{t}\right)^{(1-\phi)}\right]^{\sigma_{c}}\left(1-H_{t}\right)^{\phi}}-\frac{e_{t}^{B} \phi \sigma_{c} \tilde{X}_{t}^{\phi} \tilde{X}_{t}^{\phi-1}\left(1-H_{t}\right)^{(1-\phi)}(\phi-1)}{\left[\tilde{X}_{t}^{\phi}\left(1-H_{t}\right)^{(1-\phi)}\right]^{\sigma_{c}+1}\left(1-H_{t}\right)^{\phi}}\right\} \\
& -\mu_{32, t} \tilde{w}_{t} \xi^{W}\left(\Pi-\frac{\Pi_{t}^{W}}{\gamma}\right)+\frac{\alpha \mu_{3, t} \tilde{Y}_{t+1}}{H_{t}^{2} \mu_{t}}-A_{t} H_{t}^{\alpha-1} \alpha \mu_{1, t}\left(U_{t} e_{t}^{K} \tilde{K}_{t-1}\right)^{1-\alpha} \\
& -\frac{H_{t+1} \Lambda_{t, t+1} \Pi_{t+1}^{W} \mu_{9, t} \tilde{w}_{t+1} \xi^{w}}{H_{t}^{2} \tilde{w}_{t}}\left(\Pi-\frac{\Pi_{t+1}^{W}}{\gamma}\right) \\
& +\frac{\Lambda_{t-1, t} \Pi_{t}^{W} \mu_{9, t-1} \tilde{w}_{t} \xi^{w}}{H_{t-1} \beta \tilde{w}_{t-1}}\left(\Pi-\frac{\Pi_{t+1}^{W}}{\gamma}\right)=0 \\
& \mu_{16, t}\left[\frac{e_{t}^{I} Q_{t} \tilde{S}_{t}^{\prime} \gamma}{\tilde{I}_{t-1}}+\frac{2 e_{t+1}^{I} \tilde{I}_{t+1}^{2} \Lambda_{t, t+1} Q_{t+1} \tilde{S}_{t+1}^{\prime} \gamma^{2}}{\tilde{I}_{t}^{3}}\right] \\
& -\mu_{32, t}-\mu_{24, t} \zeta-e_{t}^{I} \mu_{12, t}\left(S_{t}-1\right)-\frac{\gamma \mu_{14, t} \psi}{\tilde{I}_{t-1}}+\frac{\gamma \mu_{13, t} \psi}{\tilde{I}_{t-1}}\left(\gamma-\frac{\gamma \tilde{I}_{t}}{\tilde{I}_{t-1}}\right) \\
& +\frac{\tilde{I}_{t+1} \gamma \mu_{14, t+1} \beta \psi}{\tilde{I}_{t}^{2}}-\frac{\tilde{I}_{t+1} \gamma \mu_{13, t+1} \beta \psi}{\tilde{I}_{t}^{2}}\left(\gamma-\frac{\gamma \tilde{I}_{t+1}}{\tilde{I}_{t}}\right) \\
& -\frac{e_{t+1}^{I} \tilde{I}_{t+1} Q_{t+1} \tilde{S}_{t+1}^{\prime} \gamma \mu_{16, t+1} \beta}{\tilde{I}_{t}^{2}}-\frac{2 e_{t}^{I} \tilde{I}_{t} \Lambda_{t-1, t} Q_{t} \tilde{S}_{t}^{\prime} \gamma^{2} \mu_{16, t-1}}{\tilde{I}_{t-1}^{2} \beta}=0 \\
& \frac{A_{t+1} e_{t+1}^{K} H_{t+1}^{\alpha} \mu_{t+1} \beta U_{t+1}(\alpha-1)}{\left(e_{t+1}^{K} \tilde{K}_{t} U_{t+1}\right)^{\alpha}}-\Psi_{t+1} \mu_{32, t} \beta-e_{t+1}^{K} \mu_{12, t+1} \beta(\delta-1) \\
& -\frac{\mu_{12, t+1} \beta \tilde{Y}_{t+1}(\alpha-1)}{e_{t+1}^{K} \tilde{K}_{t}^{2} \mu_{t+1} U_{t+1}}-\gamma \mu_{12, t}=0
\end{aligned}
$$




$$
\begin{aligned}
& \mu_{24, t}-\mu_{25, t}+\mu_{29, t}+\mu_{26, t}\left(\varrho^{L}-1\right)+\Lambda_{t, t+1} \mu_{28, t} \frac{1+R_{t}^{L}}{\Pi_{t+1}}=0 \\
& \mu_{20, t}+\mu_{15, t}\left[\Psi_{t+1}-U_{t+1} e_{t+1}^{K} F_{K, t+1}+e_{t+1}^{K} Q_{t+1}(\delta-1)\right] \\
& +\mu_{16, t}\left(\zeta \frac{1+R_{t}^{L}}{\Pi_{t+1}}-\frac{e_{t+1}^{I} \tilde{I}_{t+1}^{2} Q_{t+1} \tilde{S}_{t}^{\prime} \gamma^{2}}{\tilde{I}_{t}^{2}}\right)-\mu_{27, t}\left[\left(\frac{R_{t}^{L}-R_{t}^{D}}{\Pi_{t+1}}\right)+\theta^{L}\left(\varrho^{L}-1\right) \nu_{t+1}\right] \\
& +\mu_{28, t} \tilde{L}_{t} \frac{1+R_{t}^{L}}{\Pi_{t+1}}+\frac{\gamma \mu_{22, t} \Pi_{t+1} \xi \tilde{Y}_{t+1}\left(\Pi_{t}-\Pi\right)}{\tilde{Y}_{t}}+\frac{H_{t+1} \Pi_{t+1}^{W} \mu_{9, t} \xi^{W}\left(\Pi-\frac{\Pi_{t+1}^{W}}{\gamma}\right) \tilde{w}_{t+1}}{H_{t} \tilde{w}_{t}}=0 \\
& \mu_{23, t}+\frac{\alpha \mu_{3, t} \tilde{Y}_{t}}{H_{t} \mu_{t}^{2}}-\frac{\mu_{2, t} \tilde{Y}_{t}(\alpha-1)}{e_{t}^{K} \tilde{K}_{t-1} \mu_{t}^{2} U_{t+1}}=0 \\
& \frac{\mu_{23, t}}{M C_{t}^{2}}+e_{t}^{P} \eta \mu_{t, 22}=0 \\
& \mu_{27, t}-\eta^{L} \mu_{28, t} \tilde{X}_{t}^{L}+\frac{\Lambda_{t-1, t} \mu_{27, t-1} \theta^{L}\left(\varrho^{L}-1\right)}{\beta}=0 ; \\
& \frac{\mu_{22, t-1}\left(\frac{\tilde{Y}_{t} \xi \Pi_{t} \gamma \Lambda_{t,-1 t}}{\tilde{Y}_{t-1}}+\frac{\left(\Pi_{t}-\Pi\right) \tilde{Y}_{t} \xi \gamma \Lambda_{t,-1 t}}{\tilde{Y}_{t-1}}\right)}{\beta}-\mu_{22, t}\left(\xi\left(\Pi_{t}-\Pi\right)+\Pi_{t} \xi\right) \\
& -\frac{\tilde{w}_{t} \gamma \mu_{11, t}}{\tilde{w}_{t-1}}-\frac{\tilde{Y}_{t} \xi \mu_{32, t}\left(2 \Pi_{t}-2 \Pi\right)}{2}+\frac{\Lambda_{t-1, t} \mu_{27, t-1}\left(R_{t-1}^{L}-R_{t-1}^{D}\right)}{\beta \Pi_{t}^{2}} \\
& -\frac{\Lambda_{t-1, t} \tilde{L}_{t} \mu_{28, t-1}\left(1+R_{t}^{L}\right)}{\beta \Pi_{t}^{2}}-\frac{\left(1+R_{t-1}^{L}\right) \zeta \Lambda_{t-1, t} \mu_{16, t-1}}{\beta \Pi_{t}^{2}}+\frac{\gamma \beta \tilde{U}_{X_{t}} \mu_{8, t-1}\left(1+R_{t-1}^{D}\right)}{\beta \Pi_{t}^{2}}=0 \\
& \mu_{11, t}-\mu_{9, t}\left(\frac{\xi^{W}\left(\Pi-\frac{\Pi_{t}^{W}}{\gamma}\right)}{\gamma}-\frac{\xi^{W} \Pi_{t}^{W}}{\gamma^{2}}\right) \\
& +\frac{\mu_{9, t-1}\left[\frac{\left(\Pi-\frac{\Pi_{t}^{W}}{\gamma}\right) \xi^{W} \tilde{w}_{t} H_{t} \Lambda_{t-1, t}}{\tilde{w}_{t-1} H_{t-1}}-\frac{\xi^{W} \Pi_{t}^{W} \tilde{w}_{t} H_{t} \Lambda_{t-1, t}}{\tilde{w}_{t-1} H_{t-1} \gamma}\right]}{\beta}+\frac{\left(\Pi-\frac{\Pi_{t}^{W}}{\gamma}\right) \xi^{W} \tilde{w}_{t} 2 H_{t} \mu_{32, t}}{\gamma}=0 \\
& \mu_{17, t}-\tilde{K}_{t-1} \mu_{32, t}+\frac{\Lambda_{t-1, t} \mu_{15, t}}{\beta}=0 \\
& \mu_{18, t}+\mu_{19, t}=0 \\
& \mu_{15, t}+e_{t+1}^{I} \mu_{16, t}\left(\tilde{S}_{t}+\frac{\gamma \tilde{I}_{t} \tilde{S}_{t}^{\prime}}{\tilde{I}_{t-1}}-1\right) \\
& +\frac{e_{t}^{K} \Lambda_{t-1, t} \mu_{15, t-1}(\delta-1)}{\beta}-\frac{\mu_{16, t-1} \gamma^{2} \tilde{S}_{t}^{\prime} \Lambda_{t-1, t} e_{t}^{I} \tilde{I}_{t}^{2}}{\beta \tilde{I}_{t-1}^{2}}=0 \\
& \frac{\left(1+R_{t+1}^{L}\right) \mu_{30, t}}{\left(1+R_{t+1}^{D}\right)^{2}}-\mu_{31, t}+\frac{\Lambda_{t, t+1} \mu_{27, t}}{\Pi_{t+1}}-\frac{\gamma \beta \tilde{U}_{X_{t}+1} \mu_{8, t}}{\Pi_{t+1}}=0 \\
& \frac{\Lambda_{t, t+1} \tilde{L}_{t} \mu_{28, t}}{\Pi_{t+1}}-\frac{\Lambda_{t, t+1} \mu_{27, t}}{\Pi_{t+1}}-\frac{\mu_{30, t}}{1+r_{t}}+\frac{\zeta \Lambda_{t, t+1} \mu_{16, t}}{\Pi_{t+1}}=0
\end{aligned}
$$




$$
\begin{aligned}
& \mu_{31, t}-w_{r}-w r \exp \left[-w_{r}\left(R_{t}^{n}-1\right)\left(2 R_{t}^{n}-\frac{2}{\gamma \beta}\right)\right]+\left(R_{t}^{n}-\frac{1}{\gamma \beta}\right)^{2} \exp \left[-w_{r}\left(R_{t}^{n}-1\right)\right] w_{r}^{2}=0 \\
& \mu_{13, t}-\mu_{12, t} e_{t}^{I} \tilde{I}_{t}+e_{t}^{I} Q_{t} \mu_{16, t}=0 \\
& \mu_{7, t}-\frac{\rho \beta \mu_{7, t+1}}{\gamma}-\frac{\theta \beta \mu_{6, t+1}}{\gamma}=0 \\
& \mu_{26, t}-\frac{\varrho^{L} \beta \mu_{26, t+1}}{\gamma}+\frac{\theta^{L} \beta \mu_{25, t+1}}{\gamma}=0 \\
& \mu_{30, t}=0 \\
& \mu_{14, t}+\frac{\mu_{16, t} \gamma Q_{t} e_{t}^{I} \tilde{I}_{t}}{\tilde{I}_{t-1}}-\frac{\mu_{16, t-1} \gamma^{2} Q_{t} \Lambda_{t-1, t} e_{t}^{I} \tilde{I}_{t}^{2}}{\beta \tilde{I}_{t-1}^{2}}=0 \\
& \frac{(\alpha-1) \mu_{1, t} \tilde{K}_{t-1} H_{t}^{\alpha} e_{t}^{K} A_{t}}{\left(U_{t} e_{t}^{K} \tilde{K}_{t-1}\right)^{\alpha}}-\mu_{17, t}\left(\gamma_{1}+\frac{\gamma_{2}\left(2 U_{t}-2\right)}{2}\right) \\
& -\frac{\mu_{15, t} \Lambda_{t-1, t} e_{t}^{K} F_{K, t}}{\beta}-\frac{(\alpha-1) \tilde{Y}_{t} \mu_{2, t}}{\mu_{t} e_{t}^{K} \tilde{K}_{t-1} U_{t}^{2}}-\gamma_{2} \mu_{18, t}=0 \\
& \mu_{5, t}-\frac{\tilde{w}_{t} \tilde{U}_{X_{t}} \mu_{10, t}}{\tilde{U}_{H, t}^{2}}=0 \\
& \mu_{4, t}+\mu_{8, t}+\frac{\tilde{w}_{t} \mu_{10, t}}{\tilde{U}_{H, t}}-\frac{\gamma \beta \mu_{20, t-1}}{\beta \tilde{U}_{X_{t-1}}}+\frac{\mu_{20, t} \gamma \beta \tilde{U}_{X_{t}+1}}{\tilde{U}_{X_{t}}^{2}}-\frac{\left(1+R_{t-1}^{D}\right) \gamma \beta \mu_{8, t-1}}{\Pi_{t} \beta}=0 \\
& \frac{\tilde{U}_{X_{t}} \mu_{10, t}}{\tilde{U}_{H, t}}-\mu_{21, t}-\left(\Pi-\frac{\Pi_{t}^{W}}{\gamma}\right)^{2} \xi^{W} H_{t} \mu_{32, t}-\frac{\Pi_{t} \gamma \mu_{11, t}}{\tilde{w}_{t-1}}+\frac{\tilde{w}_{t+1} \Pi_{t+1} \beta \gamma \mu_{11, t+1}}{\tilde{w}_{t}^{2}} \\
& -\frac{\xi^{W} w_{t+1} \Pi_{t+1}^{W} \Lambda_{t, t+1} H_{t+1} \mu_{9, t}\left(\Pi-\frac{\Pi_{t+1}^{W}}{\gamma}\right)}{H_{t} \tilde{w}_{t}^{2}}+\frac{\left(\Pi-\frac{\Pi_{t}^{W}}{\gamma}\right) \xi^{W} \mu_{9, t-1} \Pi_{t}^{W} H_{t} \Lambda_{t-1, t}}{\tilde{w}_{t-1} \beta H_{t-1}}=0 \\
& \mu_{10, t}+\frac{\eta^{W} \mu_{9, t}}{e_{t}^{W}\left(\mu_{t}^{W}\right)^{2}}=0 \\
& \mu_{4, t}\left(\frac{\sigma_{c} e_{t}^{B} \phi^{2} \tilde{X}_{t}^{2 \phi-2}\left(1-H_{t}\right)^{2-2 \phi}}{\left(\tilde{X}_{t}^{\phi}\left(1-H_{t}\right)^{1-\phi}\right)^{1+\sigma_{c}}}-\frac{(\phi-1)\left(1-H_{t}\right)^{1-\phi} \phi e_{t}^{B} \tilde{X}_{t}^{\phi-2}}{\left(\tilde{X}_{t}^{\phi}\left(1-H_{t}\right)^{1-\phi}\right)^{\sigma_{c}}}\right)-\mu_{6, t} \\
& -\mu_{5, t}\left(\frac{(\phi-1) \tilde{X}_{t}^{\phi-1} \phi e_{t}^{B}}{\left(\tilde{X}_{t}^{\phi}\left(1-H_{t}\right)^{1-\phi}\right)^{\sigma_{c}}\left(1-H_{t}\right)^{\phi}}-\frac{(\phi-1)\left(1-H_{t}\right)^{1-\phi} \tilde{X}_{t}^{\phi-1} \tilde{X}_{t}^{\phi} \sigma_{c} \phi e_{t}^{B}}{\left(1-H_{t}\right)^{\phi}\left(\tilde{X}_{t}^{\phi}\left(1-H_{t}\right)^{1-\phi}\right)^{1+\sigma_{c}}}\right) \\
& +\frac{\left(1-H_{t}\right)^{1-\phi} \phi \tilde{X}_{t}^{\phi-1}}{\left(x c_{t}^{\phi}\left(1-H_{t}\right)^{1-\phi}\right)^{\sigma_{c}}}=0 \\
& \mu_{25,5}-\nu_{t} \eta^{L} \mu_{28, t}=0 \\
& \mu_{1, t}-\mu_{32, t}\left(\frac{\xi\left(\Pi_{t}-\Pi\right)^{2}}{2}-1\right)-\frac{\alpha \mu_{3, t}}{H_{t} \mu_{t}}+\frac{\mu_{2, t}(\alpha-1)}{U_{t} e_{t}^{K} \tilde{K}_{t-1} \mu_{t}} \\
& -\frac{\left(\Pi_{t+1}-\Pi\right) \tilde{Y}_{t+1} \xi \Pi_{t+1} \mu_{22, t} \gamma \Lambda_{t, t+1}}{\tilde{Y}_{t}^{2}}+\frac{\left(\Pi_{t}-\Pi\right) \xi \Pi_{t} \mu_{22, t-1} \gamma \Lambda_{t-1, t}}{\beta \tilde{Y}_{t-1}}=0
\end{aligned}
$$


The Ramsey's first-order conditions together with the 32 equations characterizing the symmetric equilibrium reported in Section C (excluding the Taylor rule and the processes for the exogenous shocks) make a system of 55 dynamic equations in 55 unknowns (33 endogenous variables and 32 Lagrange multipliers). We approximate the solution to this system by using the Dynare solver that takes a second-order Taylor expansion around the Ramsey-optimal steady state, which we compute numerically as described in Section E.3.

\section{E.3 Steady state}

The steady-state values of all endogenous variables and Lagrange multipliers in the Ramsey equilibrium are found simultaneously using a numerical procedure. In particular, the procedure is designed to choose the values of $K, H$ and $\Pi$ that simultaneously solve equations (B.26), (B.3) and (E.20) evaluated at the steady state. The value of the remaining endogenous variables is found recursively by using the relationships listed in Section D. Last, the steady-state values of the 32 Lagrange multipliers of the Ramsey problem are found by solving the system of 32 equations (linear in the Lagrange multipliers) in 32 unknowns, obtained by evaluating equations (E.1)-(E.19) and (E.21)-(E.33) at the steady state.

\section{F Data sources and transformations}

This section discusses the sources of the nine observables used in the estimation and their transformation. GDP, GDP deflator inflation, commercial and industrial loans of all commercial banks, the Federal funds rate, the three-month bank prime loan rate, civilian population (CNP160V) and civilian employment (CE160V) are downloaded from the FRED database of the Federal Reserve Bank of St. Louis. Private consumption expenditures and fixed private investment are extracted from the NIPA Table 1.1.5 of the Bureau of Economic Analysis. Average weekly hours worked (PRS85006023) and compensation per hour (PRS85006103) are downloaded from the Bureau of Labor Statistics.

Data are transformed as in Smets and Wouters (2007). In particular, GDP, consumption, investment and loans are transformed in real per-capita terms by dividing their nominal values by the GDP deflator and the civilian population. Real wages are computed by dividing compensation per hour by the GDP deflator. As shown in the measurement equations in Subsection 3.1 of the paper, the observable variables of GDP, consumption, investment, wages and loans are expressed in first differences. Hours worked are multiplied by civilian employment, expressed in per-capita terms and demeaned. 
The inflation rate is computed as a quarter-on-quarter difference of the log of the GDP deflator. The Federal funds rate and the lending rate are expressed in quarterly terms; the remaining variables are expressed as 100 times their logarithm. All series are seasonally adjusted by their sources.

\section{G Robustness of results to alternative Taylor rules}

Figure G.1 reports prior and posterior probability densities of the parameters of the alternative Taylor rules presented in Table 6 of the paper, and shows that $\rho_{s}$ is identified and positive in all cases. Tables G.1-G.6 show the parameter estimates of the alternative Taylor rules. For the sake of brevity results on the estimation of alternative Taylor rules with $\rho_{s}=0$ are not reported but are available upon request. 

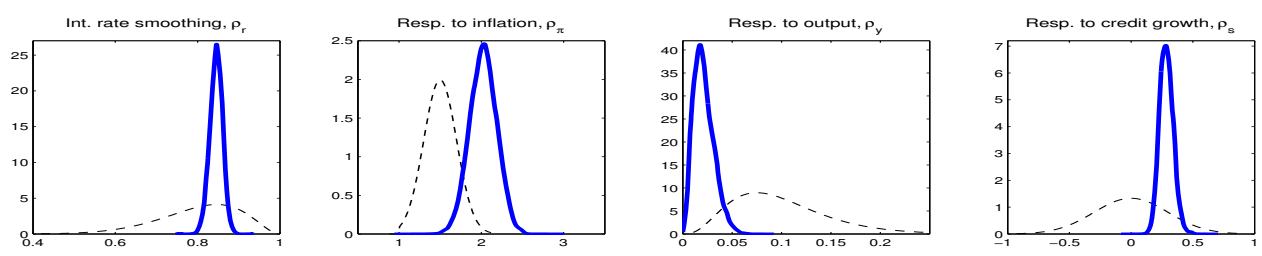

(a) Implementable (I)
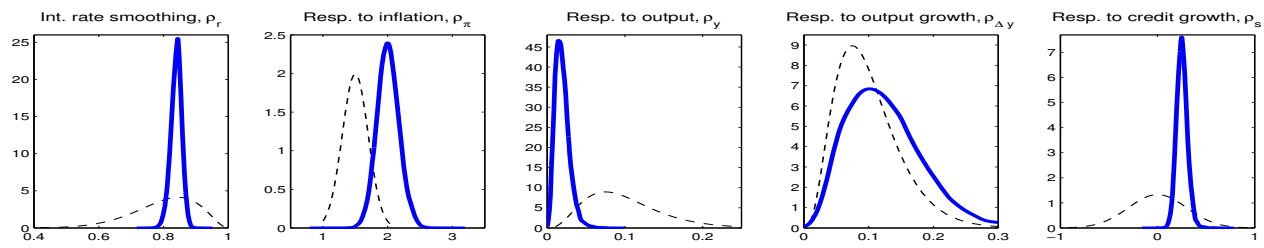

(b) Implementable with output growth (II)
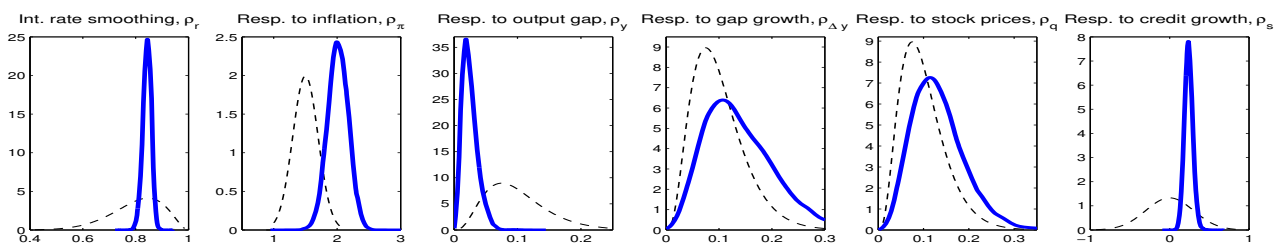

(c) Stock prices (III)
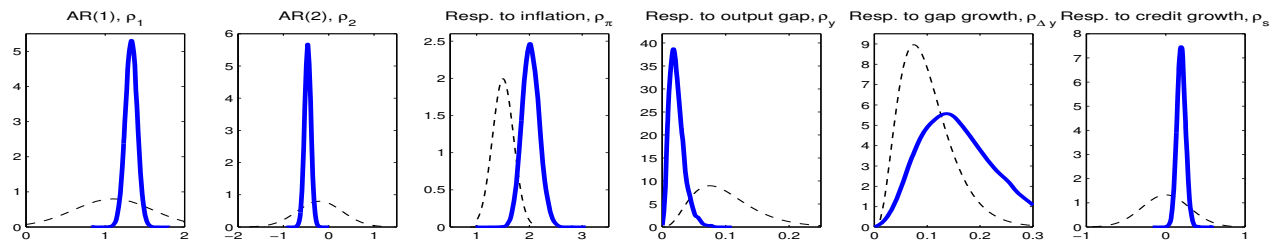

(d) $\operatorname{AR}(2)$ smoothing (IV)
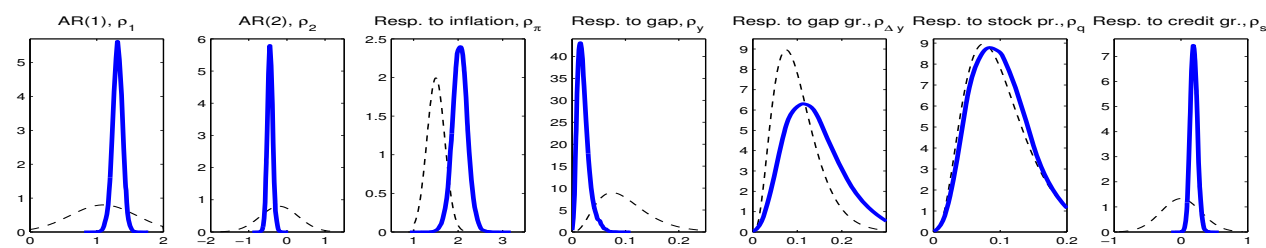

(e) Stock prices and $\operatorname{AR}(2)$ smoothing (V)
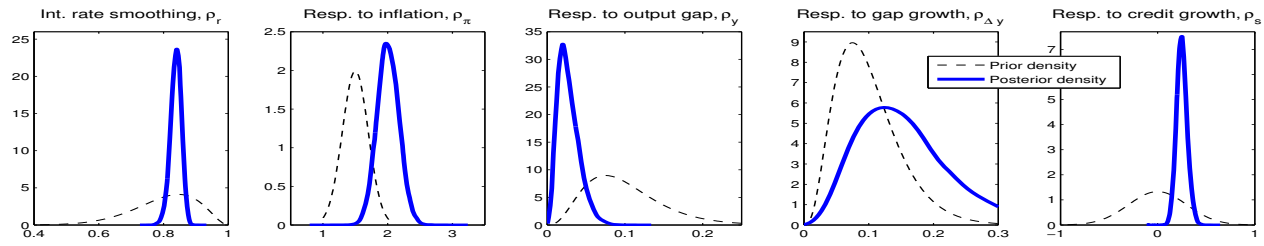

(f) Potential output with no financial frictions (VI)

Figure G.1: Prior and posterior probability densities of parameters of alternative Taylor rules 


\begin{tabular}{|c|c|c|c|c|c|}
\hline \multirow[t]{2}{*}{ Parameter } & & \multicolumn{3}{|c|}{ Prior } & \multirow[t]{2}{*}{ Posterior Mean } \\
\hline & & Distrib. & Mean & $\mathrm{Std} / \mathrm{df}$ & \\
\hline \multicolumn{6}{|l|}{ Structural } \\
\hline Relative risk aversion & $\sigma_{c}$ & Normal & 1.50 & 0.10 & $1.5719[1.4118 ; 1.7344]$ \\
\hline Habits in consumption & $\theta$ & Beta & 0.70 & 0.10 & $0.5865[0.4952 ; 0.6754]$ \\
\hline Habit persist. in consumption & $\rho$ & Beta & 0.50 & 0.10 & $0.6322[0.4992 ; 0.7776]$ \\
\hline Deep habits in banking & $\theta^{L}$ & Beta & 0.70 & 0.125 & $0.5918[0.4519 ; 0.7279]$ \\
\hline Habit persist. in banking & $\varrho^{L}$ & Beta & 0.70 & 0.125 & $0.7179[0.5369 ; 0.8961]$ \\
\hline Price stickiness & $\xi$ & Normal & 30.0 & 5.00 & $45.4599[38.4902 ; 52.3625]$ \\
\hline Wage stickiness & $\xi^{W}$ & Normal & 100.0 & 10.00 & $91.6684[71.5290 ; 109.7094]$ \\
\hline Investment adjust. costs & $\psi$ & Normal & 4.00 & 1.50 & $2.5224[0.8463 ; 3.9006]$ \\
\hline Capital utilization & $\eta_{u}$ & Beta & 0.50 & 0.10 & $0.8590[0.7762 ; 0.9501]$ \\
\hline Inflation -Taylor rule & $\rho_{\pi}$ & Normal & 1.50 & 0.20 & $2.0208[1.7482 ; 2.2845]$ \\
\hline Output -Taylor rule & $\rho_{y}$ & Gamma & 0.10 & 0.05 & $0.0213[0.0056 ; 0.0371]$ \\
\hline Credit growth-Taylor rule & $\rho_{s}$ & Normal & 0.00 & 0.30 & $0.2861[0.1963 ; 0.3726]$ \\
\hline Interest rate smoothing & $\rho_{r}$ & Beta & 0.80 & 0.10 & $0.8450 \quad 0.8187[0.8689 ;]$ \\
\hline \multicolumn{6}{|l|}{ Averages } \\
\hline Trend growth rate & $\bar{\gamma}$ & Normal & 0.44 & 0.10 & $0.3889[0.3251 ; 0.4513]$ \\
\hline Inflation rate & $\bar{\pi}$ & Gamma & 0.63 & 0.10 & $0.6722[0.5803 ; 0.7568]$ \\
\hline Interest rate & $\bar{r}^{n}$ & Gamma & 1.31 & 0.10 & $1.2876[1.1808 ; 1.3985]$ \\
\hline Hours of work & $\bar{h}$ & Normal & 0.00 & 0.10 & $-0.0024[-0.1739 ; 0.1537]$ \\
\hline Lending rate & $\bar{r}^{L}$ & Gamma & 1.98 & 0.10 & $1.9283[1.8367 ; 2.0163]$ \\
\hline \multicolumn{6}{|l|}{ Exogenous processes } \\
\hline \multirow[t]{2}{*}{ Technology } & $\rho_{A}$ & Beta & 0.50 & 0.20 & $0.9671[0.9426 ; 0.9924]$ \\
\hline & $\sigma_{A}$ & $\mathrm{IG}$ & 0.10 & 2.0 & $0.0047[0.0041 ; 0.0053]$ \\
\hline \multirow[t]{2}{*}{ Government spending } & $\rho_{G}$ & Beta & 0.50 & 0.20 & $0.9567[0.9376 ; 0.9768]$ \\
\hline & $\sigma_{G}$ & IG & 0.10 & 2.0 & $0.0239[0.0210 ; 0.0267]$ \\
\hline Interest rate & $\sigma_{R}$ & IG & 0.10 & 2.0 & $0.0014[0.0012 ; 0.0015]$ \\
\hline \multirow[t]{2}{*}{ Investment-specific } & $\rho_{I}$ & Beta & 0.50 & 0.20 & $0.3866[0.0832 ; 0.6861]$ \\
\hline & $\sigma_{I}$ & $\mathrm{IG}$ & 0.10 & 2.0 & $0.0155[0.0002 ; 0.0336]$ \\
\hline \multirow[t]{2}{*}{ Preference } & $\rho_{B}$ & Beta & 0.50 & 0.20 & $0.6893[0.4924 ; 0.8733]$ \\
\hline & $\sigma_{B}$ & IG & 0.10 & 2.0 & $0.0108[0.0081 ; 0.0133]$ \\
\hline \multirow[t]{2}{*}{ Capital quality } & $\rho_{K}$ & Beta & 0.50 & 0.20 & $0.9311[0.8992 ; 0.9640]$ \\
\hline & $\sigma_{K}$ & $\mathrm{IG}$ & 0.10 & 2.0 & $0.0024[0.0014 ; 0.0032]$ \\
\hline \multirow[t]{2}{*}{ Price mark-up } & $\rho_{P}$ & Beta & 0.50 & 0.20 & $0.8144[0.7359 ; 0.8886]$ \\
\hline & $\sigma_{P}$ & IG & 0.10 & 2.0 & $0.0150[0.0127 ; 0.0173]$ \\
\hline \multirow[t]{2}{*}{ Wage mark-up } & $\rho_{W}$ & Beta & 0.50 & 0.20 & $0.7920[0.7078 ; 0.8754]$ \\
\hline & $\sigma_{W}$ & $\mathrm{IG}$ & 0.10 & 2.0 & $0.0467[0.0347 ; 0.0593]$ \\
\hline Std - measurement error - lending & $\sigma_{\varepsilon_{L}}$ & IG & 0.10 & 2.0 & $0.0233[0.0206 ; 0.0261]$ \\
\hline Std - measurement error - lending rate & $\sigma_{\varepsilon_{R} L}$ & IG & 0.10 & 2.0 & $0.0017[0.0015 ; 0.0019]$ \\
\hline Marginal log-likelihood & & & & & -742.302 \\
\hline
\end{tabular}

Table G.1: Prior and posterior distributions of the estimated parameters of the model featuring an implementable Taylor-type interest-rate rule (I) - 90\% confidence intervals are in square brackets 


\begin{tabular}{|c|c|c|c|c|c|}
\hline \multirow[t]{2}{*}{ Parameter } & & \multicolumn{3}{|c|}{ Prior } & \multirow[t]{2}{*}{ Posterior Mean } \\
\hline & & Distrib. & Mean & $\mathrm{Std} / \mathrm{df}$ & \\
\hline \multicolumn{6}{|l|}{ Structural } \\
\hline Relative risk aversion & $\sigma_{c}$ & Normal & 1.50 & 0.10 & $1.5720[1.4118 ; 1.7367]$ \\
\hline Habits in consumption & $\theta$ & Beta & 0.70 & 0.10 & $0.5738[0.4846 ; 0.6785]$ \\
\hline Habit persist. in consumption & $\rho$ & Beta & 0.50 & 0.10 & $0.6403[0.5016 ; 0.7782]$ \\
\hline Deep habits in banking & $\theta^{L}$ & Beta & 0.70 & 0.125 & $0.5903[0.4584 ; 0.7284]$ \\
\hline Habit persist. in banking & $\varrho^{L}$ & Beta & 0.70 & 0.125 & $0.7299[0.5538 ; 0.9085]$ \\
\hline Price stickiness & $\xi$ & Normal & 30.0 & 5.00 & $45.4867[38.7090 ; 52.3285]$ \\
\hline Wage stickiness & $\xi^{W}$ & Normal & 100.0 & 10.00 & 92.2615 [72.4054;110.5169] \\
\hline Investment adjust. costs & $\psi$ & Normal & 4.00 & 1.50 & $2.5481[0.8714 ; 4.0414]$ \\
\hline Capital utilization & $\eta_{u}$ & Beta & 0.50 & 0.10 & $0.8558[0.7683 ; 0.9483]$ \\
\hline Inflation -Taylor rule & $\rho_{\pi}$ & Normal & 1.50 & 0.20 & $2.0052[1.7295 ; 2.2784]$ \\
\hline Output -Taylor rule & $\rho_{y}$ & Gamma & 0.10 & 0.05 & $0.0192[0.0052 ; 0.0328]$ \\
\hline Output growth -Taylor rule & $\rho_{\Delta y}$ & Gamma & 0.10 & 0.05 & $0.1250[0.0344 ; 0.2140]$ \\
\hline Credit growth-Taylor rule & $\rho_{s}$ & Normal & 0.00 & 0.30 & $0.2512[0.1599 ; 0.3369]$ \\
\hline Interest rate smoothing & $\rho_{r}$ & Beta & 0.80 & 0.10 & $0.8393[0.8129 ; 0.8670]$ \\
\hline \multicolumn{6}{|l|}{ Averages } \\
\hline Trend growth rate & $\bar{\gamma}$ & Normal & 0.44 & 0.10 & $0.3926[0.3287 ; 0.4585]$ \\
\hline Inflation rate & $\bar{\pi}$ & Gamma & 0.63 & 0.10 & $0.6715[0.5852 ; 0.7573]$ \\
\hline Interest rate & $\bar{r}^{n}$ & Gamma & 1.31 & 0.10 & $1.2865[1.1797 ; 1.3958]$ \\
\hline Hours of work & $\bar{h}$ & Normal & 0.00 & 0.10 & $-0.0052[-0.1638 ; 0.1534]$ \\
\hline Lending rate & $\bar{r}^{L}$ & Gamma & 1.98 & 0.10 & $1.9285[1.8423 ; 2.0185]$ \\
\hline \multicolumn{6}{|l|}{ Exogenous processes } \\
\hline \multirow[t]{2}{*}{ Technology } & $\rho_{A}$ & Beta & 0.50 & 0.20 & $0.9667[0.9421 ; 0.9913]$ \\
\hline & $\sigma_{A}$ & IG & 0.10 & 2.0 & $0.0047[0.0042 ; 0.0053]$ \\
\hline \multirow[t]{2}{*}{ Government spending } & $\rho_{G}$ & Beta & 0.50 & 0.20 & $0.9577[0.9378 ; 0.9790]$ \\
\hline & $\sigma_{G}$ & $\mathrm{IG}$ & 0.10 & 2.0 & $0.0239[0.0210 ; 0.0267]$ \\
\hline Interest rate & $\sigma_{R}$ & IG & 0.10 & 2.0 & $0.0013[0.0012 ; 0.0015]$ \\
\hline \multirow[t]{2}{*}{ Investment-specific } & $\rho_{I}$ & Beta & 0.50 & 0.20 & $0.3882[0.0541 ; 0.6803]$ \\
\hline & $\sigma_{I}$ & IG & 0.10 & 2.0 & $0.0174[0.0002 ; 0.0349]$ \\
\hline \multirow[t]{2}{*}{ Preference } & $\rho_{B}$ & Beta & 0.50 & 0.20 & $0.6908[0.5142 ; 0.8792]$ \\
\hline & $\sigma_{B}$ & $\mathrm{IG}$ & 0.10 & 2.0 & $0.0104[0.0079 ; 0.0131]$ \\
\hline \multirow[t]{2}{*}{ Capital quality } & $\rho_{K}$ & Beta & 0.50 & 0.20 & $0.9305[0.9000 ; 0.9651]$ \\
\hline & $\sigma_{K}$ & $\mathrm{IG}$ & 0.10 & 2.0 & $0.0023[0.0015 ; 0.0031]$ \\
\hline \multirow[t]{2}{*}{ Price mark-up } & $\rho_{P}$ & Beta & 0.50 & 0.20 & $0.8087[0.7328 ; 0.8866]$ \\
\hline & $\sigma_{P}$ & $\mathrm{IG}$ & 0.10 & 2.0 & $0.0150[0.0126 ; 0.0173]$ \\
\hline \multirow[t]{2}{*}{ Wage mark-up } & $\rho_{W}$ & Beta & 0.50 & 0.20 & $0.7887[0.7075 ; 0.8674]$ \\
\hline & $\sigma_{W}$ & $\mathrm{IG}$ & 0.10 & 2.0 & $0.0472[0.0345 ; 0.0587]$ \\
\hline Std - measurement error - lending & $\sigma_{\varepsilon_{L}}$ & IG & 0.10 & 2.0 & $0.0234[0.0207 ; 0.0261]$ \\
\hline Std - measurement error - lending rate & $\sigma_{\varepsilon_{R} L}$ & IG & 0.10 & 2.0 & $0.0017[0.0015 ; 0.0019]$ \\
\hline Marginal log-likelihood & & & & & -741.275 \\
\hline
\end{tabular}

Table G.2: Prior and posterior distributions of the estimated parameters of the model featuring an implementable Taylor-type interest-rate rule augmented with output growth (II) $-90 \%$ confidence intervals are in square brackets 


\begin{tabular}{|c|c|c|c|c|c|}
\hline \multirow[t]{2}{*}{ Parameter } & & \multicolumn{3}{|c|}{ Prior } & \multirow[t]{2}{*}{ Posterior Mean } \\
\hline & & Distrib. & Mean & $\mathrm{Std} / \mathrm{df}$ & \\
\hline \multicolumn{6}{|l|}{ Structural } \\
\hline Relative risk aversion & $\sigma_{c}$ & Normal & 1.50 & 0.10 & $1.5775[1.4187 ; 1.7311]$ \\
\hline Habits in consumption & $\theta$ & Beta & 0.70 & 0.10 & $0.5610[0.4690 ; 0.6526]$ \\
\hline Habit persist. in consumption & $\rho$ & Beta & 0.50 & 0.10 & $0.6727[0.5228 ; 0.8291]$ \\
\hline Deep habits in banking & $\theta^{L}$ & Beta & 0.70 & 0.125 & $0.5894[0.4481 ; 0.7285]$ \\
\hline Habit persist. in banking & $\varrho^{L}$ & Beta & 0.70 & 0.125 & $0.7301[0.5645 ; 0.9034]$ \\
\hline Price stickiness & $\xi$ & Normal & 30.0 & 5.00 & 46.3877 [39.5952;53.0912] \\
\hline Wage stickiness & $\xi^{W}$ & Normal & 100.0 & 10.00 & $94.5813[75.5621 ; 114.2490]$ \\
\hline Investment adjust. costs & $\psi$ & Normal & 4.00 & 1.50 & $2.5438[0.8043 ; 3.9209]$ \\
\hline Capital utilization & $\eta_{u}$ & Beta & 0.50 & 0.10 & $0.8594[0.7785 ; 0.9514]$ \\
\hline Inflation -Taylor rule & $\rho_{\pi}$ & Normal & 1.50 & 0.20 & $2.0114[1.7422 ; 2.2659]$ \\
\hline Output gap -Taylor rule & $\rho_{y}$ & Gamma & 0.10 & 0.05 & $0.0247[0.0061 ; 0.0433]$ \\
\hline Output gap growth -Taylor rule & $\rho_{\Delta y}$ & Gamma & 0.10 & 0.05 & $0.1394[0.0312 ; 0.2370]$ \\
\hline Credit growth-Taylor rule & $\rho_{s}$ & Normal & 0.00 & 0.30 & $0.2393[0.1500 ; 0.3215]$ \\
\hline Stock prices-Taylor rule & $\rho_{q}$ & Gamma & 0.00 & 0.05 & $0.1320[0.0407 ; 0.2196]$ \\
\hline Interest rate smoothing & $\rho_{r}$ & Beta & 0.80 & 0.10 & $0.8430[0.8170 ; 0.8688]$ \\
\hline \multicolumn{6}{|l|}{ Averages } \\
\hline Trend growth rate & $\bar{\gamma}$ & Normal & 0.44 & 0.10 & $0.3885[0.3165 ; 0.4564]$ \\
\hline Inflation rate & $\bar{\pi}$ & Gamma & 0.63 & 0.10 & $0.6680[0.5907 ; 0.7490]$ \\
\hline Interest rate & $\bar{r}^{n}$ & Gamma & 1.31 & 0.10 & $1.2729[1.1711 ; 1.3797]$ \\
\hline Hours of work & $\bar{h}$ & Normal & 0.00 & 0.10 & $0.0064[-0.1577 ; 0.1659]$ \\
\hline Stock prices & $\bar{Q}$ & Normal & 2.16 & 0.25 & $2.1682[1.7745 ; 2.5597]$ \\
\hline Lending rate & $\bar{r}^{L}$ & Gamma & 1.98 & 0.10 & $1.9253[1.8422 ; 2.0123]$ \\
\hline \multicolumn{6}{|l|}{ Exogenous processes } \\
\hline \multirow[t]{2}{*}{ Technology } & $\rho_{A}$ & Beta & 0.50 & 0.20 & $0.9600[0.9340 ; 0.9873]$ \\
\hline & $\sigma_{A}$ & IG & 0.10 & 2.0 & $0.0047[0.0042 ; 0.0053]$ \\
\hline \multirow[t]{2}{*}{ Government spending } & $\rho_{G}$ & Beta & 0.50 & 0.20 & $0.9564[0.9362 ; 0.9774]$ \\
\hline & $\sigma_{G}$ & IG & 0.10 & 2.0 & $0.0238[0.0210 ; 0.0264]$ \\
\hline Interest rate & $\sigma_{R}$ & IG & 0.10 & 2.0 & $0.0013[0.0011 ; 0.0015]$ \\
\hline \multirow[t]{2}{*}{ Investment-specific } & $\rho_{I}$ & Beta & 0.50 & 0.20 & $0.3405[0.0513 ; 0.6099$ \\
\hline & $\sigma_{I}$ & IG & 0.10 & 2.0 & $0.0191[0.0002 ; 0.0343]$ \\
\hline \multirow[t]{2}{*}{ Preference } & $\rho_{B}$ & Beta & 0.50 & 0.20 & $0.6933[0.5217 ; 0.8757]$ \\
\hline & $\sigma_{B}$ & IG & 0.10 & 2.0 & $0.0104[0.0078 ; 0.0132]$ \\
\hline \multirow[t]{2}{*}{ Capital quality } & $\rho_{K}$ & Beta & 0.50 & 0.20 & $0.9267[0.8926 ; 0.9615]$ \\
\hline & $\sigma_{K}$ & IG & 0.10 & 2.0 & $0.0023[0.0015 ; 0.0030]$ \\
\hline \multirow[t]{2}{*}{ Price mark-up } & $\rho_{P}$ & Beta & 0.50 & 0.20 & $0.7907[0.7178 ; 0.8679]$ \\
\hline & $\sigma_{P}$ & IG & 0.10 & 2.0 & $0.0152[0.0126 ; 0.0175]$ \\
\hline \multirow[t]{2}{*}{ Wage mark-up } & $\rho_{W}$ & Beta & 0.50 & 0.20 & $0.7751[0.6968 ; 0.8541]$ \\
\hline & $\sigma_{W}$ & IG & 0.10 & 2.0 & $0.0492[0.0363 ; 0.0623]$ \\
\hline Std - measurement error - lending & $\sigma_{\varepsilon_{L}}$ & IG & 0.10 & 2.0 & $0.0233[0.0205 ; 0.0257]$ \\
\hline Std - measurement error stock prices & $\sigma_{\varepsilon_{Q}}$ & IG & 0.10 & 2.0 & $0.0756[0.0666 ; 0.0842]$ \\
\hline Std - measurement error - lending rate & $\sigma_{\varepsilon_{R^{L}}}$ & IG & 0.10 & 2.0 & $0.0017[0.0015 ; 0.0019]$ \\
\hline Marginal log-likelihood & & & & & -1086.730 \\
\hline
\end{tabular}

Table G.3: Prior and posterior distributions of the estimated parameters of the model featuring a Taylor-type interest-rate rule augmented with stock prices (III) $-90 \%$ confidence intervals are in square brackets 


\begin{tabular}{|c|c|c|c|c|c|}
\hline \multirow[t]{2}{*}{ Parameter } & & \multicolumn{3}{|c|}{ Prior } & \multirow[t]{2}{*}{ Posterior Mean } \\
\hline & & Distrib. & Mean & $\mathrm{Std} / \mathrm{df}$ & \\
\hline \multicolumn{6}{|l|}{ Structural } \\
\hline Relative risk aversion & $\sigma_{c}$ & Normal & 1.50 & 0.10 & $1.5607[1.3962 ; 1.7239]$ \\
\hline Habits in consumption & $\theta$ & Beta & 0.70 & 0.10 & $0.6166[0.5311 ; 0.7088]$ \\
\hline Habit persist. in consumption & $\rho$ & Beta & 0.50 & 0.10 & $0.6173[0.4661 ; 0.7681]$ \\
\hline Deep habits in banking & $\theta^{L}$ & Beta & 0.70 & 0.125 & $0.6278[0.5009 ; 0.7618]$ \\
\hline Habit persist. in banking & $\varrho^{L}$ & Beta & 0.70 & 0.125 & $0.6994[0.5220 ; 0.8757]$ \\
\hline Price stickiness & $\xi$ & Normal & 30.0 & 5.00 & $44.9088[38.3281 ; 51.8674]$ \\
\hline Wage stickiness & $\xi^{W}$ & Normal & 100.0 & 10.00 & 91.3994 [70.9672;111.0383] \\
\hline Investment adjust. costs & $\psi$ & Normal & 4.00 & 1.50 & $3.1759[1.9232 ; 4.5183]$ \\
\hline Capital utilization & $\eta_{u}$ & Beta & 0.50 & 0.10 & $0.8356[0.7324 ; 0.9370]$ \\
\hline Inflation -Taylor rule & $\rho_{\pi}$ & Normal & 1.50 & 0.20 & $2.0225[1.7660 ; 2.2883]$ \\
\hline Output gap -Taylor rule & $\rho_{y}$ & Gamma & 0.10 & 0.05 & $0.0230[0.0047 ; 0.0402]$ \\
\hline Output gap growth -Taylor rule & $\rho_{\Delta y}$ & Gamma & 0.10 & 0.05 & $0.1632[0.0394 ; 0.2741]$ \\
\hline Credit growth-Taylor rule & $\rho_{s}$ & Normal & 0.00 & 0.30 & $0.1956[0.1103 ; 0.2845]$ \\
\hline Interest rate smoothing & $\rho_{1}$ & Normal & 1.10 & 0.50 & $1.3270[1.2089 ; 1.4512]$ \\
\hline Interest rate smoothing order 2 & $\rho_{2}$ & Normal & -0.20 & 0.50 & $-0.4623[-0.5823 ;-0.3492]$ \\
\hline \multicolumn{6}{|l|}{ Averages } \\
\hline Trend growth rate & $\bar{\gamma}$ & Normal & 0.44 & 0.10 & $0.4008[0.3351 ; 0.4641]$ \\
\hline Inflation rate & $\bar{\pi}$ & Gamma & 0.63 & 0.10 & $0.6495[0.5730 ; 0.7298]$ \\
\hline Interest rate & $\bar{r}^{n}$ & Gamma & 1.31 & 0.10 & $1.2871[1.1764 ; 1.4026]$ \\
\hline Hours of work & $\bar{h}$ & Normal & 0.00 & 0.10 & $0.0014[-0.1648 ; 0.1671]$ \\
\hline Lending rate & $\bar{r}^{L}$ & Gamma & 1.98 & 0.10 & $1.9465[1.8564 ; 2.0347]$ \\
\hline \multicolumn{6}{|l|}{ Exogenous processes } \\
\hline \multirow[t]{2}{*}{ Technology } & $\rho_{A}$ & Beta & 0.50 & 0.20 & $0.9515[0.9164 ; 0.9879]$ \\
\hline & $\sigma_{A}$ & IG & 0.10 & 2.0 & $0.0047[0.0041 ; 0.0053]$ \\
\hline \multirow[t]{2}{*}{ Government spending } & $\rho_{G}$ & Beta & 0.50 & 0.20 & $0.9517[0.9300 ; 0.9734]$ \\
\hline & $\sigma_{G}$ & IG & 0.10 & 2.0 & $0.0239[0.0211 ; 0.0268]$ \\
\hline Interest rate & $\sigma_{R}$ & IG & 0.10 & 2.0 & $0.0011[0.0010 ; 0.0013]$ \\
\hline \multirow[t]{2}{*}{ Investment-specific } & $\rho_{I}$ & Beta & 0.50 & 0.20 & $0.3883[0.1051 ; 0.6399]$ \\
\hline & $\sigma_{I}$ & IG & 0.10 & 2.0 & $0.0257[0.0107 ; 0.0458]$ \\
\hline \multirow[t]{2}{*}{ Preference } & $\rho_{B}$ & Beta & 0.50 & 0.20 & $0.6433[0.4263 ; 0.8736]$ \\
\hline & $\sigma_{B}$ & IG & 0.10 & 2.0 & $0.0115[0.0082 ; 0.0148]$ \\
\hline \multirow[t]{2}{*}{ Capital quality } & $\rho_{K}$ & Beta & 0.50 & 0.20 & $0.9003[0.8553 ; 0.9451]$ \\
\hline & $\sigma_{K}$ & IG & 0.10 & 2.0 & $0.0029[0.0017 ; 0.0041]$ \\
\hline \multirow[t]{2}{*}{ Price mark-up } & $\rho_{P}$ & Beta & 0.50 & 0.20 & $0.8181[0.7408 ; 0.8946]$ \\
\hline & $\sigma_{P}$ & IG & 0.10 & 2.0 & $0.0146[0.0124 ; 0.0170]$ \\
\hline \multirow[t]{2}{*}{ Wage mark-up } & $\rho_{W}$ & Beta & 0.50 & 0.20 & $0.7876[0.6933 ; 0.8856]$ \\
\hline & $\sigma_{W}$ & IG & 0.10 & 2.0 & $0.0473[0.0339 ; 0.0607]$ \\
\hline Std - measurement error - lending & $\sigma_{\varepsilon_{L}}$ & IG & 0.10 & 2.0 & $0.0232[0.0205 ; 0.0258]$ \\
\hline Std - measurement error - lending rate & $\sigma_{\varepsilon_{R} L}$ & IG & 0.10 & 2.0 & $0.0017[0.0015 ; 0.0019]$ \\
\hline Marginal log-likelihood & & & & & -726.302 \\
\hline
\end{tabular}

Table G.4: Prior and posterior distributions of the estimated parameters of the model featuring a Taylor-type interest-rate rule augmented with $\mathrm{AR}(2)$ interest rate smoothing (IV) $-90 \%$ confidence intervals are in square brackets 


\begin{tabular}{|c|c|c|c|c|c|}
\hline \multirow[t]{2}{*}{ Parameter } & & \multicolumn{3}{|c|}{ Prior } & \multirow[t]{2}{*}{ Posterior Mean } \\
\hline & & Distrib. & Mean & $\mathrm{Std} / \mathrm{df}$ & \\
\hline \multicolumn{6}{|l|}{ Structural } \\
\hline Relative risk aversion & $\sigma_{c}$ & Normal & 1.50 & 0.10 & $1.5696[1.4121 ; 1.7310]$ \\
\hline Habits in consumption & $\theta$ & Beta & 0.70 & 0.10 & $0.6035[0.5122 ; 0.6912]$ \\
\hline Habit persist. in consumption & $\rho$ & Beta & 0.50 & 0.10 & $0.6330[0.4792 ; 0.7896]$ \\
\hline Deep habits in banking & $\theta^{L}$ & Beta & 0.70 & 0.125 & $0.6298[0.4943 ; 0.7614]$ \\
\hline Habit persist. in banking & $\varrho^{L}$ & Beta & 0.70 & 0.125 & $0.7057[0.5281 ; 0.8793]$ \\
\hline Price stickiness & $\xi$ & Normal & 30.0 & 5.00 & $45.7520[38.8976 ; 52.5849]$ \\
\hline Wage stickiness & $\xi^{W}$ & Normal & 100.0 & 10.00 & 92.0331 [72.1401;111.6208] \\
\hline Investment adjust. costs & $\psi$ & Normal & 4.00 & 1.50 & $2.9188[1.5130 ; 4.2190]$ \\
\hline Capital utilization & $\eta_{u}$ & Beta & 0.50 & 0.10 & $0.8300[0.7298 ; 0.9320]$ \\
\hline Inflation -Taylor rule & $\rho_{\pi}$ & Normal & 1.50 & 0.20 & $2.0394[1.7770 ; 2.3140]$ \\
\hline Output gap -Taylor rule & $\rho_{y}$ & Gamma & 0.10 & 0.05 & $0.0209[0.0049 ; 0.0370]$ \\
\hline Output gap growth -Taylor rule & $\rho_{\Delta y}$ & Gamma & 0.10 & 0.05 & $0.1411[0.0376 ; 0.2429]$ \\
\hline Credit growth-Taylor rule & $\rho_{s}$ & Normal & 0.00 & 0.30 & $0.1931[0.1087 ; 0.2808]$ \\
\hline Stock prices-Taylor rule & $\rho_{q}$ & Gamma & 0.00 & 0.05 & $0.1020[0.0279 ; 0.1695]$ \\
\hline Interest rate smoothing & $\rho_{1}$ & Normal & 1.10 & 0.50 & $1.3113[1.1947 ; 1.4312]$ \\
\hline Interest rate smoothing order 2 & $\rho_{2}$ & Normal & -0.20 & 0.50 & $-0.4416[-0.5598 ;-0.3330]$ \\
\hline \multicolumn{6}{|l|}{ Averages } \\
\hline Trend growth rate & $\bar{\gamma}$ & Normal & 0.44 & 0.10 & $0.3963[0.3302 ; 0.4619]$ \\
\hline Inflation rate & $\bar{\pi}$ & Gamma & 0.63 & 0.10 & $0.6582[0.5804 ; 0.7344]$ \\
\hline Interest rate & $\bar{r}^{n}$ & Gamma & 1.31 & 0.10 & $1.2834[1.1751 ; 1.3920]$ \\
\hline Hours of work & $\bar{h}$ & Normal & 0.00 & 0.10 & $-0.0011[-0.1621 ; 0.1656]$ \\
\hline Stock prices & $\bar{Q}$ & Normal & 2.16 & 0.25 & $2.1762[1.7975 ; 2.5694]$ \\
\hline Lending rate & $\bar{r}^{L}$ & Gamma & 1.98 & 0.10 & $1.9388[1.8490 ; 2.0255]$ \\
\hline \multicolumn{6}{|l|}{ Exogenous processes } \\
\hline \multirow[t]{2}{*}{ Technology } & $\rho_{A}$ & Beta & 0.50 & 0.20 & $0.9527[0.9186 ; 0.9890]$ \\
\hline & $\sigma_{A}$ & IG & 0.10 & 2.0 & $0.0047[0.0041 ; 0.0053]$ \\
\hline \multirow[t]{2}{*}{ Government spending } & $\rho_{G}$ & Beta & 0.50 & 0.20 & $0.9516[0.9289 ; 0.9735]$ \\
\hline & $\sigma_{G}$ & IG & 0.10 & 2.0 & $0.0238[0.0210 ; 0.0265]$ \\
\hline Interest rate & $\sigma_{R}$ & IG & 0.10 & 2.0 & $0.0011[0.0010 ; 0.0013]$ \\
\hline \multirow[t]{2}{*}{ Investment-specific } & $\rho_{I}$ & Beta & 0.50 & 0.20 & $0.3853[0.0808 ; 0.6527]$ \\
\hline & $\sigma_{I}$ & IG & 0.10 & 2.0 & $0.0221[0.0003 ; 0.0353]$ \\
\hline \multirow[t]{2}{*}{ Preference } & $\rho_{B}$ & Beta & 0.50 & 0.20 & $0.6550[0.4506 ; 0.8726]$ \\
\hline & $\sigma_{B}$ & IG & 0.10 & 2.0 & $0.0115[0.0082 ; 0.0147]$ \\
\hline \multirow[t]{2}{*}{ Capital quality } & $\rho_{K}$ & Beta & 0.50 & 0.20 & $0.9008[0.8570 ; 0.9455]$ \\
\hline & $\sigma_{K}$ & IG & 0.10 & 2.0 & $0.0031[0.0019 ; 0.0043]$ \\
\hline \multirow[t]{2}{*}{ Price mark-up } & $\rho_{P}$ & Beta & 0.50 & 0.20 & $0.8084[0.7305 ; 0.8814]$ \\
\hline & $\sigma_{P}$ & IG & 0.10 & 2.0 & $0.0149[0.0124 ; 0.0174]$ \\
\hline \multirow[t]{2}{*}{ Wage mark-up } & $\rho_{W}$ & Beta & 0.50 & 0.20 & $0.7867[0.6910 ; 0.8786]$ \\
\hline & $\sigma_{W}$ & IG & 0.10 & 2.0 & $0.0476[0.0339 ; 0.0612]$ \\
\hline Std - measurement error - lending & $\sigma_{\varepsilon_{L}}$ & IG & 0.10 & 2.0 & $0.0232[0.0205 ; 0.0259]$ \\
\hline Std - measurement error - stock prices & $\sigma_{\varepsilon_{Q}}$ & IG & 0.10 & 2.0 & $0.0755[0.0667 ; 0.0839]$ \\
\hline$\underline{\text { Std }- \text { measurement error }- \text { lending rate }}$ & $\sigma_{\varepsilon_{R} L}$ & IG & 0.10 & 2.0 & $0.0017[0.0015 ; 0.0019]$ \\
\hline Marginal log-likelihood & & & & & -1074.571 \\
\hline
\end{tabular}

Table G.5: Prior and posterior distributions of the estimated parameters of the model featuring a Taylor-type interest-rate rule augmented with stock prices and $\operatorname{AR}(2)$ interest rate smoothing $(\mathrm{V})$ $90 \%$ confidence intervals are in square brackets 


\begin{tabular}{|c|c|c|c|c|c|}
\hline \multirow[t]{2}{*}{ Parameter } & & \multicolumn{3}{|c|}{ Prior } & \multirow[t]{2}{*}{ Posterior Mean } \\
\hline & & Distrib. & Mean & $\mathrm{Std} / \mathrm{df}$ & \\
\hline \multicolumn{6}{|l|}{ Structural } \\
\hline Relative risk aversion & $\sigma_{c}$ & Normal & 1.50 & 0.10 & $1.5734[1.4130 ; 1.7287]$ \\
\hline Habits in consumption & $\theta$ & Beta & 0.70 & 0.10 & $0.5707[0.4804 ; 0.6657]$ \\
\hline Habit persist. in consumption & $\rho$ & Beta & 0.70 & 0.10 & $0.6471[0.4997 ; 0.7961]$ \\
\hline Deep habits in banking & $\theta^{L}$ & Beta & 0.70 & 0.125 & $0.5803[0.4443 ; 0.7251]$ \\
\hline Habit persist. in banking & $\varrho^{L}$ & Beta & 0.80 & 0.125 & $0.7204[0.5380 ; 0.8982]$ \\
\hline Price stickiness & $\xi$ & Normal & 30.0 & 5.00 & $45.4468[38.4987 ; 51.9829]$ \\
\hline Wage stickiness & $\xi^{W}$ & Normal & 100.0 & 10.00 & $93.2614[73.5085 ; 112.6321]$ \\
\hline Invest. adjust. costs & $\psi$ & Normal & 4.00 & 1.50 & $2.6255[0.9101 ; 4.0478]$ \\
\hline Capital utilization & $\eta_{u}$ & Beta & 0.50 & 0.15 & $0.8565[0.7715 ; 0.9462]$ \\
\hline Inflation -Taylor rule & $\rho_{\pi}$ & Normal & 1.50 & 0.20 & $2.0048[1.7383 ; 2.2799]$ \\
\hline Output gap -Taylor rule & $\rho_{y}$ & Gamma & 0.10 & 0.05 & $0.0273[0.0064 ; 0.0477]$ \\
\hline Output gap growth -Taylor rule & $\rho_{\Delta y}$ & Gamma & 0.10 & 0.05 & $0.1544[0.0370 ; 0.2618]$ \\
\hline Credit growth-Taylor rule & $\rho_{s}$ & Normal & 0.00 & 0.30 & $0.2494[0.1609 ; 0.3403]$ \\
\hline Interest rate smoothing & $\rho_{r}$ & Beta & 0.80 & 0.10 & $0.8381[0.8117 ; 0.8664]$ \\
\hline \multicolumn{6}{|l|}{ Averages } \\
\hline Trend growth rate & $\bar{\gamma}$ & Normal & 0.44 & 0.10 & $0.3938[0.3283 ; 0.4564]$ \\
\hline Inflation rate & $\bar{\pi}$ & Gamma & 0.63 & 0.10 & $0.6549[0.5787 ; 0.7304]$ \\
\hline Interest rate & $\bar{r}^{n}$ & Gamma & 1.31 & 0.10 & $1.2757[1.1719 ; 1.3814]$ \\
\hline Hours of work & $\bar{h}$ & Normal & 0.00 & 0.10 & $-0.0026[-0.1705 ; 0.1586]$ \\
\hline Lending rate & $\bar{r}^{L}$ & Gamma & 1.98 & 0.10 & $1.9362[1.8469 ; 2.0222]$ \\
\hline \multicolumn{6}{|l|}{ Exogenous processes } \\
\hline \multirow[t]{2}{*}{ Technology } & $\rho_{A}$ & Beta & 0.50 & 0.20 & $0.9615[0.9357 ; 0.9884]$ \\
\hline & $\sigma_{A}$ & $\mathrm{IG}$ & 0.10 & 2.0 & $0.0047[0.0041 ; 0.0053]$ \\
\hline \multirow[t]{2}{*}{ Government spending } & $\rho_{G}$ & Beta & 0.50 & 0.20 & $0.9573[0.9377 ; 0.9884]$ \\
\hline & $\sigma_{G}$ & IG & 0.10 & 2.0 & $0.0238[0.0209 ; 0.0265]$ \\
\hline Interest rate & $\sigma_{R}$ & IG & 0.10 & 2.0 & $0.0014[0.0012 ; 0.0015]$ \\
\hline \multirow[t]{2}{*}{ Investment-specific } & $\rho_{I}$ & Beta & 0.50 & 0.20 & $0.3733[0.0596 ; 0.6653]$ \\
\hline & $\sigma_{I}$ & $\mathrm{IG}$ & 0.10 & 2.0 & $0.0197[0.0002 ; 0.0356]$ \\
\hline \multirow[t]{2}{*}{ Preference } & $\rho_{B}$ & Beta & 0.50 & 0.20 & $0.6931[0.5169 ; 0.8830]$ \\
\hline & $\sigma_{B}$ & $\mathrm{IG}$ & 0.10 & 2.0 & $0.0103[0.0078 ; 0.0129]$ \\
\hline \multirow[t]{2}{*}{ Capital quality } & $\rho_{K}$ & Beta & 0.50 & 0.20 & $0.9309[0.8984 ; 0.9654]$ \\
\hline & $\sigma_{K}$ & $\mathrm{IG}$ & 0.10 & 2.0 & $0.0021[0.0014 ; 0.0029]$ \\
\hline \multirow[t]{2}{*}{ Price mark-up } & $\rho_{P}$ & Beta & 0.50 & 0.20 & $0.8025[0.7295 ; 0.8808]$ \\
\hline & $\sigma_{P}$ & IG & 0.10 & 2.0 & $0.0151[0.0126 ; 0.0175]$ \\
\hline \multirow[t]{2}{*}{ Wage mark-up } & $\rho_{W}$ & Beta & 0.50 & 0.20 & $0.7791[0.6976 ; 0.8612]$ \\
\hline & $\sigma_{W}$ & $\mathrm{IG}$ & 0.10 & 2.0 & $0.0483[0.0356 ; 0.0609]$ \\
\hline Std - measurement error - lending & $\sigma_{\varepsilon_{L}}$ & IG & 0.10 & 2.0 & $0.0233[0.0207 ; 0.0259]$ \\
\hline$\underline{\text { Std }- \text { measurement error }- \text { lending rate }}$ & $\sigma_{\varepsilon_{R} L}$ & IG & 0.10 & 2.0 & $0.0017[0.0015 ; 0.0019]$ \\
\hline Marginal log-likelihood & & & & & -739.639 \\
\hline
\end{tabular}

Table G.6: Prior and posterior distributions of the estimated parameters of the model featuring a Taylor-type interest-rate rule in which potential output is constructed with no financial frictions $-90 \%$ confidence intervals are in square brackets 


\begin{tabular}{ccccccccc}
\hline$w_{r}$ & $\operatorname{Pr}(Z L B)$ & $\rho_{r}$ & $\alpha_{\pi}$ & $\alpha_{y}$ & $\alpha_{\Delta y}$ & $\alpha_{s}$ & $\Omega$ & $100 \times \omega$ \\
\hline \multicolumn{7}{c}{ Optimized implementable } & Taylor-type rules \\
10.00 & 0.017 & 1.000 & 0.834 & 0.003 & 0.000 & 0.003 & -246.7465 & 0.31 \\
15.00 & 0.010 & 1.000 & 0.695 & 0.000 & 0.000 & 0.003 & -246.9214 & 0.96 \\
- & 0.017 & 0.838 & 0.325 & 0.004 & 0.025 & 0.040 & -247.0609 & 1.48 \\
\hline \multicolumn{7}{c}{ Estimated } & Taylor-type rule \\
\hline
\end{tabular}

Table H.1: Optimized monetary policy rules with an alternative output-gap (potential ouput constructed with no financial frictions)

\section{H Robustness exercises for optimal policy}

This section illustrates a series of modifications in the DSGE model in order to investigate the robustness of the optimal policy results to: (i) Taylor-type rules with potential output defined as the level that would prevail in the absence of price stickiness, wage stickiness and financial frictions; (ii) Taylortype rules augmented with financial variables alternative to nominal credit growth; (iii) implementable Taylor-type rules; (iv) a higher volatility of structural shocks; and (v) superinertial rules.

\section{H.1 Alternative output gap}

Let us consider Taylor-type rules with potential output defined as the level that would prevail in the absence of price stickiness, wage stickiness and financial frictions. Table H.1 shows that the optimal $\rho_{r}$ , $\alpha_{\pi}, \alpha_{y}$ and $\alpha_{\Delta y}$ are similar to the ones under the baseline Taylor-type rule for the same probability of hitting the zero lower bound. The optimal responsiveness to nominal credit growth is negligible (equal to 0.003). The welfare loss with respect to the Ramsey policy increases for a higher $w_{r}$ and the estimated Taylor-type rule features a considerable welfare loss, equivalent to a permanent loss in consumption of $1.48 \%$. This exercise unveils that under the different specification of the output gap, optimal monetary policy is virtually the same as in the case of the standard specification of the output gap. 


\begin{tabular}{cccccccccc}
\hline $\mathcal{S}_{t}$ & $w_{r}$ & $\operatorname{Pr}(Z L B)$ & $\rho_{r}$ & $\alpha_{\pi}$ & $\alpha_{y}$ & $\alpha_{\Delta y}$ & $\alpha_{s}$ & $\Omega$ & $100 \times \omega$ \\
\hline \multicolumn{10}{c}{ Optimized Taylor-type rules } \\
$L_{t} /\left(\gamma L_{t-1}\right)$ & 20 & 0.010 & 1.000 & 0.910 & 0.000 & 0.000 & 0.000 & -246.8322 & 0.63 \\
$L_{t} / L$ & 40 & 0.010 & 1.000 & 0.806 & 0.000 & 0.000 & 0.007 & -246.8293 & 0.62 \\
$\operatorname{spread}_{t} /$ spread & 20 & 0.010 & 1.000 & 0.909 & 0.000 & 0.000 & 0.000 & -246.8322 & 0.63 \\
\hline
\end{tabular}

Table H.2: Optimized monetary policy rules with alternative financial variables

\section{H.2 Alternative financial variables}

We now report results on optimal policy when the augmented Taylor-type rule responds to financial variables different from nominal credit growth. We can write the Taylor rule as

$$
\begin{aligned}
\log \left(\frac{R_{t}^{n}}{R^{n}}\right) & =\rho_{r} \log \left(\frac{R_{t-1}^{n}}{R^{n}}\right)+\alpha_{\pi} \log \left(\frac{\Pi_{t}}{\Pi}\right)+\alpha_{y} \log \left(\frac{Y_{t}}{Y_{t}^{f}}\right) \\
& +\alpha_{\Delta y}\left[\log \left(\frac{Y_{t}}{Y_{t}^{f}}\right)-\log \left(\frac{Y_{t-1}}{Y_{t-1}^{f}}\right)\right]+\alpha_{s} \log \left(\mathcal{S}_{t}\right),
\end{aligned}
$$

where $\mathcal{S}_{t}$ is a financial variable the monetary policy rate may react to. In particular, we consider (i) real credit growth, $L_{t} /\left(\gamma L_{t-1}\right)$; (ii) the percent deviation of lending from its steady state $\left(L_{t} / L\right)$; and (iii) the bank spread, spread $_{t} /$ spread $\equiv\left(1+R_{t}^{L}\right) /\left(1+R_{t}^{D}\right) /\left(1+R^{L}\right) /\left(1+R^{D}\right)$, similarly to Cúrdia and Woodford (2010) and Aksoy et al. (2013).

Table H.2 shows that the optimal $\rho_{r}, \alpha_{\pi}, \alpha_{y}$ and $\alpha_{\Delta y}$ are similar to those under the baseline Taylortype rule for the same probability of hitting the zero lower bound equal to 0.010. Hence, the welfare loss with respect to the Ramsey policy, $\omega$, is very similar. This exercise unveils that if monetary policy responds to real lending growth, deviation of lending from steady state or the deviation of spread from steady state, it achieves virtually the same welfare outcome as in the case of nominal credit growth, by not responding to financial variables.

\section{H.3 Implementable Taylor-type rules}

Table H.3 shows the optimized coefficients in the case of the implementable Taylor-type rule, equation (II) in Table 6 of the paper, which is reparametrized as follows: 


\begin{tabular}{|c|c|c|c|c|c|c|c|c|c|}
\hline & $w_{r}$ & $\operatorname{Pr}(Z L B)$ & $\rho_{r}$ & $\alpha_{\pi}$ & $\alpha_{y}$ & $\alpha_{\Delta y}$ & $\alpha_{s}$ & $\Omega$ & $100 \times \omega$ \\
\hline \multicolumn{10}{|c|}{ Optimized implementable Taylor-type rules } \\
\hline & 13.00 & 0.017 & 1.000 & 1.066 & 0.011 & 0.000 & 0.000 & -246.8265 & 0.61 \\
\hline & 30.00 & 0.010 & 1.000 & 0.825 & 0.008 & 0.000 & 0.000 & -246.8326 & 0.63 \\
\hline \multicolumn{10}{|c|}{ Estimated implementable Taylor-type rule } \\
\hline & - & 0.017 & 0.839 & 0.322 & 0.003 & 0.020 & 0.040 & -246.8702 & 1.12 \\
\hline \multicolumn{10}{|c|}{ Optimized implementable Taylor-type rules with alternative financial variables } \\
\hline $\mathcal{S}_{t}$ & & & & & & & & & \\
\hline$L_{t} / L_{t-1}$ & 30 & 0.010 & 1.000 & 0.825 & 0.008 & 0.000 & 0.000 & -246.8326 & 0.63 \\
\hline$L_{t} / L$ & 40 & 0.010 & 1.000 & 0.806 & 0.000 & 0.000 & 0.007 & -246.8293 & 0.62 \\
\hline spreadt $_{\text {spread }}$ & 28 & 0.010 & 1.000 & 0.835 & 0.008 & 0.000 & 0.000 & -246.8323 & 0.63 \\
\hline
\end{tabular}

Table H.3: Optimized implementable monetary policy rules

$$
\begin{aligned}
\log \left(\frac{R_{t}^{n}}{R^{n}}\right) & =\rho_{r} \log \left(\frac{R_{t-1}^{n}}{R^{n}}\right)+\alpha_{\pi} \log \left(\frac{\Pi_{t}}{\Pi}\right)+\alpha_{y} \log \left(\frac{Y_{t}}{Y}\right) \\
& +\alpha_{\Delta y} \log \left(\frac{Y_{t}}{Y_{t-1}}\right)+\alpha_{s} \log \left(\frac{L_{t}}{\gamma L_{t-1}} \frac{\Pi_{t}}{\Pi}\right),
\end{aligned}
$$

where $\alpha_{\pi} \equiv\left(1-\rho_{r}\right) \rho_{\pi}, \alpha_{y} \equiv\left(1-\rho_{r}\right) \rho_{y}, \alpha_{\Delta y} \equiv\left(1-\rho_{r}\right) \rho_{\Delta y}$ and $\alpha_{s} \equiv\left(1-\rho_{r}\right) \rho_{s}$. Optimal policy results are robust to this alternative formulation of the Taylor rule: the optimal responses to output growth and to nominal credit growth are either zero or very small. The estimated implementable rule implies a consumption-equivalent welfare loss equal to $1.12 \%$, relative to the optimized rule under the Ramsey policy.

Table H.3 also shows the optimal response to alternative financial variables, $\mathcal{S}_{t}$. These results are also robust to the alternative specification of the Taylor rule.

\section{H.4 Highly volatile economy}

The shocks used for the computation of optimized simple rules are those estimated using data of the Great Moderation, characterized by low volatility of business cycle fluctuations. Therefore it seems appropriate to check whether the main results hold in more turbulent periods characterized by higher volatilities. The Great Recession witnessed a double standard deviation of real output growth compared to the average level observed during the Great Moderation.

Figure H.1 presents a counterfactual experiment in which we proportionally change the volatilities of all the structural shocks to match a double and triple standard deviation of output compared to 


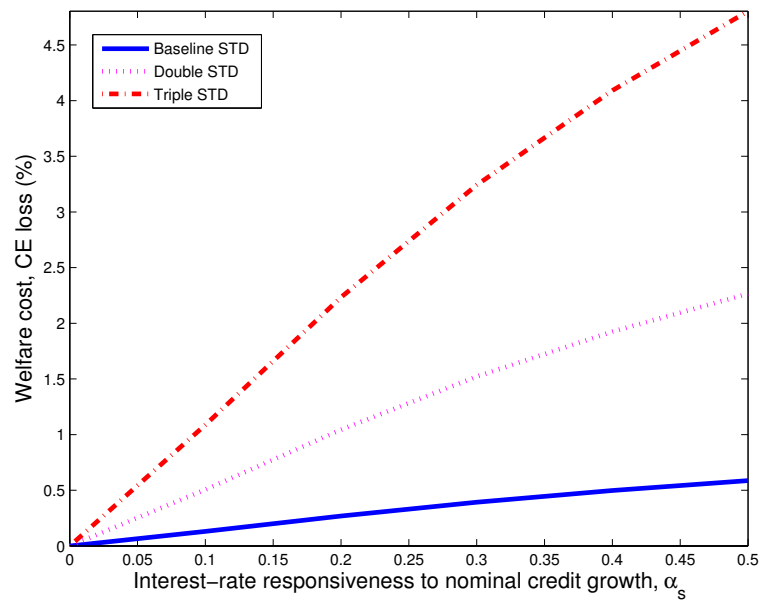

Figure H.1: Welfare cost associated to leaning against the wind for proportional increases in the volatilities of all shocks (STD $=$ standard deviation of real output growth)

the baseline estimated model - by keeping $\rho_{r}, \alpha_{\pi}, \alpha_{y}$ and $\alpha_{\Delta y}$ fixed at their optimal values and by changing $\alpha_{s}$ in the interval $[0 ; 0.5]$. The higher the standard deviation, the stronger is the trade-off between inflation and financial stabilization. Hence the welfare loss is greater under the most volatile scenario and it increases for a more aggressive responsiveness to nominal credit growth.

\section{H.5 Superinertial rules}

The optimal policy results reported in the paper rule out the possibility that interest rate inertia exceeds unity. In other words our optimized simple rules are not superinertial in the sense of Rotemberg and Woodford (1999) and Woodford (2003). Here we check whether our conclusions remain unaltered when we allow for a $\rho_{r}>1$. In particular, Figure H.2 plots the welfare changes obtained (i) by letting inertia $\rho_{r}$ and the response to credit growth, $\alpha_{s}$, vary in the intervals $[0.5,1.5]$ and $[0,0.5]$, respectively, and (ii) by re-optimizing the values of the remaining parameters in equation (23) in the paper $\left(\alpha_{\pi}, \alpha_{y}\right.$ and $\left.\alpha_{\Delta y}\right)$. The welfare change is computed, relative to a reference case of mild inertia $\left(\rho_{r}=0.5\right)$ and no response to credit growth $\left(\alpha_{s}=0\right)$, in terms of the consumption equivalent (CE) compensation that the representative agent should receive to be as well off under the reference case as any other alternative regimes. Three remarks are worth making from the inspection of the resulting surface. First, conditional on $\alpha_{s}=0$, raising $\rho_{r}$ from 0.5 to unity (price-level rule case) delivers a welfare gain of around $0.15 \%$ in consumption-equivalent terms. Second, further increases in $\rho_{r}$ (superinertial rules) foster only negligible welfare changes, similarly to Schmitt-Grohe and Uribe (2007). Third, the optimal 


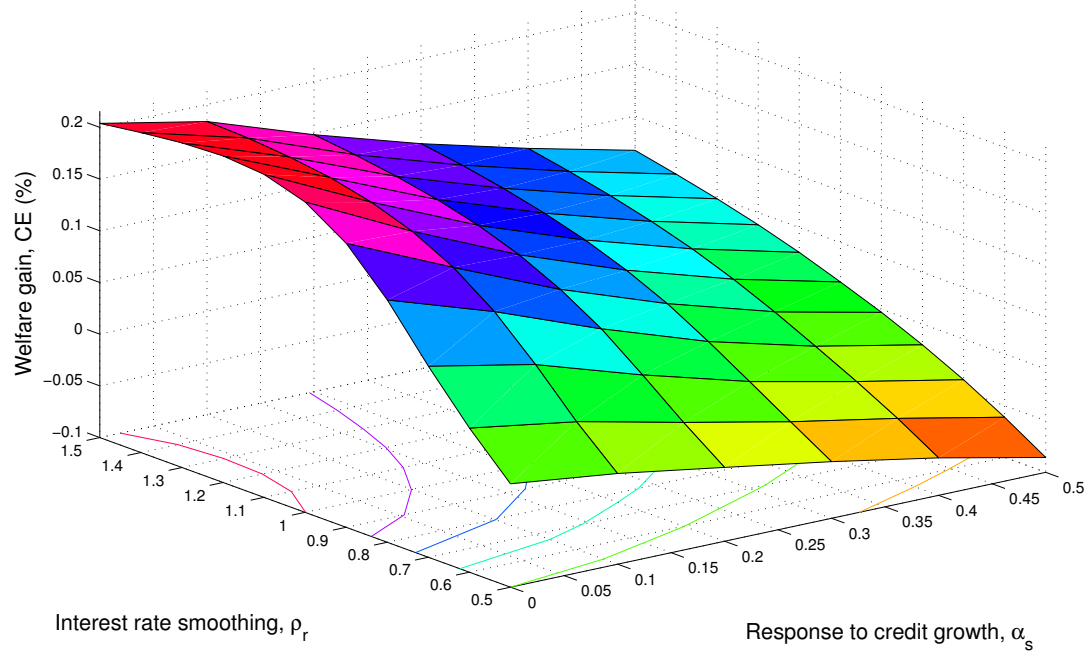

Figure H.2: Welfare change associated to interest rate inertia $\left(\rho_{r}\right)$ and leaning against the wind $\left(\alpha_{s}\right)$ relative to the case $\rho_{r}=0.5 ; \alpha_{s}=0$

value of $\alpha_{s}$ is zero for every level of $\rho_{r}$, hence higher values of $\alpha_{s}$ are welfare-detrimental. 